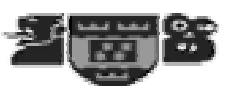

Victoria Unwersity

of Wellingtor, New Zealand

Te whare Wanango o te

Upoko a te ka a Mawh Aoteanod

\title{
Minimising Community Opposition to \\ Wind Farm Developments in New Zealand: \\ Opportunities in Renewable Energy Planning
}

\author{
by \\ Christian Berg \\ Master of Science by Thesis
}

Supervised by Dr. Sean Weaver

A thesis submitted to the Institute of Geography,

Victoria University of Wellington, in fulfilment of the requirements

for the degree of Master of Science in Geography

Institute of Geography, School of Earth Sciences, Victoria University of Wellington, June 2003 


\begin{abstract}
The erection of wind turbines, depending on their location, could significantly interfere with appreciated landscape values of a community, and consequently lead to its objection to a proposed wind energy project.

This study explores possible options, which can be applied within the community consultation process to reduce the likelihood of substantial public opposition to wind farm developments in New Zealand. The research topic was chosen to support wind farm planners and decision makers in the consultation process for wind farm developments in order to increase public acceptance of a proposed project, to evaluate possibilities of benefit sharing and public involvement, to select the most appropriate level of community participation in the planning process and consequently to enhance the ability in gaining resource consent under the Resource Management Act 1991.
\end{abstract}

The investigation covers the sequential development of public attitudes towards wind farms, the wider spectrum of public opposition, including vocalised reasons and hidden arguments, community consultation approaches and the different levels of public involvement.

The applied methodology for this research comprises a case study approach concerning a New Zealand wind farm including an analysis of submissions made into the resource consent process, follow-up interviews with affected stakeholders, an interview with a wind farm developer, and a comprehensive text analysis.

There are various opportunities to increase acceptance of wind farms including aesthetical design, sensitive siting, a pro-active approach, stakeholder analysis, participation and community ownership schemes. The results also demonstrate that increased community involvement may potentially satisfy consulted stakeholders, but could jeopardise obtaining resource consent under the current planning regime. 


\section{ACKNOWLEDGEMENTS}

A number of people have provided constructive advice concerning the content of this research as well as emotional and financial support contributing to the successful accomplishment of this thesis. I would like to take this opportunity to thank Paul Botha, Hamish Sisson and Alistair Wilson for sharing their insights and "real-life" experiences, my supervisor Sean Weaver for his guidance and patience, my parents for supporting me throughout my studies, Agnes for her motivation boosts when they were desperately required, the makers of coffee and energy drinks that kept me awake during countless days and nights while reading, researching and finally typing the following pages, and most importantly Marie for helping me in times of need.

\section{Christian Berg}

Wellington, June 2003 


\section{TABLE OF CONTENTS}

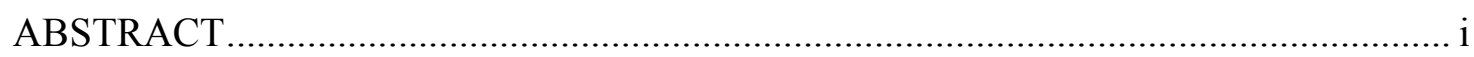

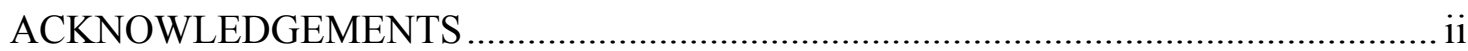

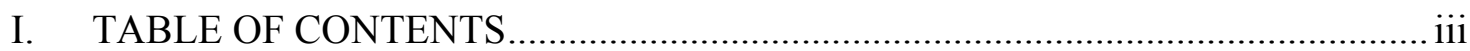

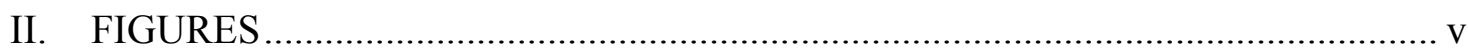

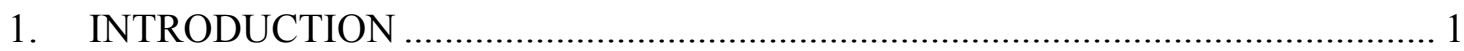

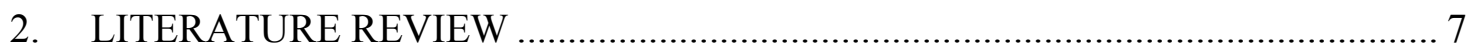

$2.1 \quad$ Public Attitudes Towards Wind Farms........................................................... 7

2.2 Opposition Towards Wind Farms ….......................................................... 10

2.2.1 The Landscape Problem...................................................................... 14

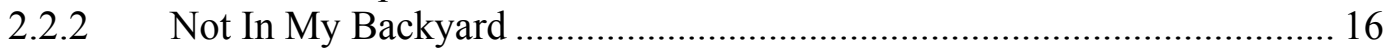

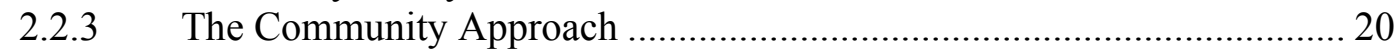

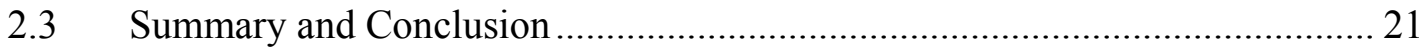

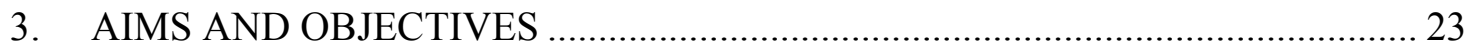

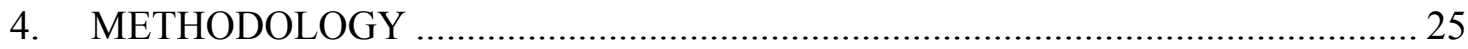

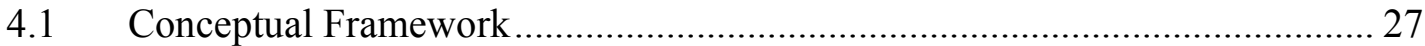

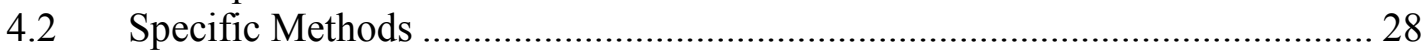

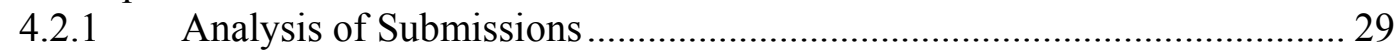

4.2.2 Interviews with Submitters ................................................................... 30

4.2.3 Interviews with Wind Farm Developments .......................................... 32

4.2.4 Discussion of Selected Literature ....................................................... 34

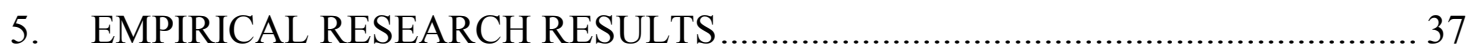

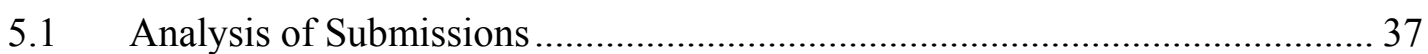

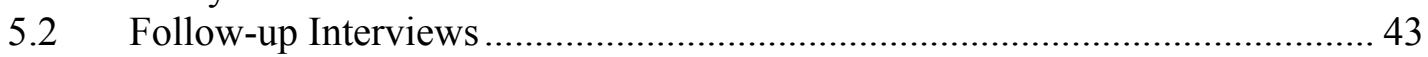

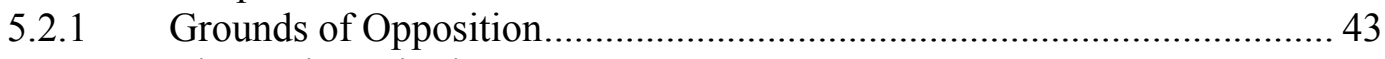

5.2.2 Change in Attitude .......................................................................... 44

5.2.3 The Consultation Process........................................................................ 46

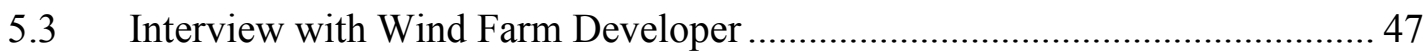

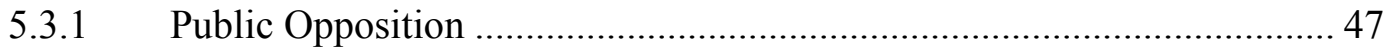

5.3.2 The Consultation Process............................................................................ 49

5.3.3 Consultation Process Applied to the Tararua Wind Farm ....................... 50

$5.4 \quad$ Summary of Empirical Research Results ..................................................... 52 


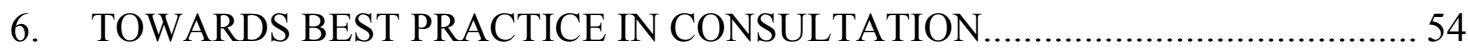

6.1 Improving Community Acceptance of Wind Farms....................................... 54

6.1.1 Minimising the Potential Impact of Wind Farms .................................... 57

6.1.2 Tools for Simulating Potential Wind Farm Intrusion ............................... 59

6.1.3 Community Involvement and Benefit Sharing ........................................ 63

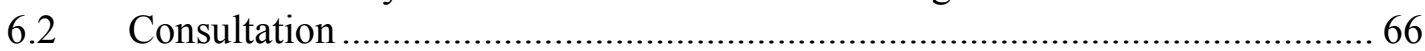

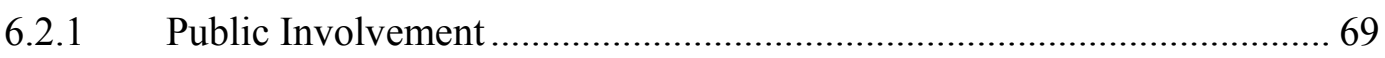

6.2.2 Stakeholder Analysis .......................................................................... 73

6.2.3 Consultation Practices for Wind Energy Projects.................................... 77

6.3 Summary of Best Practice Literature .............................................................. 82

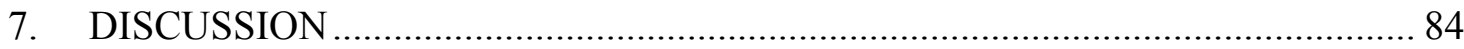

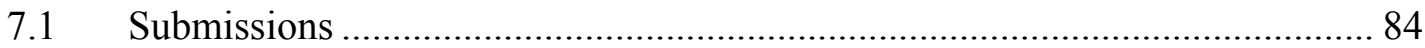

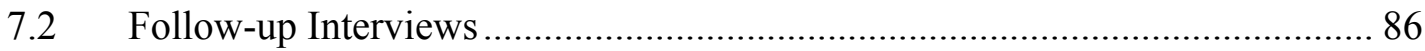

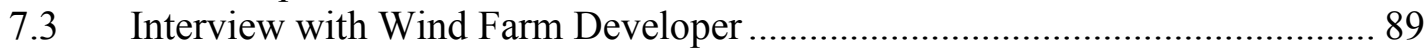

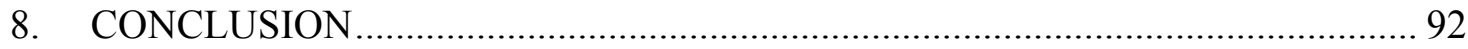

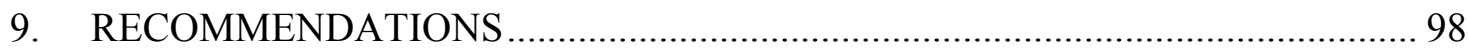

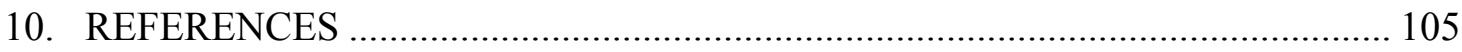

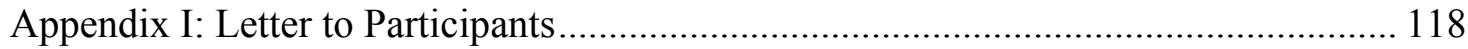

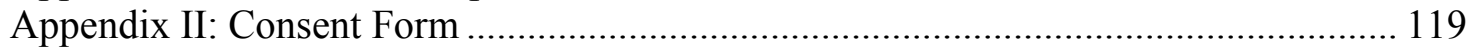

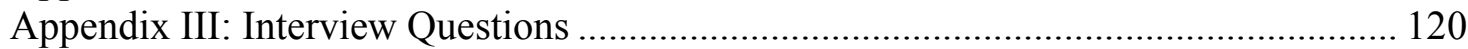

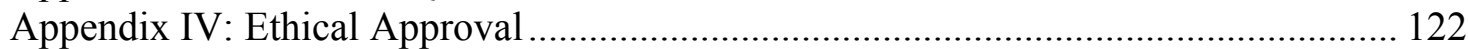




\section{FIGURES}

Figure 1: Areas with high average wind speeds in New Zealand

Figure 2: Sequence of public acceptance of wind power

Figure 3: Pros and Cons (hidden arguments in italic)

Figure 4: Power plant acceptance

Figure 5: Main arguments in support

Figure 6: Main arguments in opposition

Figure 7: Main objecting Arguments (categorised)

Figure 8: Conceptual model for research on public acceptance of wind energy

Figure 9\&10: Photomontage Process

Figure 11: Noise assessment

Figure 12: Visibility Assessment

Figure 13: Public Participation

Figure 14: Stakeholders in a wind energy project

Figure 15: Influence Matrix

Figure 16: Comparison of pre-construction concerns and actual problems

Figure 17: Alternative approach for wind turbine siting (No. 1)

Figure 18: Alternative approach for wind turbine siting (No. 2) 


\section{INTRODUCTION}

New Zealand is heading towards another power crisis in the winter of 2003. The urgency of the situation is demonstrated by vast media coverage and a governmental contingency plan announcing a nationwide 10 per cent electricity saving target (INL Newspapers, 08/05/2003 [online]). One sustainable option to meet the country's future electricity demand would suggest the use of renewable energy sources such as wind, but the proposal of wind turbines in the landscape strongly polarises attitudes for and against. Consequently, the suggestion of wind farms can often lead to the forming of passionate opposition groups within a community and the wind power industry may often find it is a major obstacle in gaining resource consent for wind farm developments. Public acceptance of wind energy projects seems to be highly dependent on where the site has been selected for development, and on the planning process that allows direct interaction between the affected community and the project developer. What is needed is an approach to community consultation, which accommodates measures for the purpose of reducing the likelihood of substantial opposition. This may mean increasing public involvement in the siting of wind farms and forms of community ownership schemes to maximise community "buy-in".

Since the government ratified the Kyoto Protocol on climate change in early 2003 New Zealand made a commitment to reduce its carbon dioxide emissions. Moreover, with the decline of the Maui gas field and the country's consistently increasing electricity demand "concerns are growing about potential power shortages in the next three years" (Dominion Post, 5/03/2003). Signs of a dry weather period in 2003, with below average inflows into the hydro catchments in the South Island similar to the 1992 and 2001 situation, indicates that there is a alarming threat of electricity blackouts during the upcoming winter (Gill, 2003 [online]). As a consequence, "industries are already 'pruning' production in response to rising [electricity] prices" (Press Release: New Zealand National Party, 17/03/2003 [online]). The electricity demand in New Zealand was consistently growing and electricity consumption has more than doubled in the past 
25 years to more than $33,000 \mathrm{GWh}(119.63 \mathrm{PJ})$ in 2000 and accounts for $19 \%$ of the 28.3 million tonnes of $\mathrm{CO}_{2}$ emissions emitted from energy sources through electricity generation (MED, 2001).

According to the Ministry of Commerce (2000), the increasing demand for electricity is likely to continue and it is projected that this surplus will be primarily met through nonrenewable energy sources. According to MP Jeanette Fitzsimons, Co-Leader of the Green Party,

"New Zealand is staring at a choice between two energy futures - one driven by coal and yesterday's fuels, leading eventually to planetary disaster; the other driven by new clean technologies such as wind" (Press Release: New Zealand Green Party, 08/05/2003 [online]).

Electricity generation through wind power has the potential to significantly increase New Zealand's power supply capacity and security in an environmental friendly and sustainable way. According to EECA (2001:8), New Zealand offers one of the best wind resources worldwide. The physical wind energy potential has been estimated with $100,000 \mathrm{GWh} / \mathrm{a}$, due to its location within the "roaring forties" with prevailing northwesterly winds. Out of this vast resource it is economically feasible to utilise approximately 10 per cent (or $10,000 \mathrm{GWh} / \mathrm{a}$ ) to generate electricity, but about 150 $\mathrm{GWh} / \mathrm{a}$, only "a tiny fraction of that potential" is currently tapped by installed wind turbines in New Zealand (Press Release: New Zealand Government, 08/05/2003). Cherry et al. (1987) identified 13 suitable areas for wind farming throughout New Zealand (Figure 1): 


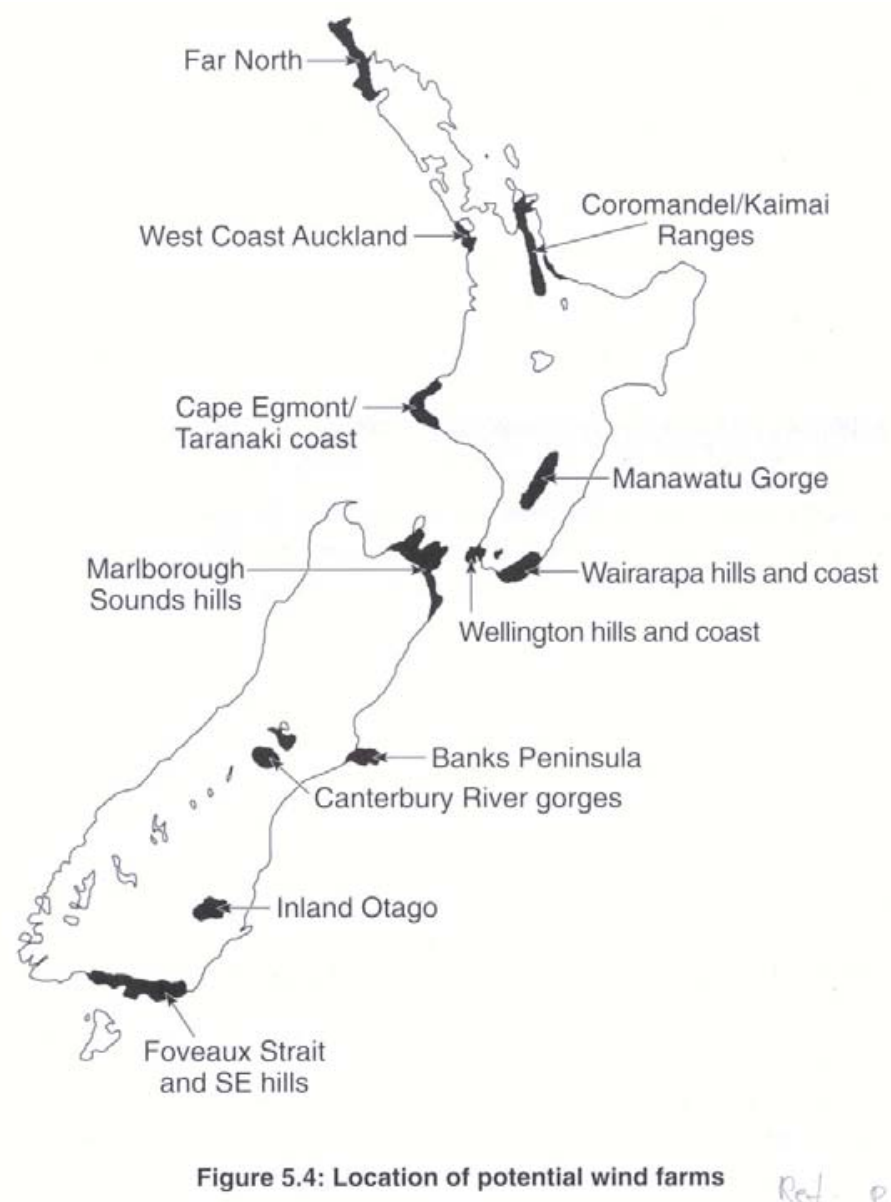

Figure 1: Areas with high average wind speeds in New Zealand (Taken from EECA, 1996:217)

These locations for potential wind farm sites offer the opportunity to provide almost one quarter of New Zealand's energy demand $(7,900 \mathrm{GWh} / \mathrm{a})$ for not more than $10 \mathrm{c} / \mathrm{kWh}$ within 10-15 years (EECA, 2001). A good example for New Zealand's wind energy potential is the Brooklyn wind turbine, a $225 \mathrm{~kW}$ turbine erected in 1993 by $\mathrm{ECNZ}^{1}$ on one of Wellington's hilltops. This turbine set a world record for electricity generation for this size of machine by producing more than 1 million $\mathrm{kWh}$ in less than a year (EECA, 1997).

\footnotetext{
${ }^{1}$ Now owned by Meridian Energy
} 
Despite this immense wind resource, only two wind farms (Hau Nui Wind Farm in the Wairarapa near Martinborough and the Tararua Wind Farm close to Palmerston North) have successfully passed through the planning process, obtained resource consent and been constructed. Two other wind farm proposals made in the 1990s (Bearing Head and Makara wind farms around Wellington) failed to get beyond the planning system, with the Makara wind farm not even reaching the stage of formal application for planning consent, due to fierce and organised community opposition.

Currently, there are at least four potential wind farms under investigation in the lower North Island (Meridian Energy's Makara-Titahi Bay and Te Apiti wind farms, Wind Farm Development's Wainuiomata hills wind farm; and a possible site in the Belmont Regional Park owned by the Wellington Regional Council) (Dominion Post, 5/03/2003, Press Release: Meridian Energy, 08/05/2003). Before these wind farms can be realised, the responsible authority has to grant resource consent. According to Meridian Energy's Chief executive Dr. Keith Turner,

"Wind is one of those energy forms that once you've got a permit you can build very quickly - and New Zealand needs more power production very quickly. We are going to be in a position where we can probably build wind farms commercially and quickly as soon as we get consents. Our only real limitation now is consenting. We think we can do several hundred megawatts of wind farms between now and 2007, so it's a very important step forward for energy supply in New Zealand" (ONE News, 24/03/2003 [online]).

The benefits and adverse effects of wind farm developments are controversially debated within the public domain. Wind farm supporters stress the positive effects on the job market $^{2}$ (Herald Sun, 01/03/2003), the additional income to land owners through rental payments $^{3}$ and multi-million dollar investments into rural and regional economies by

\footnotetext{
${ }^{2}$ The Australian Wind Energy Association released a report stating that every megawatt of installed wind generation capacity creates 3.7 job years in Australia.

${ }^{3}$ Wind developers pay between AUS\$ 3000 to 5000 per year per turbine to the landowner in Australia.
} 
developing wind farms (McArthur, 2002 [online]; Portland Observer, 1/2/2002), and its positive environmental effects and sustainable way to generate electricity (Contact, $27 / 3 / 2003$ ). In contrast, objectors to wind energy argue that wind farms impose a threat to endangered species and cause adverse effects to neighbouring residents "by noise and visual pollution, land value impacts, radiation and interference with TV reception" (McArthur, 2002 [online]) and they are afraid that "more turbines will clutter the coastline" and "will disrupt the peaceful quite" by emitting "constant noise" (Advocate, 9/2/2002).

Public exhibitions held by wind farm developers in Australia to introduce their projects to the public generally attract interest as is demonstrated by high visitor numbers (Yorke Peninsula Country Times, 1/4/2003). Such presentations allow developers to capture a snapshot of the community acceptance through public opinion surveys that predominantly illustrate that most respondents either favour a project or hold no firm view. However some community members may raise their concerns and actively oppose the development once these projects are announced and discussed in the public domain.

Examples of two Wellington wind farm proposals demonstrated that project opponents expressed their objection once they learned about the proposed development (e.g. objection to the Wainuiomata hills wind farm proposal by one opponent (Dominion Post, 19/10/2002) and the Makara-Titahi Bay wind farm opposed by the Makara Guardians (Dominion Post, 18/03/2003)). It is important, therefore for wind farm developers and planners to develop a consultation approach which would allow the integration of affected stakeholders into the planning process by enabling community concerns to influence (up to a point) the design and location of wind farm proposals.

This thesis explores available consultation options that could potentially reduce the likelihood of substantial opposition to wind farm developments in New Zealand. In order to achieve this, the Tararua Wind Farm will be utilised as a case study to investigate the community opposition and the consultation process associated with the development of this project. This approach brings the opportunity to analyse the submissions made into 
the resource consent process and to further investigate the arising issues through followup interviews with the former objectors. In addition, the staff of the Wellington based wind energy developer, Wind Farm Developments (Australia) Ltd., was interviewed to explore the problems and opportunities arising from community consultation processes. Wind farm developers and planners could benefit from these recommendations in the short term, if they help to increase the likelihood of projects successfully obtaining resource consent for proposed wind farms. In the long term all New Zealand could profit from a broad variety of associated benefits of more approved wind energy generation from the reduction of $\mathrm{CO}_{2}$ emissions, more employment opportunities, and increased security of electricity supply for the country.

This document continues with a review of literature on opposition to and acceptance of wind farm developments (Chapter 2), presents the research aims and objectives (Chapter 3), followed by the methodology (Chapter 4). The results of this study are separated into an empirical and a textual analysis. The empirical component (Chapter 5), an analysis of submissions and follow-up interviews, proved to be smaller than originally planned (see methodology section - Chapter 4 - for details), and for this reason a more comprehensive discussion was undertaken of literature on best practice in public consultation and participation in wind farm developments (Chapter 6). Examination of additional literature on wind farm best practice consultation and participation informs and assists the interpretation and discussion of the empirical results of this study (Chapter 7). The combination of the findings from the empirical component and discussion of bestpractice literature lead to the conclusion to this study (Chapter 8) and the development of a set of recommendations presented in Chapter 9. 


\section{LITERATURE REVIEW}

This review discusses selected literature concerning public acceptance of and opposition to wind energy projects. In particular it scrutinises the development of public attitudes towards wind turbines (2.1), and follows with an examination of common arguments raised by wind farm objectors and forms of public opposition (2.2). The literature review provides an introduction into the underlying issues emerging from the development of wind farms and the associated interaction with the wider public. It will also highlight the problem addressed by this study, namely, the need to overcome public opposition in order to realise a successful wind farm development. The detailed approach to the literature search, its rationale and limitation is described in the method section (see 4.2.4).

\subsection{Public Attitudes Towards Wind Farms}

An opinion survey on behalf of the Energy Efficiency and Conservation Authority (MRL Research Group, 1994) shows that almost $90 \%$ of all New Zealanders are in favour of wind power so long as they cannot hear or see the windmills, and the proportion drops to $81 \%$ if wind turbines are visible on the skyline. Nevertheless $50 \%$ favour wind power, if windmills are in proximity to their residence and clearly audible. $58 \%$ of people surveyed are willing to pay higher prices for electricity generated from wind turbines, if it would raise their electricity bill by $5 \%$, and $34 \%$ are prepared to pay up to $10 \%$ more for 'green' energy.

Similar figures representing the initial popularity of wind power in general are found in European surveys (Hill, 2001) ${ }^{4}$ : on average 7 to 8 out of 10 people asked about their attitude towards wind energy reacted positively. Moreover, responses were more positive when people are well informed about energy generation and renewables, or have an

\footnotetext{
${ }^{4}$ Drawn from an analysis in the UK between 1990 and 2001 of opinion polls carried out to investigate attitudes to wind energy
} 
economic interest in the development e.g. by being the landowner of a wind farm or shareholder of a project. Finally, participants from rural areas tend to have a more positive opinion to wind farm development than people living in a city or people who have recently moved from the city to the countryside (Damborg et al., 1998). An American survey of attitudes towards wind farm developments conducted by Thayer et al. (1991) draws a comparable picture: only $15 \%$ of the general public had a negative attitude to a local wind farm (27.5\% neutral, $57.5 \%$ in favour).

Overseas studies indicate that initial positive public responses towards wind energy in general can significantly decrease after a specific wind farm project is proposed (Gipe, 1995). When people become personally aware of a new wind farm development it becomes irrelevant whether or not wind energy is an environmental friendly form of renewable electricity generation. Such awareness can be triggered by the announcement of a wind farm project, or whenever people's values are at stake, e.g. landscape or scenic values. If a proposed project challenges these values, possible adverse effects of wind energy generation could become uppermost in the public's mind (Wolsink, 1996).

Figure 2 displays the sequential development of public acceptance of a specific wind farm project as shown by Gipe (1995:280) and Pasqualetti et al. $(2002: 163)^{5}$. The magnitude of decreased support and its subsequent re-improvement depends significantly upon the quality of the particular proposal and the characteristics of the selected wind farm location (Wolsink, 1996:1087).

\footnotetext{
${ }^{5}$ Produced by the Dutch wind power developer L. Arkesteijn from research conducted by M. Wolsink from 1985 to 1990
} 


\section{ACCEPTANCE OF WIND ENERGY}

Percent Acceptance

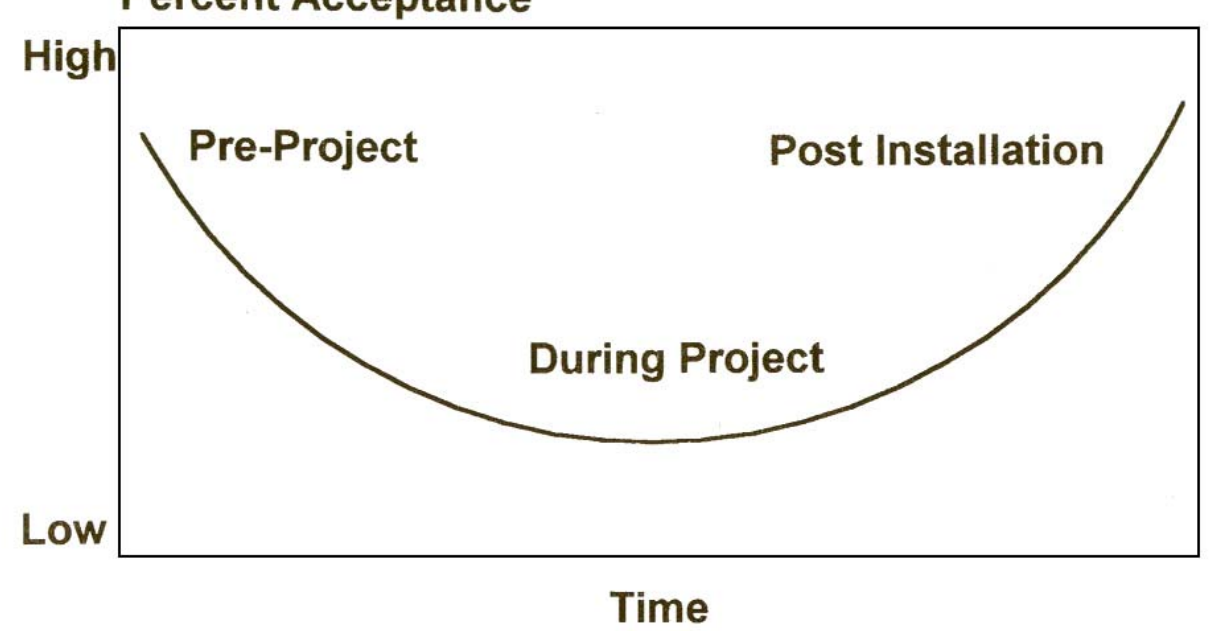

Figure 2: Sequence of public acceptance of wind power (Pasqualetti et al., 2002:163)

European surveys and opinion polls, however, have found that after a wind project has been installed and operating for a while public support increases significantly to acceptance levels that existed before the development was proposed (Gipe, 1995). This study seeks to test this theory in relation to the Tararua Wind Farm. For many community members the reality of living in proximity to a wind farm turns out much better than they initially perceived it to be.

Acceptance of wind farms often grows as communities have time to adjust and find out that many of their perceived fears were unfounded (Gipe, 1995). For example, $40 \%$ of the respondents in a Scottish pre-construction survey expected to face problems with the planned wind farm, but only 9\% experienced any (Elliott, 2001). Opponents are likely to alter their views once they have had personal experience of operating wind turbines, e.g. after they have visited an existing wind farm (EECA, 1996).

Simon (1996) observed from 13 surveys of attitudes to wind power a similar pattern of varying public acceptance pre- and post-construction. According to a survey carried out in Lancashire, UK, only $64 \%$ of the respondents felt positive about a proposed wind farm 
( $8 \%$ were strongly against). A few months later residents were questioned again: $80 \%$ now supported the wind farm while opposition dropped to $4 \%$.

The same findings were made in a two-staged survey in Cornwall where public wind farm approval rose from $40 \%$ before construction to $85 \%$ six months after construction. Across all 13 surveys, public support for wind farms increased once the community had time for direct experience of operating wind turbines. According to Elliott (2001), around $80 \%$ of those interviewed in post-construction surveys in the UK supported their neighbouring wind farm. Participants with a residence in proximity to the wind farm were more in favour than people in the outer surrounding area.

Finally, Gray (2002) [online] states that all polls into public attitudes on wind farm developments have a similar pattern of negative views (around $20 \%$ or less). Visual impact and noise were the main concerns mentioned. Wolsink (1990) adds that even if the majority reacts positively towards wind energy around $10 \%$ will tend to remain unsupportive $^{6}$ from the very beginning. Apparently, "total public agreement on any project will be difficult, indeed impossible" to achieve (Righter, 2002:24).

\subsection{Opposition To Wind Farms}

The prospect of a wind farm development seems to raise a re-occurring range of common fears among affected communities as indicated by various surveys of public attitudes to wind energy (Hill, 2001).

Firstly, the visual impact of wind turbines on the landscape will cause distress. The extent of this adverse effect depends significantly upon individual perception of operating turbines and generally causes polarised pro and anti views.

\footnotetext{
${ }^{6}$ Wolsink updates this figure by stating that general opposition against wind farm development in the Netherlands has grown to $20-25 \%$ over the last 10 years, even though the vast majority still supportwind power.
} 
Potential noise nuisance generated by rotating blades is another concern to stakeholders ${ }^{7}$. Improvements in the rotor blade configuration have made more recent wind farms far less audible to nearby residents ${ }^{8}$ compared to those with turbines of an earlier design.

The potential negative effect of wind farms on real estate values is yet another frequently mentioned concern ${ }^{9}$ and is controversially discussed by affected landowner and wind energy advocates ${ }^{10}$.

The fear of electromagnetic interference (EMI) is generally associated with the disruption of TV reception ${ }^{11}$ or telecommunication facilities (Harland, 2000). However, existing wind farms in New Zealand (Hau Nui, Tararua) and Europe (e.g. Denmark, Germany, Netherlands) already operate close to telecommunication sites or microwave corridors without causing any problems (Gipe, 2002; EECA, 1996). Depending on their location, wind farms are feared to have negative effects upon tourism (Hill, 2001), because they might deter nature-loving visitors, diminish options for eco-tourism and encourage unwanted tourists instead.

On the other hand other studies suggest wind turbines can be considered popular attractions for many tourists (Pasqualetti et al., 2002) and their enjoyment of their holiday would be unimpaired by the presence of wind farms (Clark, 2003).

EECA (1996) mentions effects on wildlife, especially bird strike, as an environmental concern. Planning South Australia (2002:6) reports that bird strike is not considered as a

\footnotetext{
${ }^{7}$ Depending on the wind speed, wind turbines emit a variable level of noise into their surroundings that declines with distance (Harland, 2000).

${ }^{8}$ Modern wind farms at a distance of $350 \mathrm{~m}$ are no noisier than a quite bedroom at night $(35-45 \mathrm{~dB}(\mathrm{~A}))$ or the background noise of the wind is higher than the turbine sound (AWEA, 2002 [online])

${ }^{9}$ Worry about declining property values is not exclusively confined to wind farm developments but takes place whenever undesirable utility scale constructions are proposed near a community.

${ }^{10}$ A recent US study found out that "the presence of a wind farm does not have an impact on the value of nearby property" (O’Bryant, 2002)

${ }^{11}$ Potential EMI effects can be easily mitigated by booster or relay stations, if necessary.
} 
"common occurrence" though it could become an issue if endangered species ${ }^{12}$ were affected by a proposed wind farm site. Consequently, risk assessment investigations into the potential impact upon local bird life and on-site monitoring measures during operation are proposed to identify possible problems and to ensure that the likelihood of bird strikes is minimal.

Connor (1988:69) describes the main reasons for public concerns as "perceived risk [and] inequity, threats to community integrity and improper or arbitrary decision-making". The perceived risk is closely linked to intuitive fears - or fear of the unknown - which, when blended with individual taste and unconfirmed information, becomes the basis of polarised opinions regarding visual, acoustic or wildlife intrusion. Aesthetic judgements of wind farms are ranging from "fascinating and artistic spectacles" to "extremely ugly" and "environmentally very intrusive" turbine noise being "equivalent to a helicopter" are misleading, but once in the public domain they become "regularly recycled and embellished" (Elliott, 1994:4), partly through media reports of this claim by wind turbine critics.

Wolsink (undated) adds, that noise is often used as an argument by wind power rejecters, but the root of their resistance is usually based on other considerations, including anticipated reduction in property values. Californian reports on bird death due to turbine collision have become another factor in regard to public acceptance to wind power (Thayer et al., 1991:38). Bird losses are the result of poor wind farm design and siting of early American projects at the Altamont and Tehachapi Pass. But once such reports were in the public domain, wind farm opponents regularly referred to these studies. Today, bird kills related to wind turbines occur "three to seven times less" than at wind farms operating for 10 years or more (O’Bryant, 2003).

\footnotetext{
${ }^{12}$ For example. the Orange Bellied Parrot in Victoria and South Australia (Australia), which is considered as an endangered species. Developers proposing a wind farm within the migration path of these parrots have to conduct a bird study under the Environmental Protection and Biodiversity Conservation Act 1999.

${ }^{13}$ Wind energy objectors in the UK gave wind turbines the name: "lavatory brushes in the sky" (Pasqualetti et al., 2002)
} 
According to Weller (1998), most of the concerns raised above can be met, but the negative impact of wind turbines on the landscape will remain an opponent's prime argument. Even if the impact upon the landscape can be demonstrated to be a genuine threat within an opponent's main protest are often hidden more personal objections. Such underlying anxieties rarely find their way into public discussion. As a consequence, public debates rarely bring to the surface the deepest or hidden concerns of objectors, which may often be the main reason they reject proposed wind farm projects. Weller (1998) identified the following "hidden" arguments:

- "Lost business", because objectors feel excluded from financial benefits.

- "Traditionalism", because wind projects have never before been approved in the region

- "Envy", because a neighbour may earn money as a result of the project

- "Personal conflicts", because they oppose everything the neighbour wants to achieve

\section{Pro Wind Energy (Benefits)}

\begin{tabular}{|c|c|}
\hline 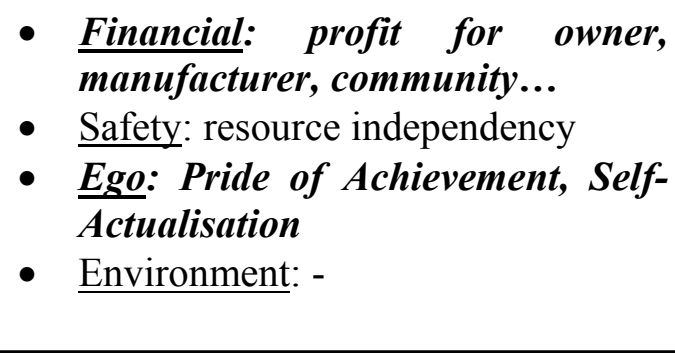 & $\begin{array}{l}\text { - } \text { Social: - } \\
\text { - } \text { Environment: renewable resources, } \\
\text { climate protection } \\
\text { - } \frac{\text { Safety: reduced nuclear power, }}{\text { indigenous resources }} \\
\text { - } \frac{\text { Financial: macro-economic benefits }}{\text { (jobs, local industry) }}\end{array}$ \\
\hline 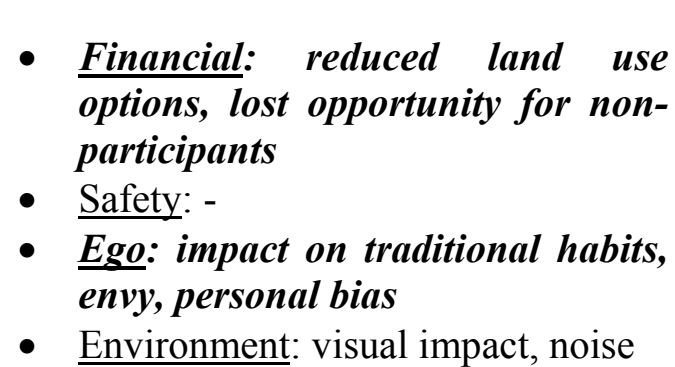 & $\begin{array}{l}\text { - } \frac{\text { Social: - }}{\text { Environment: visual impact, noise, }} \\
\text { land consumption, birds } \\
\text { - } \text { Safety: availability concerns } \\
\text { - } \text { Financial: subsidy misuse }\end{array}$ \\
\hline
\end{tabular}

Against Wind Energy (Disadvantages)

Figure 3: Pros and Cons (hidden arguments in italic) (derived from Weller, 1998) 
Figure 3 lists the major arguments of wind energy debates. The "hidden" arguments (in italics) are highly valued personal concerns, which often remain unarticulated within the discussion, but constitute valid grounds for opposing a wind farm project. If such "hidden" arguments are addressed wind farm opponents may change their negative attitude (Weller, 1998).

\subsubsection{The Landscape Problem}

Even though the development of wind farms may bring numerous environmental benefits, the main disadvantage of wind power is perceived as the unavoidable visibility of turbines leading to a "landscape problem" (Pasqualetti et al., 2002:4). According to Righter (2002:24), public reaction to landscape intrusion is based on cultural influences and individual preferences, which makes it difficult to reach a consensus between the community and the developer. Wolsink (2000:55-56) found that landscape type and site related interference are the key factors in the formation of public attitudes with regard to locations of turbines in the landscape. Therefore, site selection is crucial for the acceptance of wind power development, while environmental benefits of wind energy rarely become subject to trade-off arguments.

Fear of change to highly valued landscapes commonly leads to determined opposition. Wind farm developments are perceived as visual alteration of landscape. If people are emotionally attached (e.g. by memories) to an area proposed for of a new wind farm project, they are more likely to object to the development. Regardless of the site, somebody's values will be affected and some degree of opposition can be expected (Righter, 2002:37).

Righter (2002:29) points out, that wind farm opposition is formed predominantly on the grounds of visibility, which can hardly be mitigated unless the location is changed. The difficulty is that an alternative location is likely to have a visual impact on another set of 
community stakeholders. Turbines cannot be hidden, camouflaged nor made transparent or invisible and their presence will inevitably have some impact on the public.

Elliot (2001) adds, that wind energy generation is very visible and one can see that it interacts with the environment in a different way compared with conventional forms of electricity generation. Most people rarely come into contact with conventional power plants, which can provide high generation capacities ${ }^{14}$ from one single location. In contrast wind farms need to be spread over a larger area ${ }^{15}$ and therefore are much more likely to be widely seen. The public perception of wind turbines is widely variable: while some might consider them as "fascinating and surrealistic spectacles" (Righter, 2002:33), others rather refer to them as "hideous eyesores" (USA Today, 2002 [online]).

Planning South Australia (2002) states that the individual perception of landscape value, which by definition depends upon the subjectivity of aesthetic perception, is influenced by factors such as the "visual group" the perceiver identifies with. For example, an ecotourist is more likely to consider turbines in the landscape as a loss of visual advantage than a local community member who benefits directly from employment at a wind farm site. According to Brittan (2002), there is disagreement among scholars as to whether aesthetic judgements can be objectively based on standardised assessments (e.g. as described by Berrini et. al., 1998; Georgopoulou et al., 1998; Planning South Australia, 2002) or on the ground that all judgement of beauty is subjective and in "the eye of the beholder". Short (2002:54) adds the maxim that "quality, beauty, and ugliness are reflections of personal taste and experience". Regardless of how aesthetic values are judged as part of the decision making, potential adverse effects (e.g. to tourism) as well as benefits have to be taken into account. When it comes to the construction of wind farms, "some visual impact is unavoidable and must be accepted or no wind farms will be allowed to proceed" (Wawryk, 2002:353). Comprehensive governmental policies on renewable energy would be of assistance particularly if they weigh the benefits to society

\footnotetext{
${ }^{14}$ Usually several hundreds of megawatts per power plant.

${ }^{15}$ Modern onshore wind turbines usually have a capacity between $850 \mathrm{KW}$ and $2 \mathrm{MW}$ and are placed between 250 to $500 \mathrm{~m}$ apart.
} 
as whole by reducing greenhouse gas emissions against visual intrusion upon a local community by wind turbines in the landscape.

\subsubsection{Not In My Backyard}

Gipe (2002:176-178) explains the reduction of support for wind farm projects with the distribution of environmental and social costs vs. the benefits of having them. Most residents in proximity to a wind farm are confronted with visual intrusion on a daily basis, but very few gain any personal or immediate advantage through benefits to society such as greenhouse gas reduction and the generation of "green electricity"16. Among communities affected by a wind farm development are people who favour wind energy in general, but do not want wind turbines in their "backyard". Gipe refers to research (Figure 4) by Thayer in the Altamont Pass, U.S.A., which found that wind power is the most preferred form of electricity generation, but also attracts the most "Not-In-MyBackyard" (NIMBY) responses.

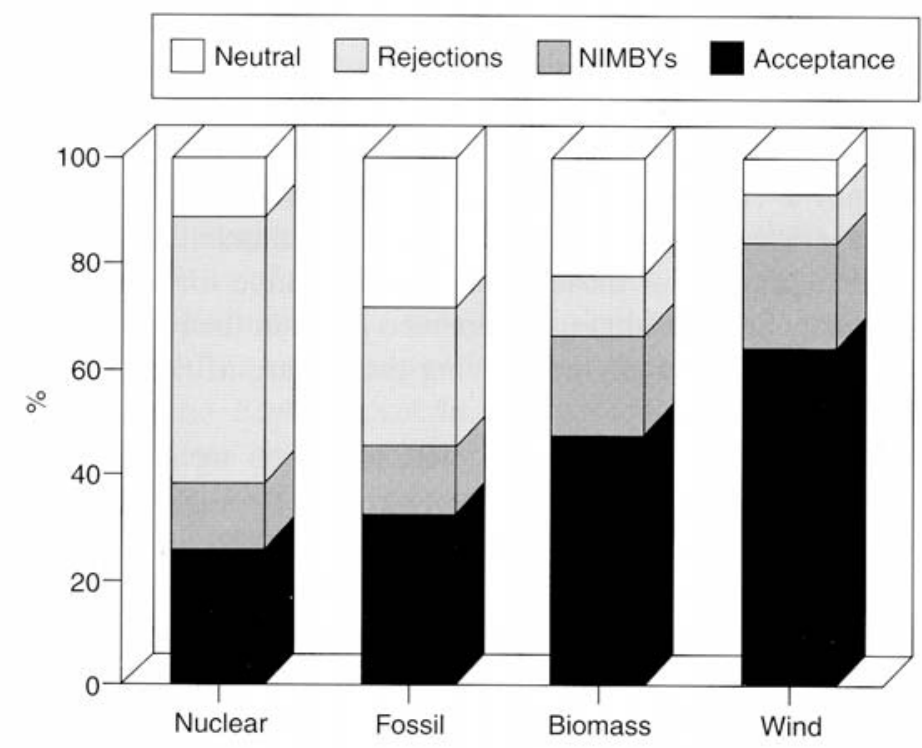

Figure 4: Power plant acceptance (Gipe, 2002:178)

\footnotetext{
${ }^{16}$ Unless stakeholders financially benefit from joint ownership schemes or turbine lease payments.
} 
Opposition towards wind farm developments is often explained in the literature as part of the "NIMBY" phenomenon (Gipe, 1995; Elliot, 1994; Thayer et al., 1991). The Not-InMy-Backyard syndrome is generally associated with opposition to infrastructure and social facility siting. In a wind energy context, NIMBYism is explained as people's opposing behaviour to wind turbine siting in their area, while they are generally in favour of wind power ${ }^{17}$ (Wolsink, 2000). USA Today (2002, [online]) put it in other words: "People expect the power to go on when they flick the switch, but they don't want to live near the source of that power".

According to Yarzebinski (1992) there are four common characteristics associated with the NIMBY syndrome whenever a specific project is opposed.

First, the underlying reason that leads to the formation of a NIMBY lobby is the "fear of change". It is an emotionally driven "anti-change" opposition aiming to preserve the "status quo" in a community.

Second, there is a risk that NIMBY groups will disrupt public meetings in order to influence the opinions of other community members by behaving in a disrespectful manner or ignoring provided facts and information. Their only solution to the problem is to have the development located elsewhere.

Third, discussions become highly emotional and often question the developer's motives for choosing a particular location.

Fourth, local government politicians can often exploit a community conflict to their own personal advantage.

\footnotetext{
${ }^{17}$ A wind farm opposition group in Victoria, Australia states: "by opposing wind turbines on the coast we are not opposing alternative energy" (Heritage Coast, undated)
} 
Thayer et al. (1991:25) identified three major groups of survey respondents of wind farm acceptability studies:

- "Acceptors", favouring wind energy and allowing turbines near their homes;

- "Rejecters", not favouring wind energy and opposing turbines near their premises;

- "NIMBYs", favouring wind energy in general, but not near their residences.

Wolsink (2000:57) states that the NIMBY explanation inadequately describes opposition to wind farm developments, which has rather more complex origins. Wolsink (op. cit.) lists variation beyond the true NIMBY point of view:

- NIMBY, attitude of people in favour of wind power, but not in their neighbourhood;

- NIABY, or Not-in-any-backyard attitude of people who reject wind power in general on the ground of scenic intrusion;

- People changing their attitude during the decision-making process from support to rejection due to their perception of risk involved; and

- People who advocate wind power under certain conditions and who limit their opposition to specific locations

Additionally, Markley (2002) identified an opposition group even more extremist than NIMBYs called BANANA - "build absolutely nothing anywhere near anything". It is described as "vocal, numerous and obnoxious" with no intention of considering any factual information and is simply against the development, they are people who are repeatedly involved in various opposition groups regardless of the project itself.

Moreover, wind farm opposition groups no longer limit their actions to objecting to a project in their community, but extend their activities in support of opposition groups in other regions so as to protect valued natural and cultural heritage sites (Heritage Coast, undated).

Even though many decision makers consider the task of transforming NIMBYs into YIMBYs (Yes-in-my-backyard) as "the modern equivalent of alchemy" (Lake, 1993), a 
first step to overcoming public distrust of a wind farm developer is to take community concerns seriously instead of labelling them as "ridiculous or irrational" NIMBY behaviour (Wolsink, 1989:205). Maize et al. (1992) stresses the importance when making a site decision of being prepared by anticipating community opposition, considering demographics of the area, and any past history of activism.

Whalen (1998) suggests seven principles, which could "neutralise" the NIMBY effect:

1. Start early with building community relations.

2. Be flexible and take community considerations into account.

3. "Cut the bull" and be honest.

4. "Don't try to buy their love" - Donations to a community could be misinterpreted and could trigger even stronger opposition.

5. Find allies within the community to build public opinion.

6. "Isolate the immovable", because they won't co-operate regardless of how much effort is invested and "few don't represent anyone but themselves".

7. "Keep the high road" - deal with community concerns patiently and respectfully, even if opposition groups don't keep to the facts and argue emotionally.

Despite the fact that only a minority of residents might actively oppose a wind farm proposal, it can take only one resolute opponent to delay a project by legal proceedings against permits to develop the wind farm (Wolsink, 1996). The New Zealand legal system offers different possibilities to formally oppose a wind farm development. For example, injunctions represent a powerful option to overrule council decisions or impose restrictions on resource consents applications if the RMA requirements have not been met (Recent Decisions, 2000, [online]). Moreover, notified resource consent applications generally allow any person to make a submission to support or oppose a consent application.

According to Kellow (1999), this opportunity was widely used by the New Zealand public to address their concerns about wind farm proposals in the 1995 Baring Head 
Wind Farm resource consent application by EnergyDirect. In case of the Makara Wind Farm proposed by ECNZ the project did not even reach the resource consent stage because of strong community opposition (Kellow, 1999). As with most forms of social change some degree of conflict seems inevitable. Wolsink refers to O'Hare et al. (1993) who claim that public conflicts have become the rule rather than the exception in planning procedures. For example, planning authorities in the UK approved only 2 out of 18 wind farm proposals in the period between 1994 and 1999. Due to public opposition, only $20 \%$ of recent projects made it successfully to the application for planning permission stage (Elliott, 2001). Therefore, gaining public acceptance becomes one of the most important factors for the successful development of any renewable energy source (Georgopoulou et al., 1998).

\subsubsection{The Community Approach}

Wolsink (2000:58) argues, that people's attitudes and behaviour are highly influenced by organisation of the planning process. For example, a likely factor to trigger public opposition to a wind farm project is a "decide-announce-defend" approach (DAD) often used by utilities (Wolsink, 1996). This approach minimises opportunities for stakeholders to influence and to participate in the planning of a wind farm project and, according to Wolsink, is rather counter-productive by causing unnecessary opposition. Therefore, public objections could occur from communities affronted by the planning process itself rather than by the proposed wind farm. This public resistance could be decreased by including the stakeholder into the wind farm location selection process through involvement, transparency and high information flow (Wolsink, 1996).

Elliott (2001) adds that if people feel powerless in protecting their interests and lifestyles they will try to create an alternative, defensive power base. The result may be an organised local campaign, anti-wind farm activism and media involvement to promote their reasons for objecting. Elliott (op. cit.) offers plausible reason for this type of behaviour: opponents might achieve a far more noticeable effect by opposing a local 
wind farm in order to protect their local environment than by campaigning to stop global warming. Some people prefer to oppose immediate and visible threats than remote, longterm dangers that seem beyond their influence. This suggests that empowering community stakeholders so they can influence land-use decisions in their community is an important component of the community building process. Wind farm developers might be more successful if they involved local communities as partners in the planning process. This thesis aims to shed more light on this possibility by means of interviews with people who opposed the Tararua Wind Farm and to assess available options that might increase public acceptance of wind farms.

\subsection{Summary and Conclusion}

The information derived from the review of selected literature gives an indication of the issues arising through the development of wind farms and covers the acceptance of and opposition to wind projects.

The general acceptance of a wind farm depends on various factors including the site selection and the associated impact on landscape and community (Wolsink, 2000, 1990; Pasqualetti et al., 2002; Righter, 2002, Planning South Australia, 2002, Brittan, 2002) as well as the project process in interaction with the community itself (Wolsink, 1996, 2000; Elliott, 2001). Agreement with a wind farm proposal is also dynamic and depends upon anticipated adverse effects and familiarity with the project as presented by the sequence of public acceptance of wind power (Wolsink, 1996; Gipe, 1995; Pasqualetti et al., 2002; EECA, 1996; Simon, 1996; Elliott, 2001). The reasons used by potentially affected stakeholders to opposing a wind farm proposal raise particular types of arguments (Hill, 2001; EECA, 1996) concerning perceived risks (Connor, 1988), but also conceal fears and concerns that are not expressed (Weller, 1998). Some scholars explain opposition to wind farms in terms of the NIMBY phenomenon whereby people generally support wind energy but oppose a specific project in their proximity (Gipe, 1995; Elliott, 1994; Thayer 
et al., 1991) while other scholars stress that this explanation is not sufficient to explain all reasons for objecting (Wolsink, 2000, 1989; Markley, 2002).

Public acceptance and the level of opposition are key factors in successfully obtaining planning approval for a wind farm. Therefore, this study will examine means of minimising the likelihood of community opposition to wind farm developments in a New Zealand context. This approach investigates a wind farm in the Wellington region as case study of difficulties and accomplishments associated with community acceptance of the wind farm, stakeholder satisfaction with the consultation process and reasons for opposition. The focus of this study will be an analysis of submissions into the resource consent as well as drawing on interviews with affected stakeholders and the staff of a wind farm developer. Besides this literature review and the empirical part of this study, a text analysis was undertaken to investigate best practice approaches to consultation and opportunities for public involvement and increasing acceptance of wind energy. The data will be used in the analysis and discussion of the research results to compare the research findings with the literature and to incorporate reviewed suggestions and practices into the final recommendations of this thesis. 


\section{AIMS AND OBJECTIVES}

The overall aim of this research is to determine effective means of consultation with community stakeholders for the purpose of reducing the likelihood of substantial community opposition to wind farm developments in New Zealand. Consequently, the central research question of this thesis can be formulated thus:

What is the most effective approach to community consultation for the purpose of reducing the likelihood of substantial community opposition to wind farm developments in New Zealand?

In order to achieve the goal of this thesis, five objectives have been defined as operational research steps.

Objective I: $\quad$ To examine the formal public opposition to the Tararua Wind Farm (TWF) development proposed, by assessing the factual accuracy of submissions, and to learn from the arguments used to oppose the proposal.

Objective II: $\quad$ To explore the reasons behind community opposition to the Tararua Wind Farm in more detail and to ascertain whether the operating wind farm (which was subsequently built) affected the attitudes of opposing stakeholders.

Objective III: $\quad$ To investigate the views of a wind farm developer concerning public consultation processes and community opposition. 
Objective IV: $\quad$ To investigate best practice in community consultation currently used in the industry internationally, and to examine measures to improve community acceptance.

Objective V: $\quad$ To investigate options available for increased community participation and involvement in wind farm project planning, in order to identify opportunities for incorporating ideas into consultation strategies for wind farm developments. 


\section{METHODOLOGY}

The overall study is in three parts:

- A literature review that provides the theoretical background information on the examined issues concerning public acceptance of and opposition to wind farm developments.

- An empirical section that utilises the Tararua Wind Farm as a case study, including an analysis of submissions and interviews.

- A discussion of selected publications that scrutinises literature on best practice in the wind energy sector, and literature on community consultation approaches and public involvement opportunities.

In February 1996 the Tararua District Council (“TDC") granted resource consent, under the Resource Management Act 1991 (RMA) for the development and installation of 103 wind turbines. The developer applied for subdivision and land use consent, and this was treated as a non-complying activity under the transitional Tararua District Plan. TDC approved the application under the implication of a few conditions with regard to turbine paint, microwave interference and air safety issues. In June 1999, stage 1 of the project was completed with the erection and commissioning of 48 Vestas V47 660Kw wind turbines. The wind farm is situated on the northern end of the Tararua Ranges just south of the Manawatu Gorge, approximately 11 kilometres east of Palmerston North (Tararua District Council, 1996).

The Tararua Wind Farm was chosen as a case study so as to:

- investigate the initial reaction of the community to the wind farm proposal,

- compare the arguments used to object to the proposal in the resource consent process with present-day experiences with the operating wind farm of affected stakeholders,

- examine the applied consultation process, and 
- to look at the experiences of the wind farm developer with regard to community consultation and public opposition.

The underlying aim of this approach was to incorporate these findings into recommendations for future consultation processes for wind farm developments in order to significantly reduce the likelihood of community opposition. The decision to choose the Tararua Wind Farm was limited by the availability of suitable projects for a case study of pre- and post-development community experiences because only two utility scale wind farms are currently operational in New Zealand. The second operational wind farm (Hau Nui, Wairarapa) received resource consent without any significant community opposition.

The initial intention of the research methodology was to analyse the submissions into the resource consent process for the TWF in order to understand the reasons behind any opposition as a first step, with subsequent follow-up interviews with each and every submitter who objected to the TWF proposal so as clarify issues in detail. The analysis was designed to

(a) evaluate the factual accuracy of objectors' concerns,

(b) understand the nature of the opposition and,

(c) identify strengths and weaknesses of the applied consultation process.

After commencing the research an unforeseen limitation of the methodology became evident with follow-up interviews, because not all submitters could be contacted or some refused to participate with the result that there was a relatively small sample set of interviewees (A total of nine stakeholders were interviewed. Only four interviewees of nine opposing submitters agreed to participate in this study. Additional information was obtained from five affected landowners and immediate neighbours.). In response to this problem a decision was made to extend interviews to staff of the wind farm developer and thus gain an industry perspective on public consultation, and also to undertake a more detailed discussion of the published literature on best practice for wind farm developments and community consultation. 
The remainder of this chapter presents the conceptual framework and the specific methods associated with each research objective.

\subsection{Conceptual Framework}

The conceptual framework constitutes the theoretical foundation of this research. Consequently, it affects the approach of the research aim and the procedure to fulfil it. The conceptual framework also determines the selection of specific methods for gathering information and the way research findings are analysed and interpreted.

Hill (1981, in Kitchin et al., 2000) points out that many geographers question the relevance of philosophical issues in geographic research. May (1997) discusses the option of disregarding social theories and concludes, by referring to Elias (1987), that relevant research can be conducted based on facts only. On the other hand, May refers to Plummer (1990) who emphasises that facts alone are insufficient and that "issues of problem, method and substance" are closely linked to theory. Kitchin et al. (2000:6) comment "it is tempting to dismiss philosophy, or to try and avoid it because it seems difficult", but "no research [...] takes place in a philosophical vacuum" (Hill, 1981 quoted in Kitchin et al., 2000).

As a theoretical foundation this study employs applied geography to interpret results and discuss findings. Applied geography takes a problem-oriented approach into a wide range of areas including "the use and management of scarce resources, the interaction between people and environment, soil conservation, vegetation management, land use conflict, place and identity, and spatial inequalities in economic and social well being" (UNSW, 2003 [online]). According to Pacione (1999:3), applied geography can be defined as "the application of geographic knowledge and skills to the resolution of social, economic and environmental problems" and it focuses on solving "real-world problems" outside the university by utilising the "particular philosophy of relevance and social usefulness". 
Applied geography was chosen as the theoretical framework for this study, because of its "holistic approach" that takes into account the practical issues associated with the relationship between people and their environment (Stamp, 1960) and its problem solving capability. The development of wind farms in our landscape can be seen as a real-world problem with the potential to impose adverse affects but it can be seen as bringing wide range of benefits to involved stakeholders and the environment. Consequently, this dilemma can trigger public opposition against a proposed project. Within this study, the conceptual framework was applied to analyse and interpret the research findings so as to develop recommendation that can contribute to the significant reduction of public opposition.

\subsection{Specific Methods}

The applied geography approach enables the overcoming of geographical intra- and interdisciplinary boundaries (Pacione, 1999) and invites the employment of mixed (qualitative and quantitative) research methods.

This research has two investigative sections: an empirical component and a text analysis. According to Hay (2000:7) the empirical component of qualitative research utilises the analysis of both textual and oral meanings: the textual empirical component of this research focused on an analysis of submissions into the resource consent process for the Tararua Wind Farm (see Chapter 4.2.1); the "oral" component involved follow-up interviews with affected residents (see Chapter 4.2.2) and interviews with the wind farm developer (see Chapter 4.2.3). The discussion of selected literature on best practice and community consultation provides further information used to interpret and analyse the empirical findings (see Chapter 4.2.4).

While the empirical component of this study (analysis of submissions and interviews) refers to research objectives one to three, the discussion of selected literature fulfils the 
fourth and fifth objective by investigating best practice consultation and possibilities for community involvement.

\subsubsection{Analysis of Submissions}

The first objective of this study focuses on the examination of the initial reasons behind public opposition to the Tararua Wind Farm proposal. Public submissions were used as an information source for exploring the initial grounds of objection, which were expressed by a number of residents in close proximity to the proposed wind farm. This information was compared with the follow-up interviews with these submitters to establish whether the initial concerns were fulfilled when the wind farm was built. The submissions were chosen as a sample set, because they represent an 'historic' documentation of public arguments against the wind farm, made within the formal process under the Resource Management Act 1991. Copies of the original submissions were obtained from the Tararua District Council.

The procedure used to analyse the submissions is described by Silverman (1993) as 'textual investigation' and is associated with the method of content analysis. This method involves the establishment of categories of information extracted from texts, allowing for the classification of these features to make them meaningful and comparable (Dey, 1993). Features can be specific words or expressed ideas that help to generate data based on the analysed information (Mayan, 2001). The analysis of submissions was aimed at classifying the submitters according to their status (company, association or individual) and their arguments against the wind farm proposal so as create a data set that could be compared with the findings of the follow-up interviews. Potter (1996) states that the examination of documents in combination with interviews may add evidence and increase the integrity of interview results. For this purpose, factual and subjective comments were extracted from the submissions and the arguments were represented in graphs. Arguments in support of the wind farm proposal were classified according to emission reduction, additional electricity capacity, ideal location, cost competitiveness of 
wind energy, employment opportunities, noise reduction, pilot project and tourist attraction. The main arguments in opposition of the proposal were identified as noise emission, electro-magnetic interference (EMI), visual intrusion, effect on eco-tourism, land devaluation, hazards associated with turbine failure, increase of traffic and airspace safety.

Potential limitations of this method are associated with the size of the sample set in comparison with the total population. It is unlikely that the submissions exactly represent the view of the whole community in the Manawatu region, but they do provide a valuable indication of community opinion and concerns, sufficient to provide local authorities with a basis for decision-making.

\subsubsection{Interviews with Submitters}

The second empirical component of this research consists of follow-up semi-structured interviews with community stakeholders who made a submission as part of the resource consent process or were consulted by the wind farm developer as part of the Environmental Effects Statement (EES) requirement.

The selected questions (see Appendix III for interview questions) acted as a guide and prompt in the semi-structured interviews. Frequently the discussion ranged beyond the questions but this was kept to a minimum. This method was chosen in order to make the interview as informal as possible, to enable the interviewer to feel relaxed and able to control the interview to some degree depending on what the interviewees considered to be the most important things to communicate. This produced more data than could be incorporated into the results but did enable the major themes to be adequately covered. The interviews were conducted between July and August 2002.

Interview participants were asked three sets of questions to elicit specific information: The first set of questions focused on the grounds of their objection, on potential 
underlying reasons for their opposition and to what degree their arguments are based on wind generation related knowledge and experience.

The second set of questions addressed the reaction of opposing submitters to the actual wind farm following its establishment, to see whether any of their views had changed (whether their level of opposition had increased, decreased, or remained the same).

The third set of questions focused on the public consultation process used during the preapproval phase. The last set of questions was particularly concerned about the introduction of the project to the community, the consultation approach and options for community involvement and participation.

Participants were selected by using names and contact details obtained from the resource consent application process for the Tararua Wind Farm. After the ethical approval was obtained from the Human Ethics Committee (see Appendix IV), a first contact was established by sending a letter to the submitters (see Appendix I) explaining the nature of the research and asking them if they would be interested in participating. One week later the potential participants were contacted via telephone and asked if they were interested in taking part in this research. If so, arrangements were made for a convenient date and time to conduct the interviews on the participant's premises. In instances were participants preferred to conduct the interview via telephone, a suitable time to ring them was arranged.

All participants who agreed to be interviewed signed a consent form (see Appendix II), after which semi-structured interviews were conducted by the 'Notepad' method applied to record information (Robinson, 1998) during the interviews. This interview strategy is content focused and allows for pursuing ordered questions without compromising flexibility (Hay, 2000). In total, nine interviews were conducted with stakeholders, five of them in face-to-face meetings at the participant's premises and four via telephone. The analysis of the interview results was based on the interview notes and transcripts. All 
results were analysed for emerging themes and patterns as suggested by Taylor et al. (1998) and described above.

There proved to be limiting constraints on the follow-up interviews.

Firstly, because of a generally high level of public support for the Tararua Wind Farm and its remote location in a rural area, only a relatively small number of residents were personally affected and made a submission in opposition into the resource consent process. Consequently, the total pool of potential interviewees was relatively small.

Secondly, people who were identified and of interest for this research no longer lived at their former address and/or couldn't been located. Thus many introductory letters could not be delivered and were returned.

Thirdly, due to confidentiality issues some former objectors refused to participate in this research as well as the corporations, which had formerly opposed the development.

A possible fourth limiting factor could arise when arguments stated in the submission are compared with the arguments investigated through these interviews. The sample sets of the follow-up interviews are not $100 \%$ identical with circumstances and form of argument the stakeholders put forward when they made a submission to the resource consent process, which potentially influenced the evaluation of the results.

\subsubsection{Interviews with Wind Farm Developments}

The final component of this research involved a group interview with the staff of Wind Farm Developments (Australia) Ltd. (WFD), which was selected to accomplish the third research objective. WFD is a Wellington based wind farm developer who planned and developed the Tararua Wind Farm near Palmerston North and is currently involved with several wind farm projects in Australia and New Zealand. Three staff members - the two 
co-directors and a project engineer - participated in the interview. The aim was to investigate the views of a wind farm developer on the public consultation processes.

The group interview questions (Appendix III) aimed at examining specific information on three main themes:

- Community opposition

- Community consultation and participation

- Development of the Tararua Wind Farm

Focus on community opposition invited investigation into the developer's understanding of a best practice approach to deal with public opposition against a wind farm developments and how community acceptance can be increased. The second theme covered the developer's viewpoint on community consultation and available options for community participation in the planning and consultation process. The third theme discussed issues associated with the development of the Tararua Wind Farm with the aim of gathering specific information on the applied consultation strategy, the experience made during the process and the developers' approach to public involvement in the consultation process.

The interview method can be described as a combination of the 'interview guide' and 'group guide' approach. Following Kitchin et al. (2000), the researcher acted as a moderator by directing the interview with three staff members of WFD. Even though there was a set of selected question for a semi-structured group interview it appeared to be more practical to use these questions as an interview guide rather than adhere to them rigidly. It allowed the interviewer flexibility to explore all areas of interest in a conversational style and the participants were given an opportunity to discuss specific topics which they considered particularly controversial. As suggested by Robinson (1998) the researcher tried to understand and get insights into the thoughts, feelings and formative experiences of the respondents in relation to the topics discussed. 
The interview was conducted in a relaxed atmosphere in the company's office. The conversation was tape-recorded and additional notes taken. After the interview the conversation was transcribed according to the procedure recommended by Wengraf (2001). The method used to analyse and interpret the interview results utilises the 'universal approach' discussed by Kitchin et al. (2000) that refers to Dey's (1993) qualitative analysis approach which consists of the description, classification and connection of qualitative data. This procedure involves:

- transcription and annotation of the recorded interview.

- interpretative analysis that places the interview material into meaningful categories according to the themes covered within the interview, to enable analysis through comparison (e.g. with the information gathered in the literature review).

- interaction between the identified categories so as to increase the understanding of their relationships and associations.

Possible limitations with this method were associated with the size of the sample set constraining the opportunity to compare responses with other developers' understanding of consultation. Moreover, it needs to be acknowledged that the interview responses represent the view of a business entity with the primary aim of developing wind farms.

\subsubsection{Discussion of Selected Literature}

The method described below to identify, limit and select the literature applies to the discussion of selected literature - Towards Best Practice in Consultation (see Chapter 6) as well as to the literature review (see Chapter 2). The methods employed are presented jointly to avoid unnecessary repetition.

The literature to be scrutinised was selected by limiting the search to the following three categories: 
- peer-reviewed literature and articles on renewable energy with specific focus on wind energy and its associated issues with regard to public acceptance of wind energy, opposition to wind farms and planning approaches.

- articles on public participatory approaches with specific attention focussed on different levels and forms of community involvement and stakeholder analysis.

- literature on consultation principles was selected, focusing on best practice guidelines on consultation for wind farm developments.

The limitations were imposed on the search to select specific literature for three key reasons. First, it was aimed at describing the circumstances leading to public opposition to wind farms, the spectrum of objections and to illustrate the public acceptance of wind farms.

Secondly, the literature on public involvement and stakeholder analysis was selected to outline possible approaches to involve affected stakeholders in the planning process and how to make an informed decision on the most appropriate level of participation in order to reduce the likelihood of opposition and how to improve wind farm acceptance.

Thirdly, the community consultation literature was scrutinised in order to describe different consultation approaches. On the one hand these are public consultation approaches which involve communities and their participation. On the other hand, they encompass consultation strategies especially designed for planners and developers of wind farms.

While the initial search for literature was limited to New Zealand publications, the search had to be expanded to include European and American literature and articles on the selected topics, due to the lack of publications dealing with wind energy in New Zealand. The underlying aim was to select the latest publications available with particular regard to surveys and research work on public attitudes towards wind farm developments. The same aim applied to the selection of Best Practice Guidelines, which are published by wind energy associations. 
Possible limitations upon the review of literature and text analysis are associated with the selected focus on the specific categories that were chosen to extract information from the literature. Some aspects that would have otherwise enhanced understanding of the discussed issues might have been unintentionally overlooked. Moreover, an additional limiting factor is that some documents, which might have contributed to the review and discussion of selected literature, have not been published or was not publicly available because of confidentiality agreements (especially corporate and internal documents about consultation for wind farm developments). 


\section{EMPIRICAL RESEARCH RESULTS}

This chapter presents the results of the three empirical components of this research. The analysis of the submissions on the Tararua Wind Farm resource consent application is presented in Chapter 5.1; the results of the follow-up interviews with opponents to the wind farm proposal and other affected stakeholder are presented in Chapter 5.2, and the results of the group interview with a wind farm developer is presented in Chapter 5.3. The results for each component were categorised into themes corresponding to its relevant research objective.

\subsection{Analysis of Submissions}

The proposal for the Tararua Wind Farm development created considerable public responses, judging by the number of submissions made into the resource consent process. There were 23 submissions altogether. Thirteen submissions supported the entire application, nine opposed and one was neutral. Some submissions represented the views of more than one person, because entire families, a consortium of people or organisations signed them, for example, one individual submission in support of the wind farm was signed by eleven people while most individual submissions in opposition were signed by all family members. These documents were analysed to investigate and identify the arguments used by the submitters in support of or against the wind farm. The analysis focused primarily on reasons for opposing the proposed wind farm.

The submissions in support of the wind farm were received from organisations (5 submissions) such as energy associations or governmental authorities, from corporations (5 submissions) such as utilities and developers, and submissions from three individuals. Eight main categories of arguments were identified and are presented in Figure 5 below. As an example, these concerns are further described by representative quotes from the submissions: 
Figure 5: Arguments in Support of the Wind Farm Proposal

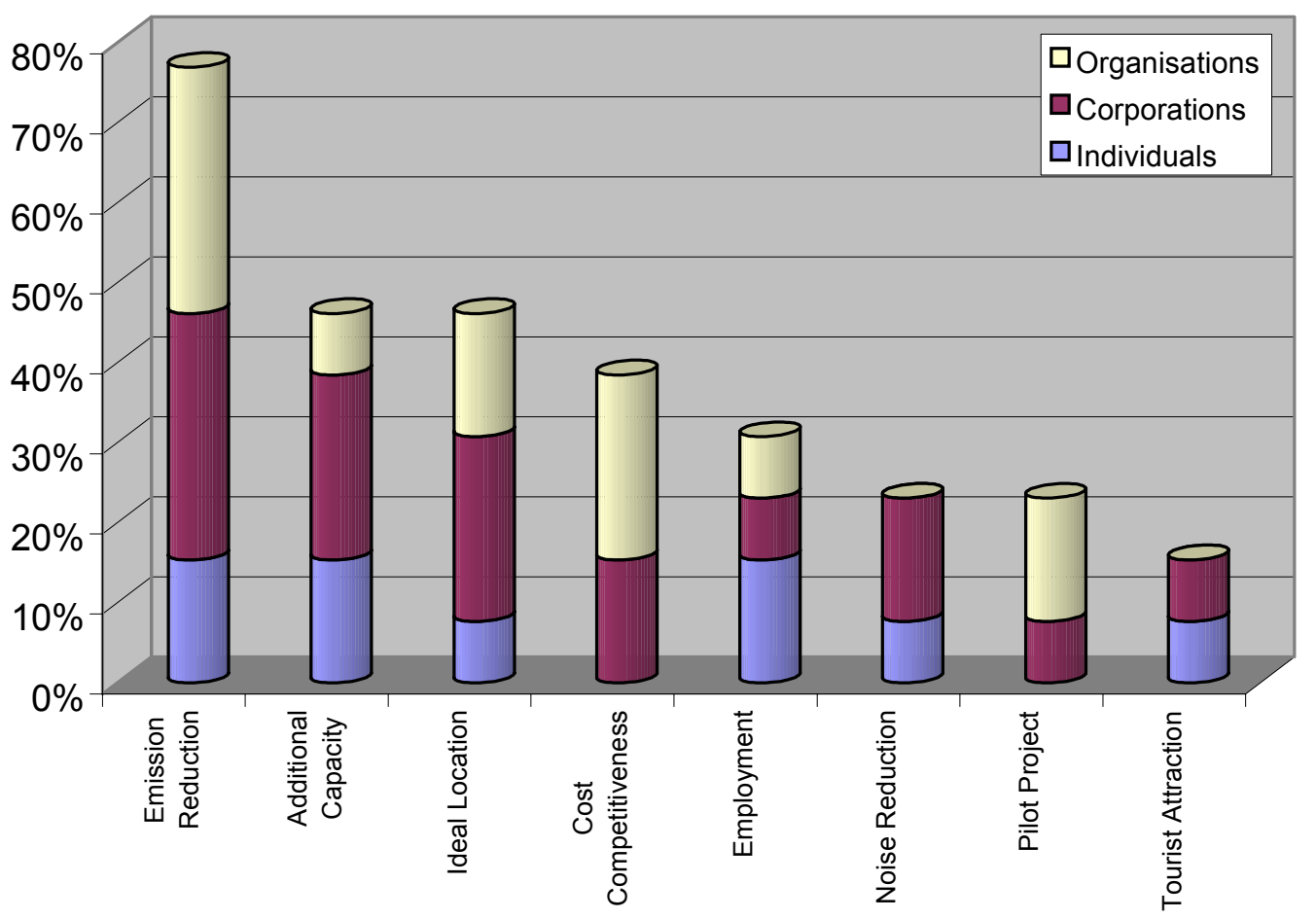

(1) Wind energy is a renewable resource and reduces $\mathrm{CO}_{2}$ emissions (argument mentioned in 10 submissions which represents $77 \%$ of all submissions in support);

"With the growing concern over the continued use of fossil fuel and the production of $\mathrm{CO}_{2}$ and other greenhouse gases any authority charged with working under the Resource Management Act should welcome wind generation as it is almost totally benign." (Organisation A)

(2) Wind energy adds electricity generation capacity and diversifies New Zealand's energy sources $(6 / 46 \%)$;

"Nonetheless by around the end of this decade it is very likely that new generation capacity will be needed. [...] The appropriate response is to build new capacity and for a variety of reasons it is desirable that this be based on renewable energy resources." (Organisation B) 
(3) The Tararua ranges represent an ideal location for wind generation (6 / 46\%); "[Our organisation] considers that the area selected by TWP (the northern Tararua Range) is an important wind resource area, and is suitable for installation of wind generation plant in both technical and environmental terms, and that overall impacts of development are minimal." (Organisation C)

(4) Wind energy is a cost-competitive option (5 / 38\%);

"Wind energy is a clean and cost-competitive power generation option that is enjoying its best year ever in terms of new installed capacity.” (Organisation D)

(5) The development could generate regional employment opportunities (4 / 31\%); "I am keen to see this project come to this area because if the jobs and business within the community it will attract." (Individual A)

(6) Possible noise effects are minor due to technical advancements in wind turbine technology $(3 / 23 \%)$;

"In the past, there were some noisy wind turbines. However, manufacturers have realised that turbines must be quiet and they have been very successful in achieving this." (Company A)

(7) The wind farm is considered to be a pilot project for New Zealand that could bring further benefits for a national wind industry (3/23\%);

"There is a potential for the Tararua Wind Farm to represent a major step forward to continue New Zealand's tradition of clean energy both as a development on its own right and also to serve as a model for other developments elsewhere in the country." (Company A) 
(8) The wind farm has the potential to become a tourist attraction $(2 / 15 \%)$.

"Wind farms are tourist attractions and as such provide additional income for local communities." (Farming business)

Other arguments, which were not categorised in this analysis stressed the potential benefits of multiple land use, land reinstatement after decommission and the increase of public awareness with respect to wind energy.

In contrast, a total of nine objecting submissions were made during the resource consent process, five opposed the entire application and four submissions which objected and which might have been resolvable through further clarification or by placing conditions on the resource consent (Tararua District Council, 1996). Five submissions were received from individuals and four from corporations. Figure 6 below displays the categories of arguments raised in the submissions:

Figure 6: Main Arguments in Opposition of the Wind Farm Proposal

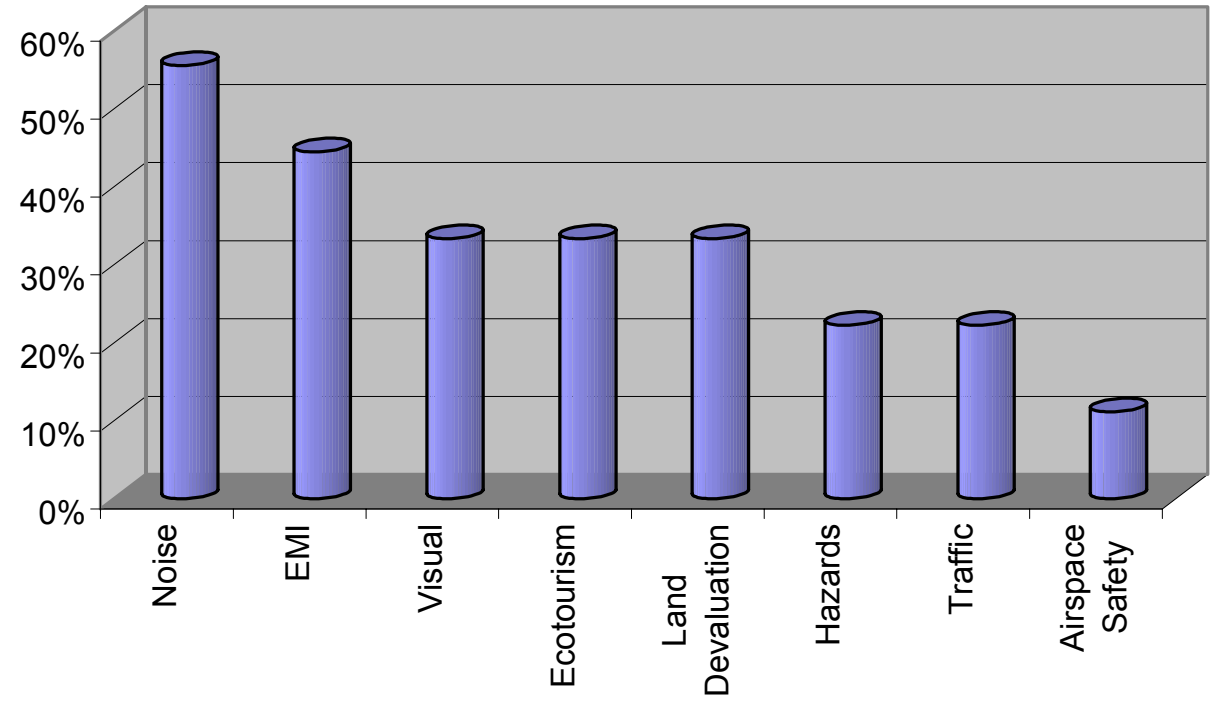

(1) All local residents perceived noise disturbance of operating turbines as an adverse effect (the argument was used 5 times representing $56 \%$ of all submissions in opposition) 
"We understand that the noise caused by wind turbines is very loud and persistent and this will be a pollutant with 137 turbines proposed for the site.” (Individual B)

(2) Electromagnetic Interferences ("EMI") with existing microwave towers or radar facilities $(4 / 44 \%)$

"The adverse effects of concern [...] include interference to a number of established strategic communication facilities operated by TNZL and TMCL in the locality, [...] [e.g.] physical obstruction of radio transmission; [and] electromagnetic interference resulting from radiation from wind turbine generators;" (Company B)

(3) Visual intrusion of turbines in the landscape (3/33\%)

"I believe the visual impact will not be consistent with the preservation of natural landscape features appropriate to the rural nature of the Tararua Ranges.”(Individual C)

(4) Threat to eco-tourism in the Tararua Ranges (3/33\%)

"As for the negative effect on our present and potential eco-tourism I feel [there] has been no real consideration, at a time when the creation of sustainable rural employment is a great and personal concern [...]" (Individual D)

(5) Land devaluation of properties in proximity to the wind farm (3/33\%)

"The installation of the wind farm will depreciate the value of and affect the resale potential of our property." (Individual B)

(6) Hazards e.g. associated with blade failure (2/22\%)

"There is no guarantee that blade failure will not be a risk to recreational users on our property." (Individual E) 
(7) Increase of local traffic during construction period and operation (2/22\%)

"The additional traffic on the local roads generated by the installation of a wind farm will also affect the tranquillity and beauty of the area and be hazardous to local residents and users of the Tararua Ranges for leisure pursuits [...]" (Individual B)

Other arguments stated in the submissions raised issues of airspace safety because the turbine height might pose a threat to aircraft using the Palmerston North Airport; inappropriateness of the proposal under the RMA because of a deficiency of measures to avoid or mitigate possible adverse effects; exclusion of the local community from the decision making process, and general intrusion of the proposed wind farm upon tranquil rural lifestyle.

Because submissions opposing of the wind farm proposal were made by local residents as well as companies facilitates categorising them according to their source (Figure 7).

Figure 7: Main objecting arguments categorised into arguments from individuals (blue/dark) and corporates (yellow/light)

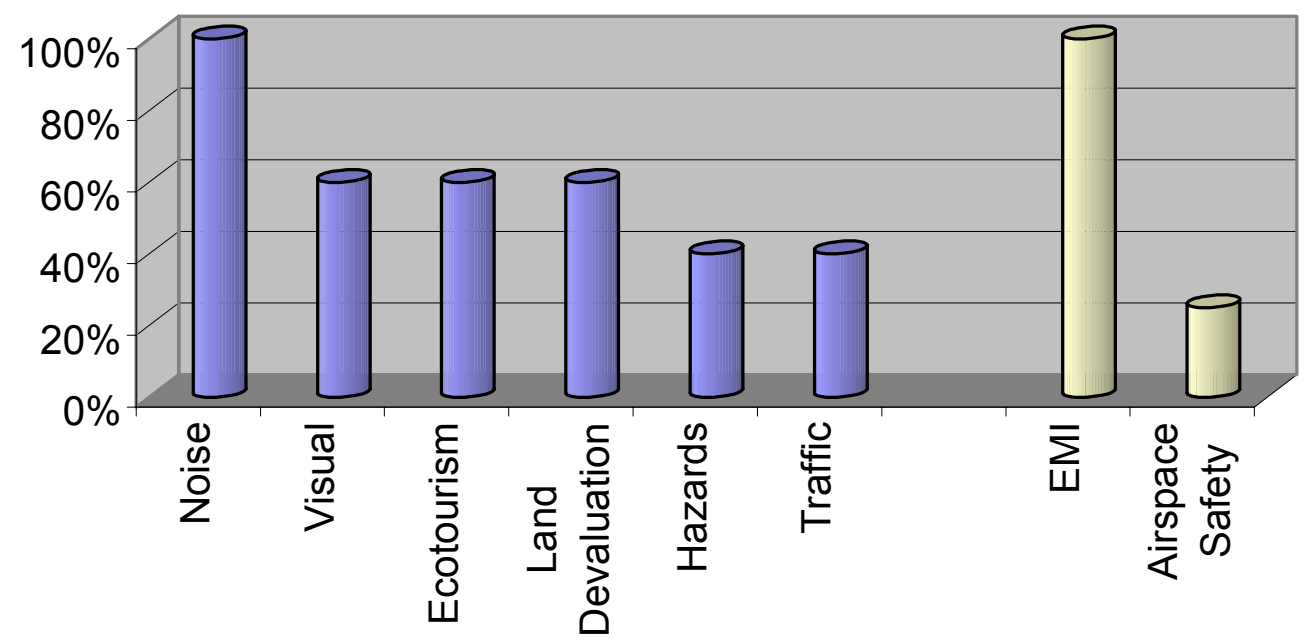

It is clear that the overwhelming concern of residents was the potential disturbance of their current living environment, primarily by turbine noise $(100 \%)$ followed by visual intrusion, threat to eco-tourism and land devaluation (all 60\%). In contrast, corporations 
are more concerned about technical issues that could affect their business ventures such as possible electromagnetic interference $(100 \%)$ or airspace safety $(25 \%)$.

\subsection{Follow-up Interviews}

The follow-up interviews represent the second part of the empirical research. Participants were selected because they made a submission opposing the proposed wind farm or were consulted during the lead-up to the public notification of the resource consent application. The results were derived from four out of the five non-corporate submissions and three affected landowners. Additional information was obtained from two participants who were consulted by the developer during the resource consent process. The method was chosen to explore the reasons behind the community opposition with respect to the second objective of this research. The interviews were conducted to collect specific information on three identified themes:

- reasons for opposing the wind farm

- any change of attitudes following the wind farm establishment

- interviewees' views on consultation process

The interview participants were predominantly active in the agricultural sector, but were also employed, self-employed or retired. More details on the method can be found in Section 4.2.2. The interview questions are presented in Appendix III.

\subsubsection{Grounds of Opposition}

When participants were asked for their initial motives for making a submission in opposition to the wind farm, their responses were twofold. Firstly, two former objectors stated that they were worried about possible adverse effects, such as noise or visual impact on the landscape, because they had little or no experience and knowledge about this new form of electricity generation. Both interviewees stated that they were scared 
and afraid of this new concept of power generation because they don't know much about it and don't really understand how the turbines would look and sound. They basically made the submission to protect themselves of visual pollution, which they considered as a potential "sacrifice" of visual amenities ("we enjoy the peace and quite, and don't wanna have no man-made things"), and potential noise intrusion due to "bad experiences with old noisy wind turbines".

Secondly, two respondents argued that they made the submission on principle because of their personal dislike of wind turbines and would possibly make another submission against a wind farm proposal at this site in the Tararua Ranges were they in the same situation again. The main grounds of opposition were visual pollution and noise ("the turbines are ugly and they shouldn't be there").

These opposing stakeholders were living in close proximity to the proposed wind farm site. They were not anticipating any direct or indirect benefits from the development, but were fearful of potential disadvantages and consequently objected the proposal in principle.

\subsubsection{Change in Attitude}

The interview responses showed, that most initial objectors - including corporations ${ }^{18}$ revised their initial objection to a more neutral standpoint or are now in support of the wind farm ("we accepted them and under certain conditions they are beautiful"). The operation of the Tararua Wind Farm apparently caused no major adverse effects to the community or environment ("they are not making a mess - they are no problem"). The majority of the interview participants (five out of seven) think that the whole region is benefiting from the wind farm and they support the idea of generating "green",

\footnotetext{
${ }^{18}$ Even though no representative of the companies who made a submission was able to participate in this research due to confidentiality issues, the wind farm developer WFD gave an assurance that all concerns in regard to EMI and airspace safety had been resolved or mitigated.
} 
environmentally friendly electricity ("[the wind turbines] are safe, clean and we are happy with them - as long as there is no nuclear reactor in New Zealand"'].

Only two former submitters had reservations about visual aspects of the development and still consider the turbine as "ugly" ("they ruin the natural landscape"). Minor problems mentioned were associated with noise ("we can hear [the turbines] sometimes outside, but not inside [the house]", "they sound like a train in the distance that never gets here like constant ocean noise"), traffic and land devaluation. The occurrence of annoyance through noise seems to depend upon the direction of the wind. One resident who lives at the foot of the Tararua ridgeline (where the wind farm is situated) stated that the emitted noise of the turbines is louder than expected. Another interviewee mentioned his dislike of increased traffic when misguided sightseers searched for the wind farm access road, which is mainly caused by poor traffic signs in the rural area (one response). Finally, one person mentioned that he is concerned about the possible devaluation of his property if he decides to sell it. In general, the participants who were opposed to the project proposal declared that the impact of the wind farm on the community is "not as bad as expected". Other residents stated that "early concerns didn't turn out to be a problem" or they simply "got used to it" and accepted its existence ("you get used to the wind turbines - like you get used to power lines in the landscape").

Moreover, local businesses experienced a spin-off since the wind farm was developed. At least two tourism companies associated with the wind farm are owned and operated by former objectors. One interviewee stated that the turbines became "a real icon in the region" and are visited by many tourists every year. Local businesses are now organising adventure and sightseeing tours to the wind farm site (4WD and ATV off-road tours, horse treks). A café ("Beyond the Bridge Café") located at the turn-off to the access road is also benefiting from more visitors, too. The turbines themselves are generating a significant income for the landowners through rent payments from the wind farm operator. 


\subsubsection{The Consultation Process}

When interview respondents were questioned about their satisfaction with the consultation process, answers varied: landowner and objectors (who afterwards positively altered their initial attitude) described the consultation approach as "appropriate" and confirmed that it was able to address their concerns by clarifying or mitigating. On the other hand, two objectors were not satisfied with the consultation approach. They disliked the way consultation was conducted and felt that their opinion had not been considered at a personal level. They had received the impression that the developer would build the wind farm irrespectively and that their concerns had not really been taken into account (These two submitters remained opposed to the wind farm development once construction was completed because of their personal dislike of operating wind turbines at this particular location).

The majority $(80 \%)$ of interviewees expressed that more information and clarity on the project would have been desirable in overcoming negativity and suspicion about the proposal. They stressed the importance of developers' understanding the local viewpoint. In the opinion of three participants the appearance of the person conducting the consultation process was inappropriate ("lawyer-type with flashy clothes") and generated the impression of a powerful "big company approach".

When interviewees were asked to what extent they were given a chance to participate in the planning process the majority replied that generally they had had no influence except in raising their concerns through submissions or during consultation. One respondent believed that his opinion was ignored ("there was no chance against these lawyers - they considered my opinion only in a formal way, but not personally - they ignored our opinion"). However, all participants claimed that they were interested in opportunities to participate, if they had been given the chance. Suggestions were made to involve stakeholders in public discussions and provide more project information on an ongoing basis after the construction of the wind farm ("it would have been nice to be kept informed - like a follow-up courtesy - but nobody showed up"). Others raised the issue 
of "localising" the project through investment opportunities in a wind farm which would increase local benefits ("the affected people should benefit from the wind farm, too, not only the owner").

The majority of the interview participants had the perception that community members had little opportunity to influence the decision except by making a submission into the resource consent process ("we made a submission, but it didn't change anything"). Only the corporations which opposed the project and the landowners who would accommodate the turbine on their properties were given a "real chance" to address their concerns throughout the planning process. The public was well aware that the final decision to permit the wind farm development was made by the District Council.

\subsection{Interview with Wind Farm Developer}

The fifth objective of this research involved gathering an industry perspective on community consultation, by interviewing the staff of Wind Farm Developments (Australia) Ltd. (WFD). The focus of this objective was to explore and understand how a wind farm developer approaches the public consultation process taking particular concern for economic constraints. The interview results were categorised according to specific information on three main themes covering public opposition, community consultation and participation, and finally the Tararua Wind Farm consultation strategy. A more elaborated description of the applied method is presented in the methodology section (Chapter 4.2.3). All interview questions are listed in Appendix III.

\subsubsection{Public Opposition}

The wind farm developer generally experienced that the majority of an affected community is supportive or indifferent towards a new wind farm proposal and around 5 to $20 \%$ of these people are outspoken in their opposition towards the project. According 
to WFD, these people opposed aim to create the impression that they are representing the views of the whole community, whereas the vast majority of the community are quite supportive, but they just don't "jump up and down" and "make all the noise". The developer understands that regardless of the project, there will be always some $5 \%$ of the community who oppose the proposal. It is just a matter of how well organised they are. Concerns of objectors are often based on a lack of understanding and the objectors are rarely willing to consider mitigating measures in any form. In this case the diminishing law of returns applies. The developer believed that despite the amount of resources spent on pacifying the objectors "you will never get them over the line". According to WFD this particular group of objectors tends to polarise the views within the community, and they are not particularly opposed to wind farms, but rather oppose any kind of development that might change or affect their life. Moreover, WFD identified a recent trend in Australia where local wind farm opposition groups use their experience to extend their activity state-wide as is happening in Victoria.

WFD staff cited the following insights and approaches that should be taken into account when dealing with community opposition to a wind farm proposal:

- retaining a certain momentum of the project is needed to avoid the gradual formation of opposition groups is one of the paramount objectives; otherwise the consultation process might become pointless.

- arguments raised by objectors must be assess to decide whether they are valid and to what degree perceived adverse effects could be mitigated or remedied.

- people should have an opportunity to visit an existing operating wind farm. It helps them to form their own perspective on noise and visual intrusion, and consequently, they may be less likely to oppose on these grounds. People come up with valid concerns, because wind farms are still a novel concept in New Zealand.

- strong opposition groups tend not to participate in the consultation process. They just ask for information and state their demands, but do not participate in finding a 
solution, which could accommodate their concerns. If such objectors are not willing to cooperate despite numerous attempts to convince them, it could be more effective to ignore them, because the costs to pacify this $5 \%$ are "not insignificant".

- the developer criticises the resource consent process under the RMA as being predominantly designed to consider opinions of people who object to a project. In practice, only objectors write a submission yet hardly any support groups actually participate in wind projects unless a community has the prospect of economic benefits e.g. through lease agreements for the construction of turbines on private property.

The developer expressed the belief that submissions from opposing groups carry more weight at panel hearings than submissions in support. WFD referred to some cases where objectors paid expert witnesses to defend their opinion $t$ so as to lend credibility to their argument and include other arguments which they did not necessarily hold themselves. Moreover, WFD stressed that possible local adverse effects have to be weighted against national benefits such as $\mathrm{CO}_{2}$ emission reduction. Therefore, an independent decision maker is required to ensure a fair outcome. Finally, according to the wind farm developer, it is important that authorities who permit a project to proceed acknowledge that it is impossible to satisfy every single stakeholder in the community, i.e. by taking into account that $95 \%$ are "quite happy, supportive or don't really care" about a wind farm proposal, instead of focusing only on the 5\% opposing a project.

\subsubsection{The Consultation Process}

The wind farm developer emphasised the necessity to continuously refine the consultation strategy, because the success of the consultation approach substantially affects the ability to gain resource consent. The consultation process is ideally a mutual course of action. It should commence "at an early stage, but not too early". The developer 
provides project information to the stakeholders and collects their feedback in return, and if possible, takes their comments into account.

According to the developer's experience, one-on-one sessions are preferable to public meetings, because they allow information to be disseminated and to more readily an individual stakeholder's concerns, and forestall the risk that a community meeting will get "out of control". One-on-one consultation is considered as one of the most effective forms of consultation. It is essential for the success of the project to maintain momentum by using a team of consultants to meet community stakeholders.

The developer acknowledges that it is challenging to involve the community in the planning process. On the one hand, WFD believes that the vast majority are quite apathetic about opportunities in participation: they "come, listen, [are] satisfied and go away". On the other hand, WFD staff suggested that on the whole the objectors are interested in forms of participation so as to "use the process to get ammunition" in form of information. They believe information is sometimes used in order to "kill your project, stop you or slow you down, frustrate you, make life difficult" until the developer goes somewhere else. Generally, WFD staff considers consultation an important part of the resource consent process in New Zealand. They do see a danger, however, where consultation can be overdone, become very costly and at worst cause the project to fail as a result.

\subsubsection{Consultation Process Applied to the Tararua Wind Farm}

The developer conducted a stakeholder consultation process before submitting the resource consent application. The selected stakeholders were directly affected groups and individuals that were primarily identified by the Tararua District Council who provided a list of affected parties and neighbouring landowners to be consulted. The project was established by sending "introductory letters" and project descriptions to the affected parties in September and October 1995. In addition, meetings were held with most 
stakeholders as an opportunity to discuss the project details. During this process stakeholders were asked to sign an "affected party consent form" which gave their approval to develop the wind farm as proposed (Tararua Wind Power, 1995).

The developer stated that their focus for the consultation process was informing the people and receiving their consent for the development with the intention of "avoid[ing] the project being received as committed when the economic viability was very finely balanced". The approach was one-on-one consultation with the directly affected parties. WFD did not consider public meetings be necessary or desirable due to a general high level of awareness and public support, and because of increased risk of empowering community groups in opposition (as happened with ECNZ during the consultation process for the Makara Wind Farm proposal in 1997).

Consulted parties included local authorities such as Tararua District Council, Palmerston North District Council, Manawatu-Wanganui Regional Council; environmental conservation groups (Wellington Fish and Game Council, Royal Forest and Birds Protection Society, Department of Conservation, New Zealand Historic Places Trust), Iwi authorities, the Civil Aviation Authority of New Zealand, as well as affected landowners, occupiers and corporations.

Additional public consultation activities were a promotional brochure giving information on the wind farm project, an editorial in the local newspaper (Manawatu Evening Standard), and a public display at the Woodville Service Centre and the showroom at CentralPower Limited, Palmerston North (Tararua Wind Power, 1995). Consultation during the post-application phase of the project involved ongoing dialogue with the objectors to the wind farm. The developer also organised two 'open days', which attracted several thousand people, post-construction site tours to involve the public in the project and the construction of a public viewing platform.

According to the developer, the main difficulties during consultation related to the delaying procedure of dealing with the objections from corporations, which were 
concerned about the wind farm's possible effects on airspace security and on existing microwave towers because of electro magnetic interference (EMI). Eventually the issue of airspace safety was resolved by altering the flight path approach to the Palmerston North airport, and the possible problem of disturbance to microwave towers caused by EMI was successfully prevented by identifying and avoiding existing Fresnel Zones ${ }^{19}$ during the construction of the wind farm.

\subsection{Summary of Empirical Research Results}

Analysis of the submissions identified the main arguments that were used to support or oppose the wind farm proposal. Supporters mentioned such advantages as emission reduction, additional power generation capacity and the Tararua ranges as an ideal location for a wind farm. Objectors raised concerns about noise, EMI, visual intrusion, threat to eco-tourism and land devaluation. The nature of the argument was highly dependent on the submitter itself: while individuals worried about the potential noise impact, corporations were concerned about expected EMI and airspace security.

Follow-up interviews revealed that the submissions opposing the resource consent application where made due to anticipated adverse effects or out of principle. The majority of the initial objectors adjusted their attitudes to a more neutral or supportive view once they experienced the operating wind farm in their vicinity. In addition many community members stated that they now benefited from business opportunities associated with numerous tourists visiting the wind farm. While two former submitters remained concerned about the visual intrusion of the wind farm, most other issues associated with noise, EMI and eco-tourism were no longer seen as major problems. The majority of interview participants considered the approach used by WFD during the consultation process to be appropriate but would have welcomed more information on the

\footnotetext{
${ }^{19}$ Definition of Fresnel Zone: "the area around the visual line-of-sight that radio waves spread out into after they leave the [microwave] antenna. This area must be clear or else signal strength will weaken." (Webopedia.com, 2003 [online])
} 
project. Many community members stated that they would have been interested in more opportunities to participate in the project e.g. through public discussions or by various forms of local ownership.

The interview with the wind farm developer has shown that they believe the majority of an affected community supports or is indifferent to their wind farm proposal, while 5 to $20 \%$ express their objection and are unlikely to change their stance. In order to successfully deal with opposition groups, WFD highlights the importance of a certain project momentum which forestalls opposition; that the validity of opposing arguments has to be assessed and that mitigating measures need to be taken wherever possible; that fierce objectors are unlikely to participate in a mutually rewarding consultation process and, in some cases, it might be more beneficial for the project's success to ignore the opposition groups. In the RMA consent process the developer suggests that permitting authorities need to acknowledge more the national benefit of using wind energy and that vocal opposition groups do not necessarily represent the majority of a community, who are often quite supportive of or neutral about a wind farm proposal.

In general, consultation requires a reciprocal process of information exchange in order to be successful. A consultation approach that maintains its momentum throughout the process and focuses on one-on-one consultation sessions appears to be an effective way of consulting with stakeholders. WFD believes that involving the community in a participatory process is often difficult to achieve and not necessarily in their own best interest. WFD experiences indicate that most community stakeholders in support are not interested in increasing their level of input in contrast to wind farm objectors, who might use any opportunity to prevent the proposed development. 


\section{TOWARDS BEST PRACTICE IN CONSULTATION}

This analysis of wind energy literature explores best practice approaches for wind farm developments, public acceptance of wind power projects, consultation processes, and public involvement in resource planning. The first part of this chapter deals with possible ways to improve community acceptance of wind farms (Section 6.1) followed by a presentation of consultation approaches and options available for public involvement in wind farm projects (Section 6.2). Where appropriate, examples from the empirical research results are included.

\subsection{Improving Community Acceptance of Wind Farms}

Wind farm developers and planners have a range of tools and approaches to improve community acceptance of wind farms including different methods of consulting with and involving affected stakeholders, planning measures and computer based simulation tools to minimise the potential impact of wind farms, as well as strategies to involve the community in the project and share the benefits of the development. These opportunities are described and discussed below in order to evaluate their value to best practice in planning and consultation for wind farm developments.

Receiving planning approval for future wind farms is highly dependent upon the developer's ability to gain community acceptance of the proposal. Gipe (2002:180) concludes that there might be no means of eliminating every objection to visual intrusion by wind turbines on the landscape, but it is possible to minimize them.

Geuzendam (1998) developed a conceptual model (Figure 8) for researching public acceptance of wind energy to explain the interacting variables which influence public approval of a particular wind farm project. 


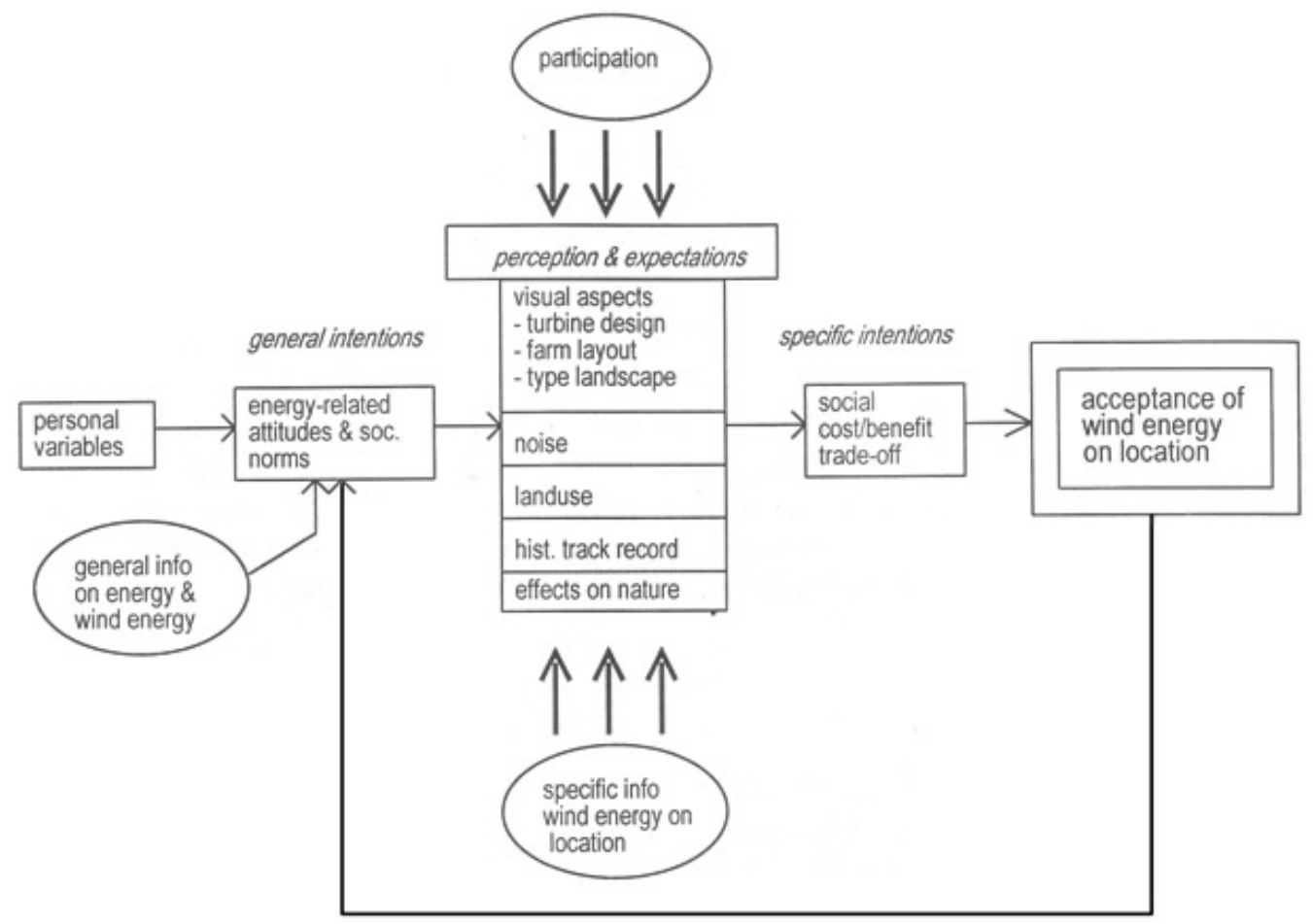

Figure 8: Conceptual model for research into public acceptance of wind energy. (Geuzendam, 1998:136)

The boxes represent a static series of variables explaining a certain level of acceptance of wind energy on location at a certain moment. There are two stages where these variables can be influenced externally (circled). First, by providing general information on energy and wind energy at an early stage to alter general intensions of the public such as energyrelated attitudes and social norms. Secondly, perceptions and expectations can be influenced by providing site-specific information and offering stakeholders opportunities to participate in the project e.g. financial involvement. Once these external influences have altered the acceptance of wind energy on location, a feedback mechanism loops back to general intentions forming a dynamic process. A similar view is shared by Connor (1988) who states that project-related education and involvement in the decision making process are likely to reduce perceived risks which could produce opposition. 
Weller (1998) developed a four-step-process to improve wind project acceptance:

1) A pro-active approach might help to prevent the development of negative attitudes by setting the project in a positive surrounding. A development can be turned into a "community project" by providing a range of information on wind energy and its benefits, the project and on the approval process itself. All stakeholders should be offered the possibility to participate and benefit from the project.

2) Stakeholder analysis helps to understand the views of all objectors in detail. This approach might reveal expressed and hidden arguments, relationships of stakeholders to other key players in the development process, and information about project issues.

3) An individual action plan for each major project opponent (person or group) is needed so as to develop the most suitable strategy for consultation. The project acceptance can be improved, if personal objections are counterbalanced by suggesting personal benefits and collective objections can be forestalled by suggesting collective benefits.

4) The ultimate goal should be a win-win situation whereby objector and developer find the right level of compromise. This type of solution can be helpful to enforced power-solutions.

Weller (1998) acknowledges that from a project developer's point of view (as observed by WFD staff), absolute opponents with "fundamental views" are difficult to deal with and suggests two measures to deal with them:

a) keep them isolated and support counterforces which neutralise them; or

b) abandon the project and find a better opportunity to develop a wind farm, if the opposition group is too strong.

Connor (1988) adds that providing information is unlikely to change the view of organised objectors. Connor (op. cit.) agrees with Weller's suggestion of utilising peer pressure from the wider community to adjust the opponent's standpoint. In the context of 
the Tararua Wind Farm this approach may involve increasing the profile of supporters of the wind farm project with public events and publicity designed to reinforce the positive attitudes in the community. In the case of b) above, opposition may be particularly strong when a wind farm proposed is targeting site of very high scenic value. In such situations it could be more effective to relocate that project (i.e. go elsewhere when opposition is likely to be lower).

The occurrence of absolute opponents is likely to happen regardless of the project or the chosen location (Wolsink, 1990; Righter, 2002) as WFD experienced and was discussed earlier, while the number of opponents may vary from place to place and their political effect can be significantly reduced. Even though this form of fundamental opposition is inevitable it can sometimes be a helpful means of identifying the motives behind their objection, which may become further apparent during a consultation process.

\subsubsection{Minimising the Potential Impact of Wind Farms}

When it comes to the public acceptance, the most important decision, for the development of a wind farm, is choosing an appropriate location (Wolsink, 2000:59). Local concerns about the possible consequences of a wind farm form the ground for opposition ranging from impact on the landscape to electromagnetic interferences (Wolsink, 1990:728).

Choosing the ideal location for a wind farm often poses a dilemma: a desirable site has to be economically viable and the potential level of intrusion has to be minimal. ${ }^{20}$ The economic viability of a wind farm depends on high-sustained wind speeds ${ }^{21}$ and proximity to load-centres ${ }^{22}$ and existing infrastructure. ${ }^{23}$ Developed infrastructure can

\footnotetext{
${ }^{20}$ It is important that these locations affect the environment, including flora and fauna, as little as possible, as well as local residents and tangata whenua (EECA, 2001).

${ }^{21}$ Annual average wind speeds of $10 \mathrm{~m} / \mathrm{s}$ or higher with low turbulence levels are required to develop a wind farm in New Zealand that could be operated close to economic criteria (EECA, 2001).

${ }^{22}$ Load-centres are areas with high electricity demand and electricity end users, e.g. the Wellington region or Auckland.
} 
usually be found near urban region, while high wind speeds tend to occur along ridgelines and coastlines - areas associated with scenic beauty and often highly visible, or located at great distances from urban centres (and the greatest number of potential consumers of electricity generated by wind energy). Attempts are necessary to minimise the impact on the landscape and to optimise the site location. Such measures need to take into account economic feasibility, environmental sensitivity and visual intrusion (Planning South Australia, 2002; EECA, 2001).

Two recently unsuccessful wind farm proposals in New Zealand were situated in the Wellington region (Baring Head in 1995 and Makara in 1997). Wellington has an aboveaverage wind pattern, as demonstrated by the performance of the Brooklyn Wind Turbine which operates with an average capacity factor of around $50 \%{ }^{24}$ Because of the population density in the Wellington area, potential wind farm sites are likely to be highly visible to a large number of people. In 1990, this factor (among others) lead to fierce public opposition to the two wind farm proposals and contributed to their failure to progress through the planning system (Harland, 2000). This experience highlights the need to integrate a number of different information types at the planning stages.

Geographical Information Systems (GIS) became an important planning tool in making preliminary assessments of location suitability for wind farm development. With the help of GIS applications developers have the ability to combine data on wind speeds with a variety of spatial information, and other relevant factors such as population density and topographical characteristics in order to predict the likely noise intrusion and visibility of the planned wind farm. This enables wind farm planners to define and display possible exclusion zones and thus avoid siting a wind farm in environmentally and culturally sensitive areas (Berrini et al., 1998).

\footnotetext{
${ }^{23}$ In order to minimise electricity transportation losses, the optimal wind farm site is near major load centres (urban centres or major industries) with an existing transmission grid and it must be easy accessible to avoid additional costs for road works (EECA, 2001).

${ }^{24}$ The capacity factor is calculated by dividing the actual output by the theoretical maximum, which depends on the turbine power and the annual availability e.g. wind farms are developed in Australia with an average capacity factor of 32 to $40 \%$, and with around $27 \%$ in Germany (figures with courtesy of Wind Farm Developments).
} 
Planning South Australia (2002) describes how planning authorities are dealing with issues concerning wind farm visibility, the coast and the environment, but are not addressing particular wind farm policies in Australia. Exclusion zones can be defined within development plan policies. The Government could provide a broad planning framework while councils can take unique local circumstances into account and develop appropriate wind farm related planning policies for the local area. Examples of exclusion zones are:

- coastal areas of outstanding beauty or natural significance.

- landscapes of aesthetic value and natural beauty.

- $\quad$ sites of heritage, cultural, environmental and landscape significance.

- habitats, wetlands, dune systems, lakes, native vegetation and other items of natural significance.

If there had existed in New Zealand planning policies which included a clear definition of where wind farms would be excluded, the failure of the Baring Head project could have been avoided by proposing a wind farm located in a more appropriate place. The planning authority in charge (the Hutt City Council) believed that the wind farm proposal was not contrary to the policies and objectives of the District Plan, however the location was considered to be within the coastal environment. Resource consent was not granted because of a likely visual intrusion into the natural character of the coastal environment in accordance with the New Zealand Coastal Policy Statement and the Wellington Regional Council's Regional Policy Statement (Kellow, 1999). Strong vocal community opposition to the proposed location undoubtedly influenced the decision to not proceed.

\subsubsection{Tools for Simulating Potential Wind Farm Intrusion}

Today, computer based wind farm development programs can simulate the likely impact of a project on a location. These programs integrate technical and environmental aspects of a proposed wind farm into one model and can be utilised for visual or noise impact 
assessments, by generating photomontages or noise intensity maps (Georgopoulou et al., 1998). Examples of visual and noise simulations are given in the following figures 9 to 12.
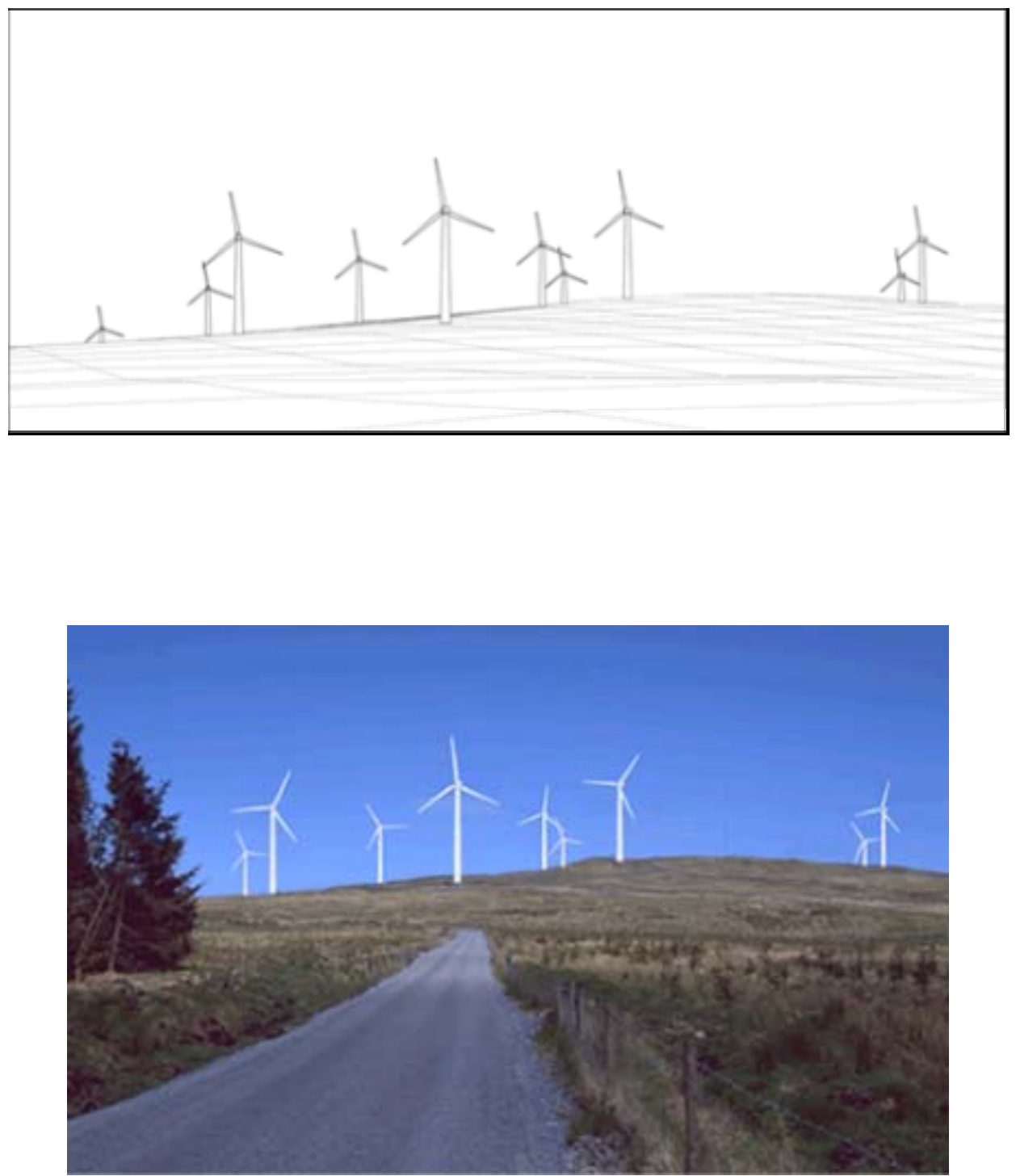

Figure 9 and 10: Photomontage Process - A computer generated 3D model can be combined with a photograph to simulate the planned wind farm's likely impact on the landscape (Courtesy of Wind Farm Developments (Australia) Ltd.) 


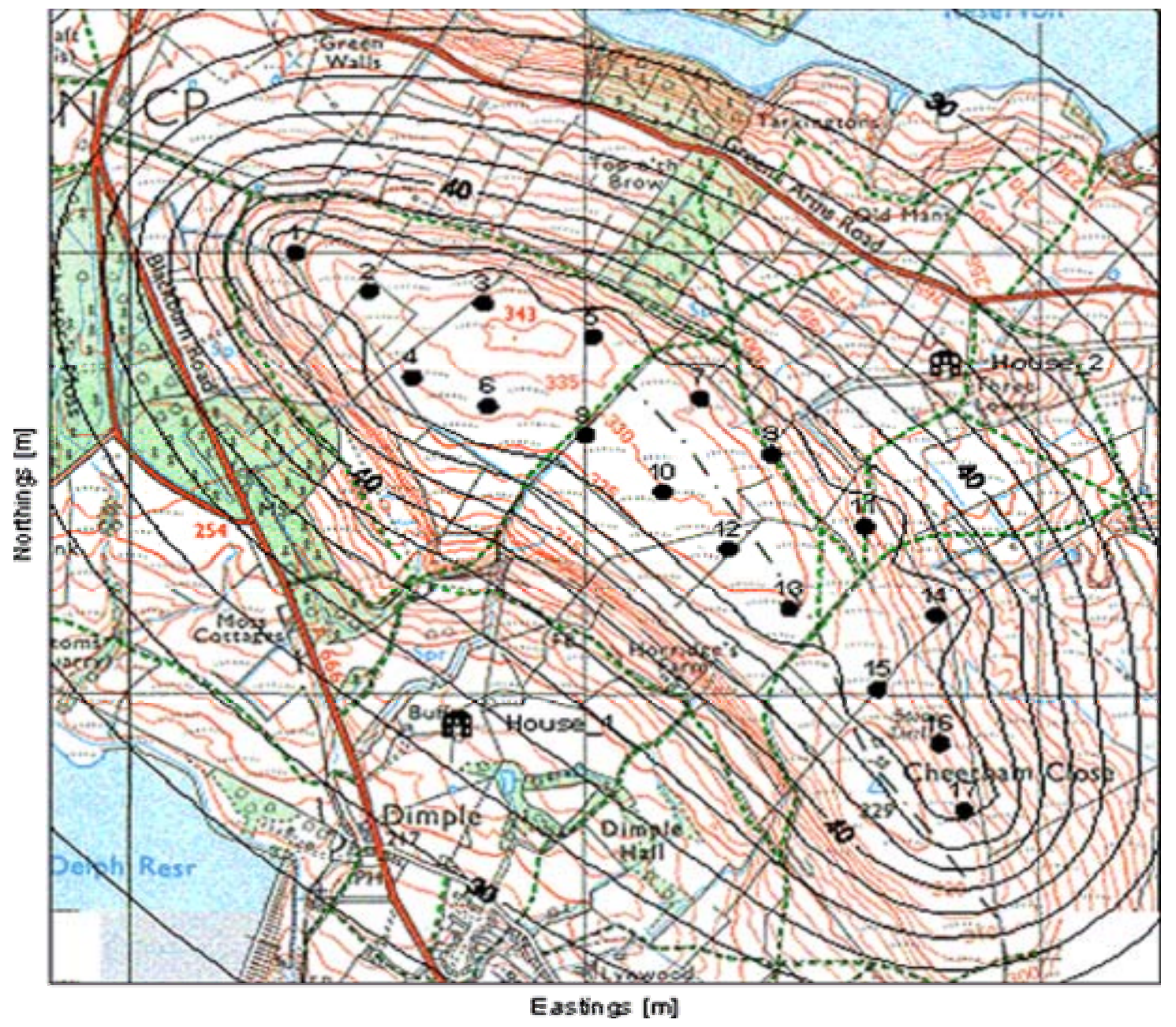

Figure 11: Noise assessment - the "iso-noise" map contains contours of predicted noise levels (Courtesy of Wind Farm Developments)

Another means of determining the visibility of a proposed wind farm at an early stage is to generate a visibility map. This technique allows the visual impact of given turbines to be displayed in the landscape on a map by dividing it into sectors, which contain the number of turbines visible from each considered territory cell (Andolina et al., 1998). 


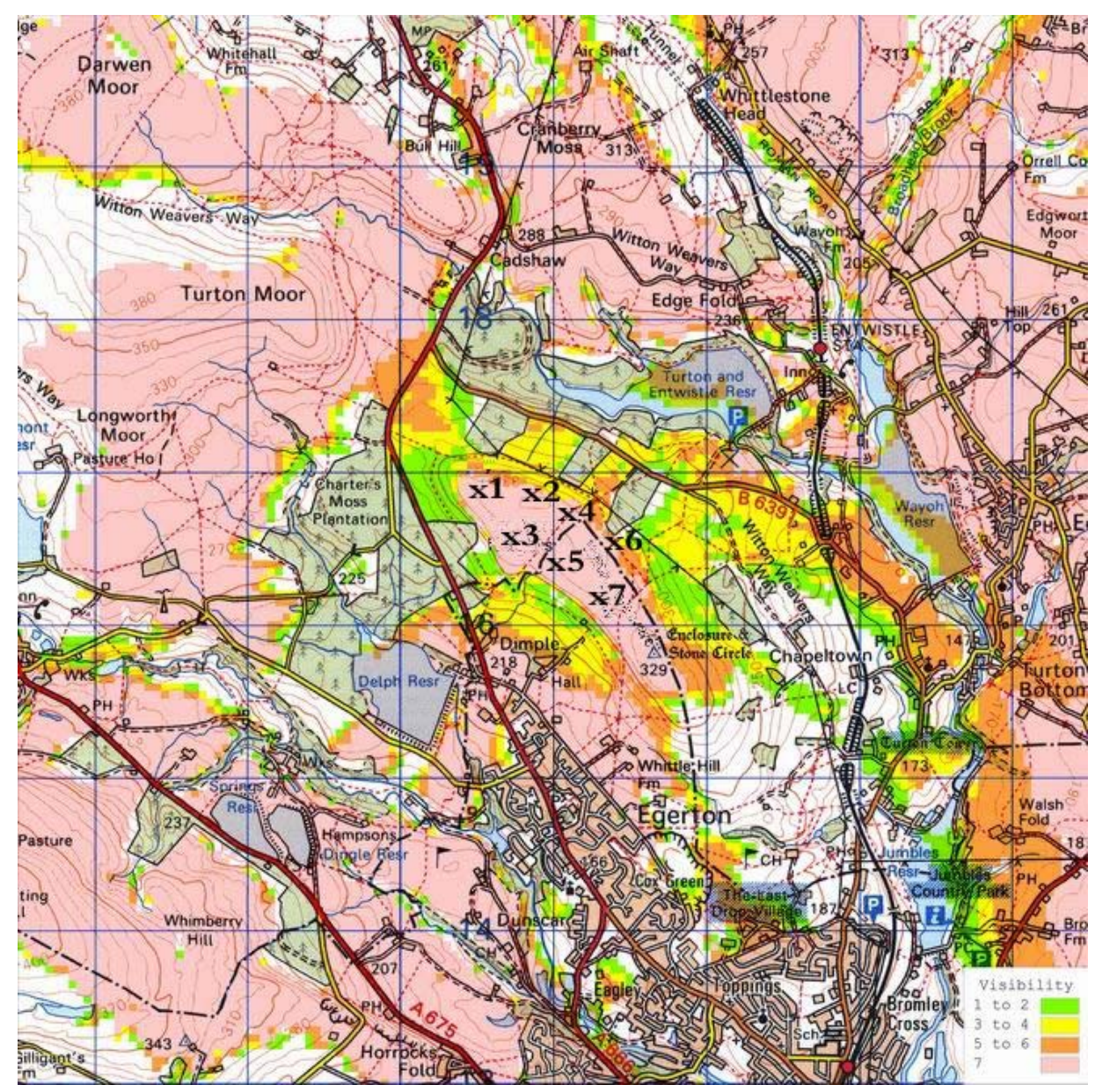

Figure 12: Visibility map (ZVI = Zones of Visual Intrusion)

(Courtesy Wind Farm Developments)

These graphical tools can be utilised in combination with design techniques to conduct a visual impact assessment, to identify key issues by evaluating the existing environment and consider any likely impact of a proposed wind farm on that environment. The assessment takes into account the extent of physical modification on the landscape (visual modification) and the perceived degree and nature of viewer sensitivity to the proposed modifications. By applying this approach wind farm developers build up comprehensive information to modify a proposal at an early stage in order to minimise the visual impact (Planning South Australia, 2002). In this way it is possible to address and mitigate (at least to a degree) community objections to noise and/or visual intrusion. 
The scope of such mitigation may not satisfy every objector but may satisfy a significant number to enable a proposal to gain planning approval.

These three tools of photomontages, noise and visual impact assessment are widely used in public consultation processes (such as public meetings) to receive feedback from stakeholders and to discuss a potential impact on the community.

Moreover, a visually appealing wind farm design has contributed to increased public acceptance. Gipe (2002:180-209) summarises key lessons from experiences in America and Europe to improve aesthetics of a wind farm and reduce objections to visual interference. Gipe (op. cit.) recommends such simple measures as visual order and uniformity of the wind farm lay-out, so as favour turbine clusters rather than utility scale wind parks, keeping the site tidy and avoiding visual obtrusion through ancillary structures or construction impacts. But most importantly, the turbines should be kept spinning to support the public's perception that turbines are functioning and serving a purpose, namely generating electricity. Thayer et al. (1987) note that viewers associate non-operating turbines with unreliability and that can negatively affect public acceptance of wind farm developments.

\subsubsection{Community Involvement and Benefit Sharing}

Pesch (undated) stresses that the media plays an important role in increasing public interest and strengthening identification of the local community with a wind farm project. Wind farm developers have the opportunity to raise the public awareness of the advantages to utilise wind as a renewable energy source at a pre-approval phase of the project e.g. by issuing fact sheets on a particular project and information on wind energy generation in general. After gaining approval and, from the developmental phase until the official opening of the wind farm, media releases, newsletters and opening events are important means of integrating the affected community and keeping the wider public informed of progress in the construction of the project. 
Opening celebrations can be organised to stimulate publicity and to include the general public as well as wind farm investors. "Open house" events give critics and supporters the opportunity to obtain firsthand information on wind turbines. In Germany such celebrations are attended by large numbers of the public and are now an integral part of wind project completion (Hoppe-Kilpper et al., 2002). This strategy was also applied for the Tararua Wind Farm as identified by the case study.

The key to acceptance of wind energy by local communities seems to be the promotion of a wind farm proposal as a community project rather than having it stigmatised as an "invasion". Pesch suggests communicating wind farm development plans with the local people, offering opportunities for financial involvement and limiting the wind farm size to small clusters (wind farms with no more than 3 to 7 turbines) increases local and regional identification with a project (Pesch, undated). Wolsink (1996:1087) asserts that "any procedure that does not offer all involved parties real opportunities for influence on projects will make people more opposed than necessary".

Examples of successful community involvement in wind power generation can be found in Denmark and Germany, where local people own most wind turbines. Three quarters of all Danish wind turbines are owned privately e.g. by individuals and wind co-operatives (Tranaes, 1997 [online]). Co-operatives enable individual members of a community to benefit directly from it as an investment. These projects were initiated by local communities and thus enjoy a high degree of acceptance.

According to Elliott (1994), the key to these developments is that some form of control, economic benefits, and indirect gains remain within the community and, consequently, local adverse impacts are judged more positively. In general, community ownership schemes could range from shareholding of a project, to full-scale local ownership (Elliott, 1994, 2001; Gipe, 1995; Tranaes, 1997 [online]). Local ownership schemes contributed to reducing wind farm opposition despite local environmental disadvantages. The Danes say: "your own pigs don't smell" (Toke et al., 2000). These local investment 
opportunities attracted thousands of community members, who now form a strong wind energy lobby. The financial involvement of the wider public improved the prospect of gaining planning approval, and also influenced the cultural and political atmosphere with regard to public support of wind energy. By contrast, wind farm developments that were proposed by remote utility-backed developers were often confronted with strong local opposition. Affected communities perceived these utility scale developments as a "rip off" and considered the proposed wind turbines as foreign elements and unreasonable (Toke et al., 2000).

A common concern of communities considering a wind farm proposal is that local people will suffer social costs (in form of loss of visual amenities as mentioned by two objectors to the Tararua Wind Farm) while financial benefits will go to the remote developer and utility companies (Elliott, 2001). Consequently, any possible benefits are perceived as offset by the loss of amenities (Gipe, 1995:325).

The major disadvantage associated with wind power (as well as other renewables such as hydro power schemes) is that economic and environmental benefits affect society as a whole, while potential impacts affect only the local community (Hoppe-Kilpper et al., 2001).

In the interview results of the Tararua Wind Farm case study, some participants indicated that they would have welcomed an opportunity to invest in a co-ownership scheme of the wind farm in order to draw some direct financial benefits from the development in their community. Such an initiative would have enabled interested community members (besides landowners who would have the wind turbines on their property) to share the benefits from the wind project and might have increased the public acceptance of the turbines. 


\subsection{Consultation}

Consultation with the local community is an essential part of any wind farm development as is the case with all forms of developments in democratic societies. However there are various approaches to consultation available, depending upon which process is believed to work most efficiently to reach a desired outcome. British studies show that business driven developers tend to rush this process and thereby foment public opposition at an early stage (Elliott, 1994). Such businesses may regard the consultation process only as an opportunity only to generate opposition and therefore take a heavy-handed approach. Such an approach may, in the long run, work against wind energy development in a country like New Zealand because of the negative associations that such approach can generate in the broader political community. In contrast, consultation approaches, which are less confrontational and aim to resolve or avoid inevitable social conflicts accommodate methods of social negotiation, community involvement and participation, but they can be more costly and time intensive. This was one of the key concerns expressed by WFD staff when interviewed.

The consultation process is capable of improving a proposed development and increasing community support but much depends on how the process is designed and managed. If it is started early, is sustained throughout development and encompasses all affected stakeholders, consultation assists in obtaining resource consent because it minimises “precautionary and spurious" objections and submissions in opposition (Harland, 2000). Therefore, wind farm developers should consider the value of gaining opposing views as form of market research so they may understand and learn from community concerns. Such knowledge may be profitably used to address these concerns and may improve the design of a proposed wind farm.

In New Zealand, a resource consent application for a wind farm development must be submitted to a local authority accompanied by a detailed assessment of environmental effects (AEE). The Fourth Schedule of the RMA (1991) Clause (h) states that an AEE is to include "an identification of those persons interested or affected by the proposal, the 
consultation undertaken, and any response to the views of those consulted" (Barton et al., 1999; Kellow, 1999). While most resource consent applications are non-notified, only about $2 \%$ are public notified applications (Palmer, 2002 [online]) and call for submissions.

The developer has to ensure that all stakeholders have had reasonable time to fully understand the proposal and that a reasonable amount of information is provided. This consultation procedure can establish good relationships, allow community involvement and minimise fears or misunderstandings, and this in turn can help to receive approval from affected parties (Wellington City Council, 2001:7). The Ministry for the Environment (2002 [online]) cites three further benefits of effective consultation. First, consultation accommodates concerns of all interested or affected parties. Second, it helps to identify possible environmental effects and to develop solutions to overcome or mitigate them. And third, it helps to estimate the magnitude of public concern with regard to an application.

For consultation to be successful, sufficient time and accurate information are needed to allow stakeholder participation and informed decision-making (MfE, 2002 [online]). The choice of the most appropriate consultation method "should be a considered decision based on the nature of the project, the scale of community interest and the project timeframe" (Barton et al., 1999:28).

Means of consultation are suggested by Barton et al. (1999), WCC (1996) and MfE (2002 [online]):

- public meetings

- meetings (with small groups or individuals),

- public forums/open houses/ information days/site visits

- exchange of letters and informative material

- inviting for written comments

- workshops

- focus groups 
- telephone discussions / telephone hotlines (e.g. 0800 free call hotlines)

- websites and emails

Barton et al. (1999) considers that the traditional approach of consultation by public meeting could cause problems. Such events are in danger of being "captured" by participants who intend to demonstrate community solidarity and possibly opposition. This could prevent the effective presentation of information and obtaining constructive feedback from the public. It is suggested that small group or individual meeting are more valuable for small-scale and less sensitive project proposals while a public meeting, an open house or an information day is more appropriate for larger projects or institutions. This particular strategy is currently used and recommended by WFD which uses one-toone consultation sessions to discuss specific project related issues and a public information session to introduce the project to the wider community.

In general, public meetings offer an opportunity to distribute information on the project and the consultation process. The meeting should be scheduled at a time suitable for all involved stakeholders and should be advertised well in advance. The developers should be prepared to respond to any questions that may arise during the meeting (Barton et al., 1999).

Corydon Consultants Ltd. (2002), an environmental consultant firm in Wellington, summarises the "essential ingredients" for a mutually rewarding consultation process derived from New Zealand case law: ${ }^{25}$

- be prepared to participate and willing to compromise, ${ }^{26}$

- be open minded and prepared to make changes in response to feedback,

- ensure that representative stakeholders of all affected parties are consulted and give them an opportunity to present their concerns,

- obtain and provide sufficient information to allow informed discussion,

\footnotetext{
${ }^{25}$ For example, the Air New Zealand case (Air New Zealand \& others vs. Wellington International Airport \& Attorney General in the High Court - CP403/1991)

${ }^{26}$ Compromising over an inessential matter is a key theme in conflict resolution and non-violence, and can help to build a partnership atmosphere in consultation and negotiation.
} 
- the proposal should be presented as simply and clearly as possible and the information provided has to be accurate and honest, ${ }^{27}$

- listen and find out about stakeholder concerns during the consultation process rather than promoting the proposal,

- adequate discussion and feedback requires sufficient time,

- provide feedback to consulted people on the outcome of their participation and explain the results of the consultation process.

Harris (1995) points out that consultation ideally relies on mutual communication and shall not be misused as form of "corporate marketing". In order to communicate effectively, both parties have to overcome their distrust by acknowledging the other's needs and interests.

In order to minimise potential conflicts, Wolsink (1996) suggests offering real opportunities for all to become involved in the planning process. Many of those interviewed expressed concerns of this nature with $80 \%$ of the participants expressing their interest in more information and clarity about the project, as well as wanting opportunities to participate in the planning process.

\subsubsection{Public Involvement}

The involvement of affected stakeholders in the decision making process could "ultimately lead to better decisions" through a range of process benefits, including the identification of "alternative values and solutions", determination of "inequities in land allocation", enhancement of "fairness in decision making" and a decrease in potential conflicts (Jackson, 2001). Jackson (op. cit.) proposes a dynamic five-stage model for public involvement covering a spectrum of informing (1), public education (2), testing reactions (3) and generating ideas (4) and seeking consensus (5). This model requires

\footnotetext{
${ }^{27}$ Misleading information can easily backfire and give opposing groups or individuals an ideal opportunity for discrediting the sincerity and integrity of a wind farm developer.
} 
ongoing analysis and allows "the employment of each of these levels of public involvement at various stages of a planning process" (Jackson, op. cit.:141). The model aims to assist decision makers to choose the most appropriate form of public involvement "based on stakeholder analysis and objectives".

(1) The first stage intends to inform the general public or unaware stakeholders. It can introduce a new project, as a first stage for further involvement or to keep the general public informed on progress on higher involvement levels.

(2) The second stage focuses on educating stakeholders, who are already aware of the issues but require additional information. Public education can increase the level of awareness, provide background information or prepare participants for a higher involvement stage.

(3) To test the reactions of stakeholders requires that they have a certain level of awareness and background information at their disposal and that individual stakeholder should represent a wider stakeholder group. This stage of involvement is appropriate for evaluating options and seeking input on existing ideas.

(4) Participants at the idea-generating stage should have special knowledge at their disposal and/or some expertise in the issues and an appropriate degree of commitment to the process. This degree of participation is desirable if creative solutions are needed or local knowledge can contribute to "in-house experts' options".

(5) If the process requires shared decision making to reach a consensus on ongoing conflict situations, participants need to be well informed and knowledgeable, highly committed and believe in the process, they need to be willing to share information and to build trust in the organisation and with other stakeholders.

Following the pattern of Jackson's (2001) model of public involvement, Figure 13 (derived in part from iPlan, 2003 [online]; Commission on Resources and Environment, 2002 [online]; Dorcey et al., 1994) demonstrates the spectrum of public participation covering the stages from information, consultation, involvement, collaboration to 
empowerment. Each participation stage has an assigned underlying objective that making specific promises to the public and relevant means of ensuring the promises are met.

Spectrum of Participation:

\begin{tabular}{|c|c|c|c|c|}
\hline INFORMATION & CONSULTATION & INVOLVEMENT & COLLABORATION & EMPOWERMENT \\
\hline \multirow{2}{*}{\multicolumn{5}{|c|}{ Increasing Level of Public Impact, Commitment and Expectations }} \\
\hline & & & & \\
\hline $\begin{array}{l}\text { To provide the public } \\
\text { with balanced and } \\
\text { objective information } \\
\text { to assist them in } \\
\text { understanding the } \\
\text { problem, alternatives, } \\
\text { or solutions }\end{array}$ & $\begin{array}{l}\text { To obtain public } \\
\text { feedback on analysis, } \\
\text { alternatives, or } \\
\text { decisions }\end{array}$ & $\begin{array}{l}\text { To work directly with } \\
\text { the public throughout } \\
\text { the process to ensure } \\
\text { that public and } \\
\text { private concerns are } \\
\text { consistently } \\
\text { understood and } \\
\text { considered }\end{array}$ & $\begin{array}{l}\text { To partner with the public } \\
\text { in each aspect of the } \\
\text { decision including the } \\
\text { development of } \\
\text { alternatives and the } \\
\text { identification of the } \\
\text { preferred solution }\end{array}$ & $\begin{array}{l}\text { To place final decision } \\
\text { making in the hands of } \\
\text { the public }\end{array}$ \\
\hline \multicolumn{5}{|c|}{ Promise to the public: } \\
\hline $\begin{array}{l}\text { We will keep you } \\
\text { informed }\end{array}$ & $\begin{array}{l}\text { We will keep you } \\
\text { informed, listen to and } \\
\text { acknowledge your } \\
\text { concerns, and provide } \\
\text { feedback on how public } \\
\text { input influenced the } \\
\text { decision }\end{array}$ & $\begin{array}{l}\text { We will work with you } \\
\text { to ensure that your } \\
\text { concerns and issues } \\
\text { are directly reflected } \\
\text { in the alternatives } \\
\text { developed and } \\
\text { provide feedback on } \\
\text { how public input } \\
\text { influenced the } \\
\text { decision }\end{array}$ & $\begin{array}{l}\text { We will look to you for } \\
\text { direct advice and } \\
\text { innovation in formulating } \\
\text { solutions and incorporate } \\
\text { your advice and } \\
\text { recommendations into } \\
\text { the decisions to the } \\
\text { maximum extent possible }\end{array}$ & $\begin{array}{l}\text { To place final decision } \\
\text { making in the hands of } \\
\text { the public }\end{array}$ \\
\hline
\end{tabular}

\section{Application Methods:}

\begin{tabular}{lllll}
\hline - Meeting & - Citizens' panel & - Facilitation & - Advisory committee & - Citizens' jury \\
- Public notice & - Community & - Planning focus & - Charette & - Search conference \\
- Website & information and & meeting & - Facilitation & \\
- Written information & feedback session & - Precinct committee & - Policy round table & \\
& - Facilitation & & - Regional forum & \\
& - Focus group & & - & \\
& - Meeting & & \\
& - Public hearing & & \\
& - Public meeting & & \\
& - Questionnaire & & \\
& - Website & & \\
&
\end{tabular}

Figure 13: Spectrum of Participation (derived in part from iPlan, 2003 [online]; Commission on Resources and Environment, 2002 [online] and Dorcey et al., 1994) 
The spectrum of participation model offers an overview of different levels of public participation to choose from. The figure clearly displays that an increased level of public participation requires a greater degree of commitment, raises the expectations in the process and represents a higher impact on the public. The most appropriate level for a wind farm resource consent consultation process depends upon the consultation objective and the developer's expectation of the outcome. In the Tararua Wind Farm case study the requirements of the second stage 'consultation' have most likely been met. Consultation certainly facilitated progress beyond the 'information' level but can't claim to have reached the 'involvement' stage.

Buchy et al. (2001) refer to four "good practice" principles of community participation covering commitment and clarity (1), time and group dynamics (2), being representative (3), and the transfer of skills (4).

1) Commitment and clarity can be achieved if the participation the public is precisely described from the beginning to prevent confusion and false expectations in the process.

2) The participatory process requires sufficient time so as commitment can be measured and to allow group dynamics to become functional.

3) To be genuinely representative the selection of stakeholders needs to be open and transparent without discriminating any group. Moreover, the consultative process itself should not exclude any stakeholder group by default and relationships among potential participants have to be taken into account to ensure a well-balanced interaction.

4) Effectiveness of the involvement of communities in the participatory process depends on their ability to transfer necessary skills to the community, if they are required.

From comparing the two participation models, Jackson's stages of public involvement and the spectrum of participation by iPlan, the Commission on Resources and Environment and Dorcey, it is obvious that both approaches favour five levels of public 
participation in decision-making processes. The main difference lies in the discussed range of public participation, while Jackson's model ends at a 'shared decision making' stage, and participation extends to the level of public 'empowerment'. Moreover, Jackson includes a 'public education' stage, which was not described in detail in the participation model but, nevertheless, represents the level of involvement that took place in the Tararua case study.

In order to increase the effectiveness of public participation in future wind farm consultation processes the task for the developer will be to decide the most appropriate level of involvement for each individual stakeholder instead of making a generalised approach to the wider community. As proposed by Jackson (2001), a stakeholder analysis could support wind farm developers and consultants in making an informed decision on a suitable participation level.

\subsubsection{Stakeholder Analysis}

To design a participatory process that focuses upon the essential issues, Jackson (2001) recommends that a stakeholder analysis can be conducted beforehand in order to collect information on the involved stakeholder. According to Jackson (op. cit.), stakeholder analysis can be utilised as a tool to "identify and analyse" potential stakeholders and subsequently decide on the "appropriate objectives" of public involvement. The underlying purpose of this approach is to understand and analyse all stakeholders and at the same time acknowledge the sincerity and values behind the opposing arguments. Moreover, in order to be able to understand the fears of involved stakeholders and the underlying values behind their concerns, it is necessary to acknowledge people's perceptions (Kellow, 1999).

A stakeholder can be defined as "anyone significantly affecting or affected by a decision making activity" (Chevalier, 2001 [online]). Jackson (2001:140) points out that "stakeholders are those who believe themselves to have an interest or stake, not those 
which the agency deems to have a stake, or would like to include". With regard to wind energy, stakeholders are representatives from the community, industry and government "who have a moral or financial stake in, or influence on, a wind farm project" (Teoh, 2000:1). Moreover, those stakeholders can be subdivided into primary, secondary and key stakeholders according to their significance and influence in a project (ODA, 1995).

Stakeholder analysis can identify and describe stakeholders by exploring their attributes, power interrelationships and interests. This method uses qualitative criteria to describe, differentiate and rate individual characteristics. The information is presented in appropriate matrices to display attributes like interests, influence and importance (Ramirez, 1999:102-103). Stakeholder analysis can be conducted with a multi-step approach as derived from ODA (1995), the World Bank (2002, [online]) and the International Institute for Environment and Development (2001, [online]):

Step 1: purpose and procedures of analysis need to be developed

Step 2: identify key stakeholders

Step 3: investigate stakeholders' interests, characteristics and circumstances

Step 4: investigate interaction between stakeholders

Step 5: assess stakeholders' importance, their relative power/influence and potential roles

Step 6: assess options and use findings to make progress by formulating a stakeholder participation strategy

The information derived by these steps can be organised in relation to stakeholders' interests and their potential impact on the project in a "stakeholder table". Furthermore, stakeholders can be ranked according to relative importance and influence on project objectives within a "matrix classification of stakeholders" (MacArthur, 1997).

While governments and agencies predominantly use stakeholder analysis to improve the implementation and impact assessment of policies and projects with the underlying aim to empower involved stakeholders (Grimble et al., 1997), stakeholder analysis can also 
be utilised to influence or manipulate certain stakeholders in order to address and minimise potential objections against a proposed project. Teoh (2000) points out that stakeholder management in wind energy projects is basically a "risk mitigation exercise" which can lead to mutual understanding and stakeholder equity.

Weller (1998) proposes a stakeholder analysis approach, which aims at reducing public opposition against wind farm projects. Weller (op. cit.) continues that it is an "unmanageable task" to influence all opposing stakeholders and recommends focusing on those parties whose attitudes can be most efficiently changed. Consequently, the first step of this approach is to identify all major stakeholders in a wind energy project (Figure 14).

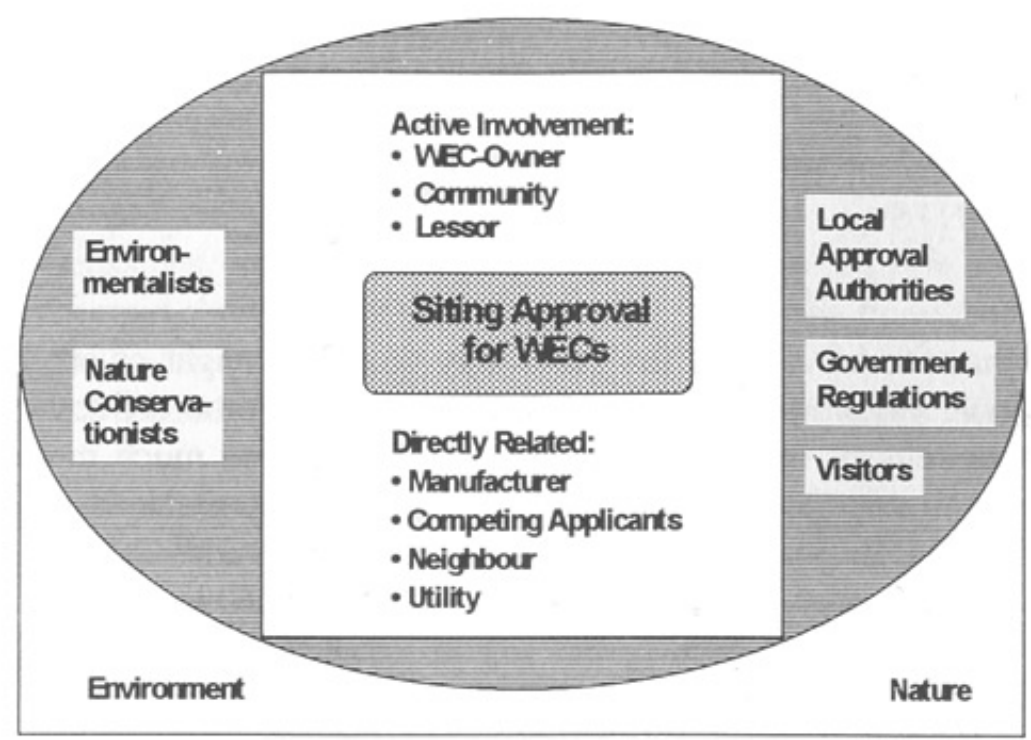

Figure 14: Stakeholders in a wind energy project (Weller, 1998:143)

Secondly, the stakeholder's degree of influence and their interactions can be defined and visualised according to their characteristic position within a matrix. This measure helps to assess the stakeholder importance for a particular wind farm project (Figure 15). 


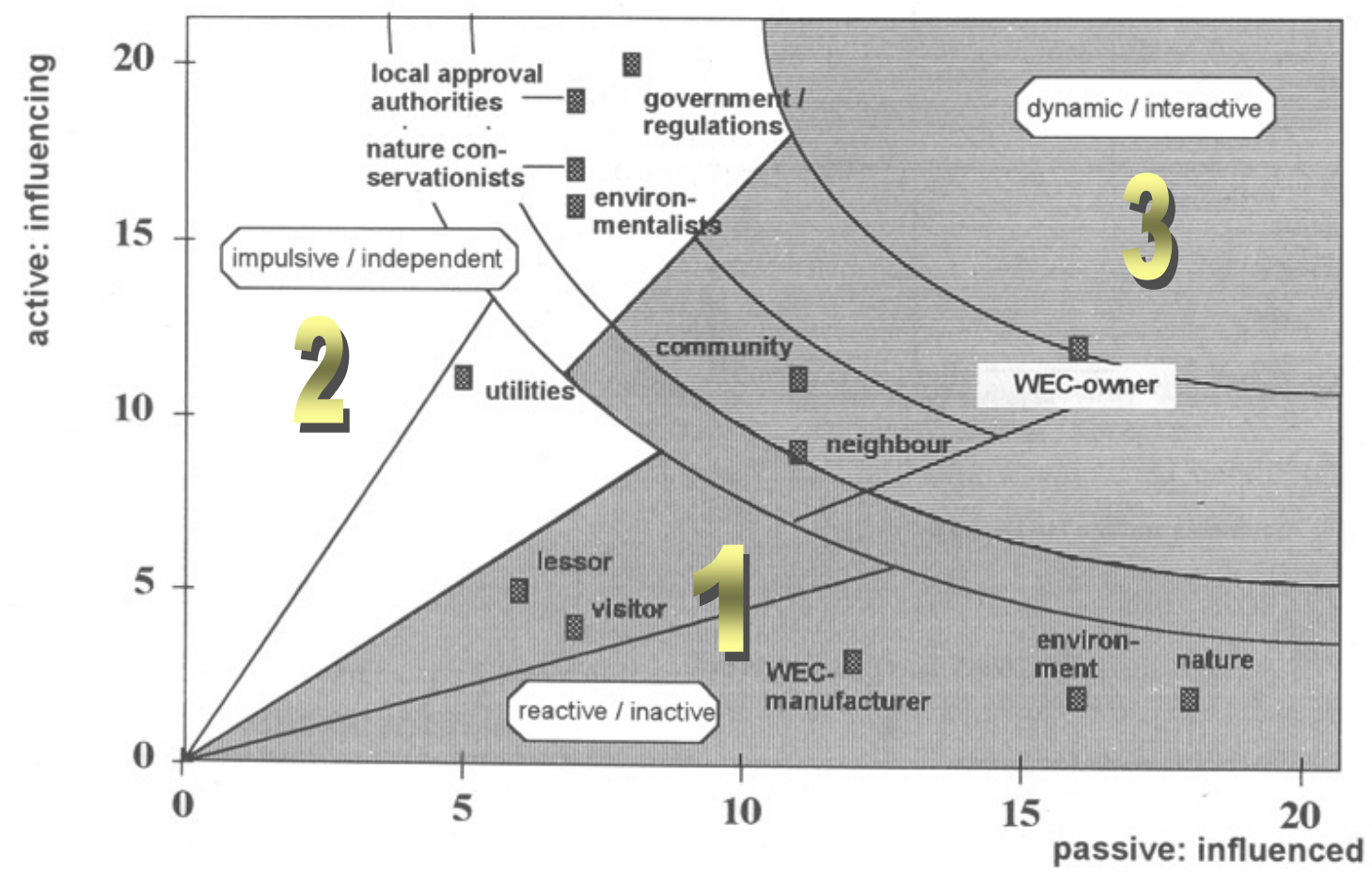

Figure 15: Influence Matrix (Weller, 1998:143)

Weller (1998) identified 3 major stakeholder groups within this diagram:

1. Reactive or inactive stakeholders who represent the lowest degree of interaction with others, e.g. visitor or turbine manufacturers

2. Impulsive or independent stakeholders, who are hard to influence but who exercise themselves strong influence. This particular stakeholder category imposes the conditions on the planning framework, e.g. Governments, nature conservationists or environmentalists

3. Dynamic or interactive stakeholders who influence other stakeholders but also get influenced by others, e.g. community and neighbours.

Weller (op. cit.) considers the third stakeholder group as the most suitable candidate for behaviour improving activities. Other stakeholders are not significant enough (group one) or are too difficult to influence (group two). 
To demonstrate how Weller's (1998) 'Influence Matrix' may be utilised as a tool, the participating stakeholders in the Tararua case study could be classified in the third group of identified stakeholders (dynamic or interactive stakeholders) and would have qualified as 'primary targets' of a behaviour improving consultation process by being community members or neighbours in proximity to the operating wind farm.

As recommended by Jackson (2001) and Weller (op. cit.) a stakeholder analysis should have been conducted beforehand to identify and analyse all involved stakeholders by assessing their importance, influence and roles in order to enable a wind farm developer to make an informed decision on the most appropriate involvement level according to the spectrum of participation. Given the importance of maintaining a high level of public support during the planning process of a wind farm proposal with respect to the sequence of public acceptance (see Chapter 2), using stakeholder analysis as an integrated part of the consultation process in combination with a suitable level of public involvement could significantly contribute to the success of the project. This approach may be considered as more costly, complicated and time consuming but it will enable wind farm developers to offer opportunities for public participation in the planning process without increasing the potential risk of the consultation approach abuse.

\subsubsection{Consultation Practices for Wind Energy Projects}

Most international wind energy associations have released best-practice guidelines for wind energy developments (AusWEA, 2002 [online]; EWEA, 1998 [online]; BWEA, 1994 [online]). In New Zealand this task was accomplished by the Energy Efficiency and Conservation Authority (EECA) in its guidelines for the wind energy industry (EECA, 1995). The guidelines provide information on the different project development phases and address technical and commercial aspects, environmental issues and give guidance on stakeholder consultation. They outline seven generic project phases and each phase addresses its own specific issues. This section considers the recommended approach for stakeholder consultation at each stage of the wind farm development life cycle. 


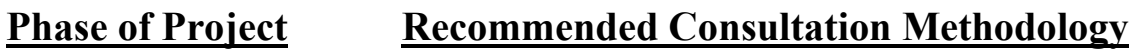

I. Site Selection: Preliminary consultation:

- Initiate contact with landowners, local planning authority and major stakeholder.

- Discuss consent requirements with local authorities.

- Gather and distribute information

II. Project

Feasibility:

III. Assessment:

IV. Planning

Application:
Submission of resource consent applications

and accompanying $A E E$ 
V.Construction: - Continuing information provision including landowner, neighbour and local community liaison, media and general public relations.

- Minimise construction impact upon local residents, be accessible and deal with complaints quickly and responsibly.

VI. Operation and: - Ongoing dialogue with local authority and community, media Maintenance and general public relations.

- Implementation of programme to respond to inquiries on operation of project (good neighbour policy)

- Be accessible and keep community informed

\section{Re-commiss-}

ioning or land Further consents may be needed if re-commissioning reinstatement:

This recommended methodology in best-practice guidelines for wind energy developments is not very specific on details as to how the recommended practice should be undertaken. It offers, however, an opportunity to integrate Weller's (1998) and Jackson's (2001) models into this framework.

A stakeholder analysis could fit into Phase I or II of this approach to identify and analyse all involved community members and local planning authorities. Knowledge gained from the analysis can be subsequently utilised to make an informed decision on the most appropriate level of public participation in Phase II and III in order to involve stakeholders in the planning process by jointly determining, preventing and solving any arising issues. Moreover, wind farm developer may also consider offering investment opportunities to the affected community into co-ownership or shareholding schemes as integrated part of the consultation process. 
EECA (1997) suggest that the key stakeholders who need to be consulted are the local community, particular neighbours, interest groups and local authorities (including iwi authorities). Providing sufficient information can (for example, by fact sheets) assure the majority of interested parties that their interests "will not be adversely affected". The developer should provide general information on wind farms and discuss their "positive and negative impacts" (Teoh, 2000). The consultation process also helps to identify all concerns and issues so as to develop adequate remedy or initiate mitigating remedies which would satisfy potential objectors (EECA, 1997). Therefore, consultation is an essential and helpful tool to obtain community support and, if necessary, could assist to improve wind farm proposals in order to avoid opposing submissions and false objections.

Stakeholders need to be regularly informed of progress or changes in initial timeframes (AusWEA, 2002 [online]). The European Wind Energy Association (EWEA, 1998 [online]) identifies a certain dilemma: open dialogue with stakeholders should commence as early as possible after a developer has selected a site. Yet as long as a wind farm proposal remains at a speculative stage, developers can only provide sparse information on the planned wind farm and premature community consultation may trigger unnecessary concern or excitement about a proposal (EWEA, 1998 [online]). Therefore, stakeholders need to be advised that a proposed project will only be taken to the construction phase only if certain criteria can be satisfied. Stakeholders, as well as developers, should allow some flexibility in project design and layout changes (AusWEA, 2002 [online]). The developer should always be open for feedback from stakeholders and offer opportunities to supporters as well as to objectors to express their views. Finally, the wind farm developer should be prepared to explain how comments and suggestions, collected during the consultation process, were taken into account (BWEA, 1994 [online]).

The Stanwell Corporation (2001) developed a communication plan as part of the community consultation for its Nirranda Wind Farm proposal in Australia. The aim of this approach was to build community trust and support, to design an open and 
transparent planning process and to integrate the community. Stanwell is dedicated to build a "strong community bond" based on open communication and trust to generate community acceptance, local support for the project and an informal partnership with the community. To achieve these objectives, the developer promotes the distribution of accurate information and the involvement of media and the broader community in all communication activities. Stanwell's approach consisted of an open and transparent fourphase strategy (Feasibility, Construction, Commissioning and Production) to build trust and support, and to involve the landowners into the process. Applied key campaign elements were consultation, issues management, media-, government- and community relations.

Another example of a consultation approach, which focused on stakeholder participation, was with the Portland Wind Energy Project (Sinclair Knight Merz, 2001). Their consultation objectives were to inform the community and offer opportunities to participate in the process, to obtain an overview of community issues and concerns, to develop stakeholder profiles and consider their views in the final wind farm layout. They used a range of techniques, such as workshops, public information sessions, newsletters and consultation with community groups and individuals (including face-to-face meetings and telephone calls). The stakeholder consultation process was started at an early stage to identify the main issues before the beginning of detailed studies. In addition, the governmental Department of Infrastructure established stakeholder reference group to identify key issues that needed to be addressed.

The findings of this study may help to suggest ways of how these best practice recommendations can be achieved or undertaken as part of a community consultation process for wind farm developments. The integration of a stakeholder analysis and the models of public participation levels as discussed above is only one example to achieve this aim. Further benefits might be derived from the lessons learned within the empirical component of this study with respect to the development of public acceptance, forms of opposition and consultation. In combination, these means may significantly contribute to reduce the likelihood of community opposition to wind farm developments. 


\subsection{Summary of Best-Practice Literature}

Within the selected literature there are many ideas on how to improve the public acceptance of wind farms and to avoid community opposition. Firstly, a landscapesensitive wind farm design minimises objections from the beginning (Berrini et al., 1998; Planning South Australia, 2002; Georgopoulou et al., 1998; Andolina, 1998; Gipe, 2002; Thayer et al., 1987). The community should be approached pro-actively and educated on wind energy and planning process matters (Weller, 1998; Whalen, 1998; Geuzendam, 1998; Connor, 1988).

Individual one-on-one consultation is recommended for interacting with stakeholders to inform them and to seek their feedback (Weller, 1998; Harland, 2000; Corydon Consultants, 2002). A stakeholder analysis provides wind farm developers with the opportunity to investigate and analyse potentially affected stakeholders at an early stage of the project (Weller, 1998; Jackson, 2001; Ramirez, 1999; ODA, 1995; World Bank, 2002 [online]; Grimble et al., 1997).

Moreover, it is useful to make an informed decision on the most appropriate level of participation to realise a collaborative planning process that prospectively increases the degree of project acceptance (Jackson, 2001; Buchy et al., 2001). Finally, community involvement and benefit sharing in a form of providing opportunities for investment in community ownership schemes of wind farms offer an additional chance to significantly enhance the likelihood of wind turbine acceptance (Pesch, undated; Hoppe-Kilpper et al., 2002; Elliott, 1994, 2001; Gipe, 1995; Tranaes, 1997 [online]; Toke et al., 2000).

The reviewed best practice guidelines prepared by international wind energy associations offer practical advice to wind farm developers on how to design consultation strategies but do not always provide details on how to undertake some of the recommended practices. Drawing on broader literature can be valuable for filling in detail, as is 
demonstrated by the suggested integration of stakeholder analysis and the model of public participation.

The publishers of these guidelines unanimously agree that it is important to commence consultation at an early project phase, so as involve all major stakeholders, to maintain an ongoing dialogue with the involved parties and the media throughout the project, to provide sufficient information and to take stakeholder feedback into account (AusWEA, 2002 [online]; EWEA, 1998 [online]; BWEA, 1994 [online]; EECA, 1995). However, they do not offer options for increased collaborative planning and community involvement other than providing information and collecting feedback. Nevertheless, recent consultation approaches indicate that wind farm developers generally follow best practice recommendations, but also aim to integrate opportunities for community participation in their consultation strategy (Stanwell, 2001; Sinclair Knight Merz, 2001). 


\section{DISCUSSION}

Within this chapter, the results associated with each empirical research component are separately discussed and evaluated. These components are the submissions into the Tararua resource consent process, the follow-up interviews and the interview with the wind farm developer. Each of these parts is associated with a separate research objective. The theoretical foundation of applied geography was used as a viewfinder to interpret the research results. In addition, the objective achievement as well as possible limitations associated with the applied methods has been evaluated.

\subsection{Submissions}

The examination of the submissions made into the Tararua resource consent process identified the range of arguments that were used to support or oppose the wind farm proposal. A significant discrepancy was exposed by comparing the characteristics of the arguments: the arguments in support of the wind farm are predominantly based on comprehensive and empirical facts, e.g. reduction of $\mathrm{CO}_{2}$ emissions, diversification of electricity generation and cost-competitiveness. In contrast, the concerns of the objectors can be described as anticipated adverse effects - outcomes that are feared to occur, e.g. noise, EMI, visual intrusion and land-devaluation. Moreover, the motives for concerns are apparently quite different: while the industry representatives try to prevent any potential disadvantages (e.g. by EMI) to their businesses, individuals tend to be concerned about potential loss of amenities or they are trying to protect appreciated landscape values.

Comparing the Tararua objections with those in the reviewed literature, their reasons appear to be identical with the arguments of wind farm objectors overseas (Hill, 2001; EECA, 1996). The concerns mentioned can be described as "perceived risk" that are related to the "fear of the unknown" (Connor, 1988). While most of these arguments can 
be refuted by scientific studies and turned out to be negligible (AWEA, 2002 [online]; EECA, 1996; O'Bryant, 2002; Clark, 2003), the visual impact of wind turbines on the landscape remains a controversial and highly polarised discussion on aesthetic taste (Brittan, 2002; Short, 2002; Planning South Australia, 2002; Righter, 2002; Elliott, 1994; Pasqualetti et al., 2002). Some authors pointed out that the main reasons of opposition to wind farms can be found in underlying unspoken arguments (Wolsink, undated; Weller, 1998). These concerns are related to personal values, which could be adversely affected the alteration of the landscape (Pasqualetti et al., 2002, Wolsink, 2000, Righter, 2002). Moreover, the public perception of not being appropriately involved in the planning and decision-making process may cause further opposition (Connor, 1988; Wolsink, 1996, 2000). The exclusion of stakeholders from the planning process represents an imbalance of power between the developer, who is planning a wind farm to make revenue, and the affected community, who will ultimately bear all the cost by losing valued landscape amenities. This situation requires an evaluation of possible options to be incorporated in the planning and consultation process in order to avoid opposition and will be further discussed in the synopsis section.

The first research objective has been fulfilled because initial arguments, mentioned in the submissions into the RMA process of the Tararua Wind Farm, were identified, compared and evaluated. Additionally, reviewed literature has been used to interpret the findings and assess their accuracy. Potential limitations have included the sample size of the submissions and a lack of details within the submissions. It would have been preferable to have extracted the research results from a greater number of submissions and analysed the underlying reasons and motives in greater detail. It is understood that the submissions do not necessarily represent the view of the entire community, but rather provide an impression of some of the concerns that the submitters held. 


\subsection{Follow-up Interviews}

While the majority of the community was in support of the project or had a rather neutral opinion, five individuals expressed their concerns by means of a submission in opposition. They expected significant adverse effects through an operational wind farm in the Tararua rages. Two believed that a development at the proposed site would challenge their landscape values and therefore opposed the project out of principle. This attitude suggests a certain affinity to the NIMBY syndrome, which describes objectors who are generally in favour of wind energy but not in the proximity of their residence (Thayer et al., 1991; Wolsink, 2000). In contrast, involved landowners who expected an income from the proposed turbines on their land were very much in favour. It seems, that the anticipated effects (disadvantages as well as personal benefits) associated with the development significantly affected the initial position towards the wind farm proposal.

Follow-up interviews revealed that the opposing submission writers significantly altered their attitude towards the wind farm. Overseas experience indicates that public support of wind energy utilisation significantly decreases after the proposal of a particular wind farm, which would challenge certain values (e.g. landscape values). This alteration of attitudes is illustrated by the sequential development of public acceptance (Wolsink, 1989; Gipe, 1995; Pasqualetti et al., 2002). Once the community has had a chance to adjust and has had personal experience of seeing turbines in operation, the degree of acceptance increases closer to the levels of acceptance prior to the announcement of the project (Elliott, 2001; EECA, 1996). Most objectors to the Tararua Wind Farm revised their opinion into being more supportive or being more neutral. Through experiencing the operating wind farm on a daily basis, people realised that their initially perceived concerns did not occur or were of significantly lower magnitude than they had expected. For example, concerns about possible noise nuisance have proved not to be the problem they initially expected. Only two submitters remained sceptical about the aesthetic appeal of the turbines in the landscape. The majority of the residents reported that they had used to the view of wind turbines on the ridge line or even liked them. 
While the fear of potential land devaluation and increased traffic poses only a minor problem, other issues associated with tourism, possible hazards, electromagnetic interference and air space safety were resolved. With tourism, the operating wind farm rather provided a boost than an obstacle to the local economy and the entire community has benefited from emerging business opportunities whenever tourists visit the wind farm. By comparing the initial opposing arguments (pre-construction) with the interview findings based upon actual experience of the operating wind farm as a 'neighbour' (postconstruction), a significant reduction in perceived adverse effects can be visualised. The results are presented in the following graph (Figure 16):

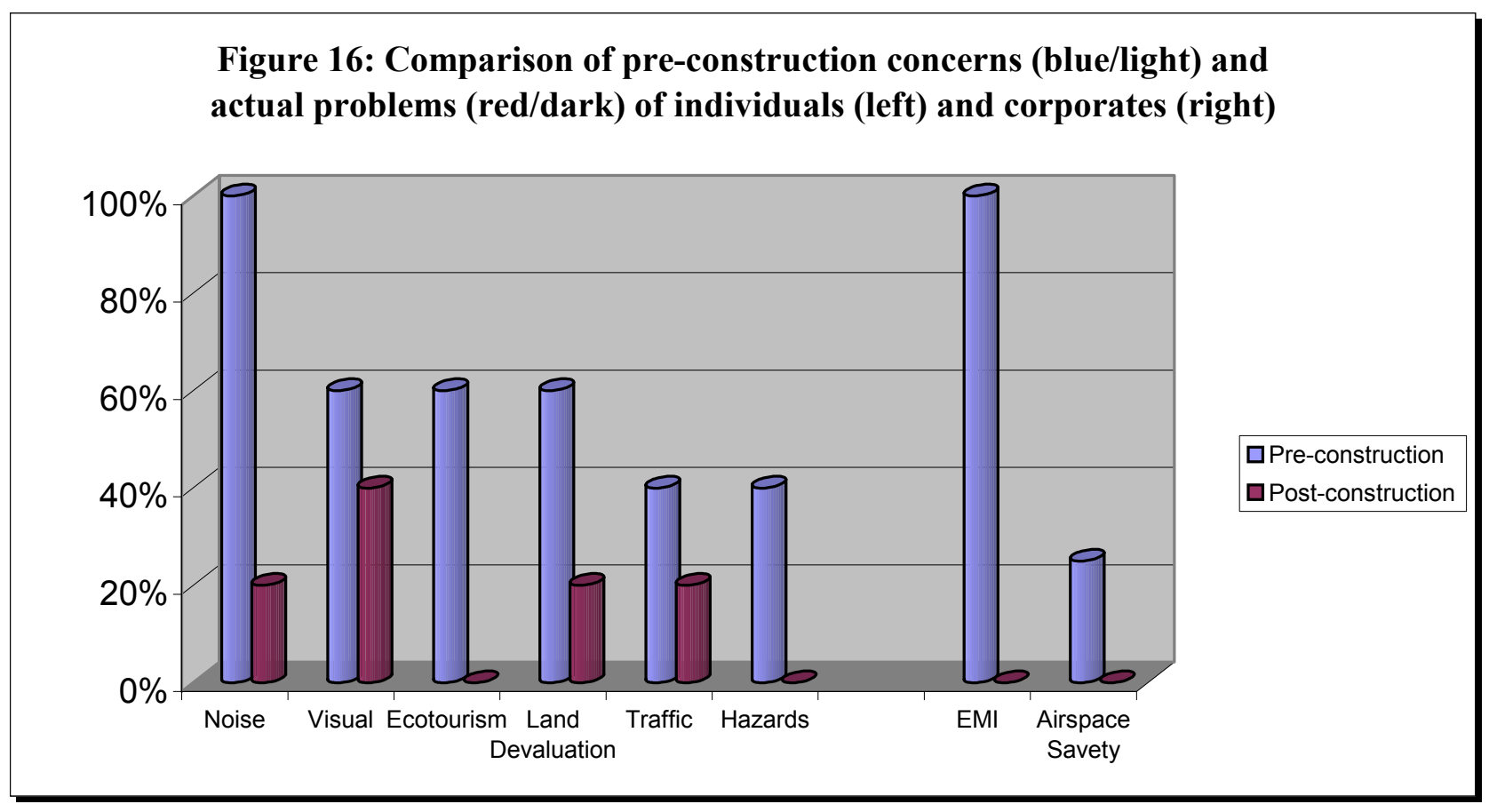

The goal of resolving every issue and reaching complete public agreement is considered as difficult if not impossible (Righter, 2002). Survey findings from Europe indicate that regardless of how many people favour a wind farm, some $5-25 \%$ of the community will tend to remain unsupportive during the project process (Simon, 1996; Elliott, 2001; Wolsink, 1990). 
The public consultation process employed for the Tararua Wind Farm was widely considered to be appropriate, but not everybody was satisfied. Considering that many perceived adverse effects, as stated in the submissions, did not turn out to be an issue and that $80 \%$ of the interview participants would have preferred to be given more project related information, suggests that further public education and awareness of the local viewpoint might have reduced the number of submissions significantly. All participants mentioned that they would have favoured a higher degree of involvement, e.g. through public discussions or investment opportunities. However, some objectors received the impression that the wind farm would have been build anyway and that they were given little opportunity to participate in the planning process other than addressing their concerns via a submission into the resource consent process.

Such an impression was reinforced by the appearance of the consultants representing a "big company approach" and possibly intimidated some rural residents. Even though the Tararua Wind Farm attracted a relatively small number of submissions in opposition compared to the vast support from the community, agencies and associations, many objecting submissions could have been probably avoided through better stakeholder involvement. Generally speaking the absence of opportunity to influence a project has negative effects upon community acceptance of a project (Wolsink, 1996). Available options for community involvement are discussed in detail in the conclusion section of this study (Chapter 8).

The research results, which were gathered to fulfil the second research objective, described in more detail reasons for opposition to the Tararua Wind Farm and applied the sequential development concept of public acceptance to explain the identified change of attitude among the former objectors. Supplementary information was derived from the interview questions about consultation explaining to how much the consultation process might have affected stakeholder attitudes.

Possible limitations of the applied method are associated with the absence of a pre- and post-construction opinion survey. It would have been preferable to have had an 
evaluation of the development of public acceptance in a New Zealand context on the basis of polls conducted before and after the construction of the wind farm. Such polls are frequently used in Europe to investigate the change in public acceptance of wind farm projects. Moreover, the sample size and availability of interview participants may have limited results which do not represent opinions of the whole community.

\subsection{Interview with Wind Farm Developer}

Generally, the developer is committed to providing project information and seeks feedback from affected stakeholders but doubts that further public involvement will necessarily increase community support due to previous experience with determined objectors. These objectors participate in the consultation process to collect information in order to use them to stop the project. This situation raises the question about the amount of financial resources that should be spend on consultation measures to satisfy every stakeholder or at which point it is appropriate to uphold the project momentum and ignore these $5 \%$. The wind farm developer's point of view is valid and certainly applies in various situations, but it also may prevent benefiting from opposing views in a constructive way, e.g. through utilising a well designed consultation process that offers the most appropriate level of involvement to each individual stakeholder.

One approach to neutralising opposition from people who are not willing to find a solution in co-operation with the developer is the principle of disregarding objectors (Whalen, 1998; Weller, 1998). Alternatively, it might be desirable to identify the underlying motives behind their opposition and avoid unnecessary distrust by labelling their concerns "ridiculous or irrational" (Wolsink, 1989). This can be achieved by means of a stakeholder analysis at an early stage of the project to decide on the most appropriate degree of stakeholder involvement in the planning process (Jackson, 2001; Weller, 1998). The development of an individual action plan might help a decision on the most appropriate consultation approach (Weller, 1998) and could help to minimise the risk of potential abuse of the consultation process. Moreover, by conceding that it is unlikely or 
even impossible to satisfy all stakeholders regardless of the effort spend to deal with their concerns (Wolsink, 1990; Righter, 2002) local authorities need to demonstrate that they represent everyone in the community (and not only just one interest group or industry) in resource consent processes for wind farms under the RMA.

A developer's understanding of how to apply consultation widely, complies with the approach suggested by international best practice guidelines from wind energy authorities (EECA, 1995; AusWEA, 2002 [online]; EWEA, 1998 [online]; BWEA, 1994 [online]) which recommend focusing on the inclusion of all stakeholders, an early pro-active commencement of consultation, distributing and gathering information to jointly identify and solve potential problems, and, finally implementing ongoing community liaison services. The developer's underlying aim of consultation is to achieve a mutually rewarding exchange of information by providing project information to stakeholders and collecting their feedback in return. One-on-one consultation sessions prove to be the most effective means of informing affected parties and addressing possible concerns. This relatively low degree of involvement, with respect to Dorcey's et al. (1994) spectrum of public participation, seems to satisfy the stakeholder majority.

Deciding on the most appropriate time to commence consultation is a crucial decision in order to avoid unnecessary confusion and to retain a certain momentum in the process. One risk of consultation is that it can be "overdone" with the result of cost increase and the emergence of determined opposition groups more interested in delaying or stopping a wind farm than finding a mutually beneficial solution. This particular problem is not only limited to wind energy but it has been generally identified in other public consultation processes.

The consultation process employed for the Tararua Wind Farm was conducted in accordance with the developer's strategy described above to satisfy the RMA consultation requirements. A key element of this approach was one-on-one sessions with affected stakeholders to provide information, discuss arising concerns and ask their consent with regard to the development of the wind farm. Additional information was 
later communicated through promotional material, media coverage, an open day and site tours. Despite relatively limited opportunities for public involvement, according to Dorcey et al. (1994) spectrum of public participation, the Tararua Wind Farm successfully gained resource consent in 1996. This raises the question whether a greater degree of public involvement could have increased the support within the community and reduced the number of opposing submissions or whether it made the consultation more expensive, time consuming and gave objectors the opportunity to organise an effective opposition group. This issue will be further discussed in the following synopsis.

According to the aim of the third research objective, the results and analysis of this empirical component indicate how a wind farm developer approaches the public consultation process and explains the challenges, which are associated with this practice. Specific information was obtained from the group interview on three topics concerning public opposition, community consultation and participation, and the Tararua Wind Farm consultation. Any potential limitation of the selected method is associated with the size of the sample set. Interviews with the staff of only one wind farm developer does not make the results necessarily representative of the entire industry and lacks comparison with other developers' consultation approaches. 


\section{CONCLUSION}

The conclusion of this study is based on the analysis and discussion of the empirical components (Chapter 7) in combination with the literature presented in Chapter 6 to fulfil the underlying aim of this research - the determination of the most effective means of consulting with community stakeholders for the purpose of reducing the likelihood of substantial community opposition to wind farm developments in New Zealand.

The arguments used to oppose the Tararua Wind Farm, as identified through analysing submissions, predominantly anticipated adverse effects such as noise, EMI, visual intrusion and land-devaluation. These perceived risks of affected stakeholders are comparable to European experiences where similar arguments have been used to oppose wind farms (Hill, 2001; EECA, 1996). Risk awareness may arise because people fear the effects of this new concept of power generation (Connor, 1988) that could impose a certain change on their daily life. The findings from follow-up interviews suggest that the submissions were made to protect appreciated landscape values (Pasqualetti et al., 2002, Wolsink, 2000, Righter, 2002) and business operations, which were feared to be adversely affected by the proposed wind farm development.

While the initial concerns were certainly perceived as real threats, additionally, there may have been some underlying unexpressed concerns about landscape values (Wolsink, undated), financial and personal issues (Weller, 1998) that also motivated opposition to the project. That negative responses change once the Tararua Wind Farm was established, allows the assumption that there a predictable degree in the development of public acceptance (Pasqualetti et al., 2001; Wolsink, 1996) also occurs in a New Zealand context. The majority of the initial objectors significantly changed their opinion after they realised that the operating wind farm did not cause the anticipated adverse effects or adverse effects occurred to a lesser extend than expected, and that the presence of the wind farm offered various local business opportunities instead. 
The consultation about the Tararua Wind Farm was designed to be undertaken as a mutually rewarding process between developer and stakeholders, and generally followed best practice by trying to provide information, explore concerns that arose during consultation, take stakeholder feedback into account and apply mitigation measures, whenever possible or necessary. Although interview participants considered the consultation process as appropriate, their interest in additional information and involvement opportunities remained partly unsatisfied. The current best practice approach to consultation could gain in clarity and efficiency, as discussed, by integrating stakeholder analysis and models of public participation into this framework.

Regardless of the support a wind farm might receive, a proportion of the community will remain opposed to the project with a share ranging between 5 and 25 per cent (Elliott, 2001; Wolsink, 1990; Righter, 2002). Underlying motives of wind farm objectors vary and do not necessarily represent the NIMBY syndrome alone (Wolsink, 2000) so that jumping to conclusions should be avoided by taking community concerns serious (Wolsink, 1989). In contrast, advocates of the BANANA attitude are unlikely to modify their opinion, because they do not oppose wind farms in particular but object development in general (Markley, 2002). Even though determined objectors may not change their attitude, some principles may reduce the "NIMBY effect" (Whalen, 1998), including the formation of alliances with supportive community members to build up public opinion in favour and to isolate any fierce objectors, who consider any form of compromise as unacceptable.

In any democratic society, a diversity of public opinion is highly desirable and probably not all opposition against wind farms can be entirely resolved and brought to a consensus, but it can certainly be minimised. The example of the Tararua Wind Farm shows that an appropriate consultation process and even a relatively low level of public involvement, with respect to the available spectrum of community engagement techniques (Jackson, 2001; Dorcey et al., 1994; iPlan, 2003 [online]), can lead to successful project accomplishment. This raises the question, whether a higher level of public involvement would necessarily cause fewer opposing submissions and increase community support, or 
would it result in a resource consuming process that gave objectors ample time and information to organise an effective opposition group. Nevertheless, the following measures concerning wind farm design, community approach and involvement could be considered and integrated into future community consultation processes to reduce the likelihood of community opposition.

Minimising the potential impact on the landscape and the community is certainly one of the chief means of avoiding unnecessary opposition. It could be achieved by selecting an appropriate location and by imposing minimal adverse effects in the first place (Wolsink, 2000; Planning Australia, 2002; EECA, 2001). Moreover, design measures could enhance the aesthetic appeal of a wind farm (Gipe, 2002), for example, by limitation of the project size to clusters and keeping wind turbines operational at all times except for maintenance. Currently, various computer-aided tools can make preliminary assessment of potential noise and visual intrusion on the landscape, and enable developers to evaluate and minimise the likely impact at an early stage of the planning process (Berrini et al., 1998; Georgopoulou et al., 1998; Gipe, 2002; Andolina, 1998; Planning South Australia, 2002).

In addition, central government could develop a framework of national planning policies that define exclusion zones, and that prohibit the development of wind farms in certain coastal areas, landscapes and habitats of natural significance (Planning South Australia, 2002) to provide planning clarity to the wind energy industry.

The way in which a project is introduced to the public can influence the community response and consequently the level of support. For example, the "Decide-AnnounceDefend" (DAD) approach (Wolsink, 1996) is likely to trigger unnecessary opposition and distrust among the affected community because it causes people to object to the developer and the process rather than to the proposed wind farm. In contrast, a "proactive approach" (Weller, 1998) can help to turn a development into a "community project" by providing information and possibilities to participate in and benefit from the project to ultimately achieve a "win-win situation" between developer and community. In 
the case of the Tararua Wind Farm, a more open and community-focused approach might have resulted in a further increase of public project acceptance.

The procedure of stakeholder analysis can be utilised to identify and analyse involved stakeholders (Jackson, 2001) so as to make an informed decision on the most appropriate degree of involvement depending on the objectives of the consultation process. Stakeholder analysis can also identify, analyse and understand hidden arguments, underlying values and community structures (Kellow, 1999; Weller, 1998; Jackson, 2001). This approach enables the analyst to distinguish characteristics of stakeholders (i.e. between corporations and individuals) and to explore power interrelationships (i.e. between developer and stakeholders) in relation to their interest, influence and importance (Ramirez, 1999) in order to design an individual consultation strategy (Weller, 1998). An individual approach for each stakeholder and determining the most appropriate level of participation minimises the possibility that project objectors might abuse the consultation approach and might permit committed parties to work together with the developer on a favourable solution.

The key elements of the recommended consultation processes are inclusion of all representative stakeholders, providing sufficient information and adequate time, and taking stakeholder comments and feedback into account (Corydon Consultants, 2002). The specific approach and timing of the consultation process depends upon the phase of the development which addresses the relevant issues associated with each project stage (EECA, 1995; AusWEA, 2002 [online]; EWEA, 1998 [online]; BWEA, 1994 [online]). While it might be desirable to offer "real" participation opportunities to the affected community (Wolsink, 1996) and increasing the involvement level by employing techniques that engage the community (Dorcey et al., 1994; iPlan, 2003 [online]), a higher community participation stage requires adequate and appropriate resources, commitment by all affected stakeholder representatives, open communication and mutual trust in order to work successfully. This approach bring a risk (that can be anticipated and minimised by such means as stakeholder analysis of being abused so as to deliberately delay or stop the development on the one hand, but also can prove to be opportunity to 
reduce the likelihood of substantial community opposition to wind farm developments. Regardless of the participation level, it might be desirable to maintain a certain momentum of the process to avoid additional costs for the developer and unnecessary frustration for the community extending uncertainty about the outcome.

In general, public acceptance of wind farms increases if affected stakeholders are educated and informed about wind energy and the project itself, and become financially involved in the development (Damborg et al., 1998; Geuzendam, 1998; Connor, 1988). Examples of community ownership schemes in Denmark (Elliott, 1994, 2001; Gipe, 1995; Tranaes, 1997 [online]) demonstrate that financial involvement successfully prevents the alienation and exclusion of the community from wind farm projects. The Danish experience of local ownership of turbines significantly increases wind farm acceptance among communities and influences the cultural and political atmosphere by the formation of a strong pro wind farm lobby (Toke et al., 2000).

At first glance, this concept of successful financial involvement seems to be hardly transferable to a New Zealand context because the government does not subsidise renewable energy and electricity prices are relatively low. On the other hand, wind farm developers or utilities might consider a strategy for future projects that invites affected stakeholders to buy into a co-ownership or to become wind farm shareholders ${ }^{28}$. Electricity consumers may be attracted to paying off a debt or buying wind farm shares at a premium instead of paying a monthly power bill. After a certain time and depending on the degree and type of investment, some consumers might receive local electricity for a lower price, free of charge or even be able to earn revenue by selling an electricity surplus. Local ownership schemes could also benefit from the interests of the government to increase the renewable energy share to meet future electricity demand and to ensure the security of power supply. Therefore, the government may (in the near future) be motivated to offer loans to communities on a low or no interest basis so as to stimulate local ownership schemes of wind farms and to make them affordable to individual

\footnotetext{
${ }^{28}$ The Christchurch based wind turbine manufacturer Windflow, for example, invited the public to invest in company shares to realise a two-bladed turbine prototype at Gebbies Pass (Windflow, 2003)
} 
community members. This approach could lead to an enormous win-win situation by increasing public acceptance of wind farms, creating wealth and assets of New Zealanders, by contributing to emission reduction and the diversification of the country's electricity market, and by adding urgently required generation capacity to prevent a future electricity crisis. 


\section{RECOMMENDATIONS}

There is a range of measures available that wind farm developers should consider in order to ensure a mutually rewarding consultation and planning process that minimises the likelihood of community opposition.

- It is crucial to choose a wind farm location that poses a relatively low level of intrusion upon the landscape and, thus, minimise adverse effects to the affected community. It is recommended to apply aesthetic design methods and avoid sensitive areas of natural significance to cause a minimum of intrusion upon the landscape. This approach may need to take into account the WF size (number of turbines) and the micro topography leading to a more sustainable development, higher public acceptance levels and allow for developing more turbines at less intrusive sites than in controversial 'optimal' locations.

\section{Examples:}

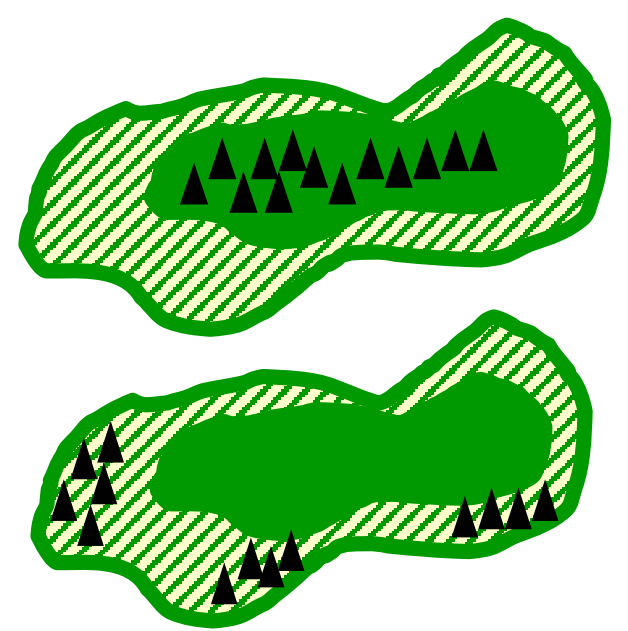

Instead of positioning the turbines in a utility scale WF with turbines cluttered together in a highly visible location...

...it may be advantageous to a developer to situate the turbines in small to medium sized clusters leading to higher acceptance among affected communities.

Figure 17: Alternative approach for wind turbine siting (No. 1)

Key: Maximum wind velocities (e.g. exposed ridge lines)

Sub-optimal wind velocities within the feasible range (e.g. still high wind velocities but lower than the best sites)

$\Lambda \quad$ Wind Turbines 

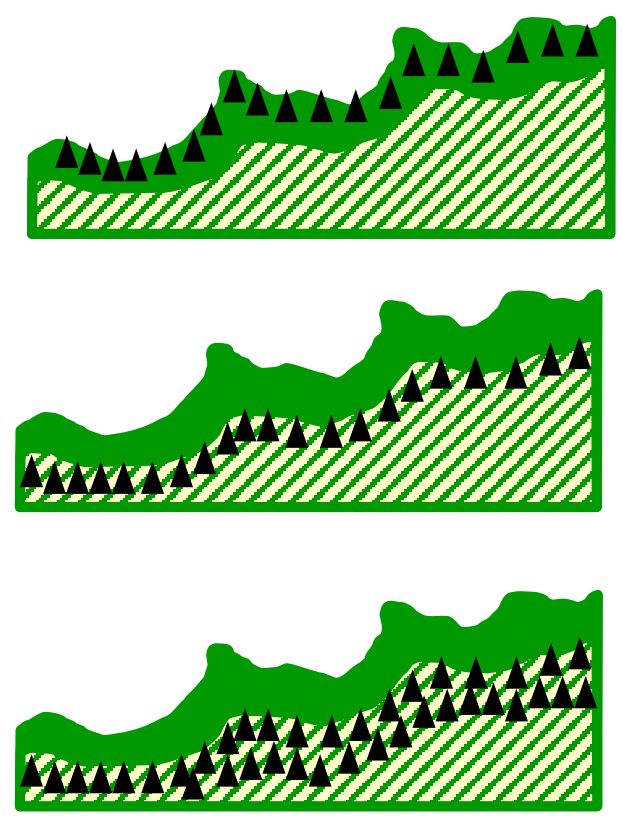

...the construction of a wind farm in areas with highest wind speeds (coastlines) may cause significant environmental adverse effects and visual intrusion.

By situating the turbines off the 'optimal' location and accepting slightly lower wind speeds at an inland location...

...public acceptance may increase leading to the construction of even more turbines than initially planned on a coastline location.

Figure 18: Alternative approach for wind turbine siting (No. 2)

Key:

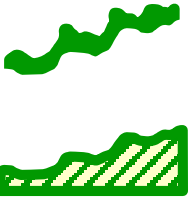

Maximum wind velocities (e.g. exposed coastline)

Sub-optimal wind velocities within the feasible range (e.g. still high wind velocities but lower than the best sites)

$\mathbf{M} \quad$ Wind Turbines

- A pro-active planning approach to increase the acceptance of a wind farm development by providing information, opportunities to participate and benefits to the community. Wind farm developers should carefully plan the introduction of a proposed project to the community and, if possible, offer all affected stakeholders 'real' opportunities to participate in the planning process. By taking into account stakeholder concerns at an early stage, projects can be improved, adverse effects identified and mitigated in order to achieve a win-win situation for developers and community. 
- Stakeholder analysis offers planners and decision makers a sophisticated planning tool to identify stakeholders, underlying motives of objectors and assist in making an informed decision on the most appropriate level of stakeholder involvement. Wind farm developers may consider integrating stakeholder analysis as a key measure in their best practice approach to consultation.

- The community consultation process should be mutually rewarding and offer participation opportunities for committed stakeholders. This approach requires time and resources, as well as commitment from all involved stakeholder representatives, open communication and mutual trust. Therefore it is important to take into account the background of the stakeholders to consult in order to prevent negative impressions (i.e. a "big company approach") by sensibly selecting appropriate clothing and/or language. Moreover, the broad interest in increased involvement expressed by the participants of this study indicates that wind farm developers will not lack committed and interested stakeholders who are willing to contribute to participatory planning processes in a constructive way.

- Apart from informing and educating the public on wind energy issues and specific wind farm projects to overcome suspicion and negativity, financial involvement in form of a community ownership scheme probably represents the most effective option for significantly increasing public awareness and acceptance of wind farms. This concept allows developers to share the financial benefits of a wind farm development not only with landowners but also with the affected community that bears all the cost in terms of loss of visual amenities. Denmark provides a range of examples where individuals or communities own single turbines or small clusters. In New Zealand joint ownership schemes may be realised by offering the affected community a proportion of the wind turbines, e.g. through share holding. 
Obtaining resource consents for proposed wind farms also depends on the RMA process itself. It requires an independent decision maker who also considers national benefits of renewable energy, takes into account that a proportion of the community will remain opposed regardless of the project, acknowledges the attempts undertaken to involve the community in the planning process and understands that some of the project opponents will positively adjust their attitudes towards a wind farm after they have personally experienced that the operating turbines cause significantly less (or none) adverse effects than initially anticipated.

By taking into account the measures and information discussed above the following recommendations were developed:

\section{A) Joint ownership of wind farm projects}

Wind farm developers should reconsider their approach to the project ownership. By moving away from the current sole ownership approach to become a partner in a jointownership scheme with the affected community, public acceptance of locally operating wind turbines will significantly increase and the project could provide substantial financial benefits to the investors. While in New Zealand there is no precedent for wind farm co-ownership, a developer could seek government support for testing the feasibility of pilot projects. Government funding (e.g. through the Sustainable Management Fund) could offset initial losses or costs to realise a wind farm joint ownership. Financial disadvantages to the developer may be potential loss in revenue or a significantly higher investment of human resources to set up a community joint project. However they could be compensated by an increased likeliness of gaining resource consent. 
Pros: significantly higher degree of community support, benefit sharing with affected community, increased likeliness of gaining resource consent, feasibility studies funded by government to offset initial losses or costs

Cons: adjustment of current approach, currently no precedent in New Zealand, potential risks such as loss in revenue or higher demand of human resources

\section{B) From economies of scale to economies of scope}

With emerge of co-ownership schemes in the medium term wind farm developers may need to adjust the scale of their expectations in terms of project design and project size. If joint ownership wind farms facilitate the likelihood of larger number of projects with a higher degree of community support, developers may need to refocus on the development of numerous small to medium sized wind turbine clusters with public involvement in the planning process and in sharing the benefits of owning the turbines with the wider community (not only landowners) instead of constructing a few large scale wind farms that have a greater impact on the landscape, are less accepted by the public and are solely owned by a single utility which keeps most financial benefits to itself.

Pros: turbines in numerous wind turbine clusters could outnumber the total of turbines installed in a few utility scale wind farms, significantly higher degree of community support of projects through benefit sharing and joint ownership with affected communities

Cons: requires refocus of a developer's scale of expectations and adjustment of the current approach to developing wind farms in New Zealand, might increase the costs per turbine "in the ground" (because costs of groundwork and grid connection are similar regardless of wind farm size) 


\section{C) Community consultation}

The community consultation approach needs to exceed a merely informational/ educational purpose in order to increase the level of public participation into the planning process. By increasing the degree of community empowerment affected stakeholders gain the opportunity to become project partner and therefore become directly involved in the design of the development (e.g. in the siting decision). A preliminary stakeholder analysis allows making an informed decision on the individually most appropriate level of participation and involvement in the process to ensure a mutual rewarding co-operation and to prevent any potential abuse of the consultation approach by people who are not committed to develop a consensus-based solution.

Pros: approach generally promises a higher level of public support and project acceptance, offers affected stakeholders an opportunity to get directly involved in the decision making process, formation of project partnership

Cons: more expensive and time consuming than conventional approach, requires more human resources and appropriate skills, approach increases risk of hostility from wind farm opposition groups

In long term, the political consequences arising from this innovative approach to the development of wind farms are likely to be beneficial to open-minded developers who aim at continuously operating in the sustainable energy sector. Even though a proposed wind farm is unlikely to receive unanimous agreement among affected communities, it is simply a matter of maximising wider acceptance of wind turbines. Any increase of public support for wind energy strengthens a new lobby in favour of wind farms in New Zealand. This support - as demonstrated by many other industry sectors - is likely to attract an increase of governmental support by funding initiatives to further enhance the development of New Zealand's wind power potential (e.g. changes in taxation conditions for renewables that might offset any existing financial disadvantages and inviting investment in community owned wind farms). Subsequently a spin-off of New Zealand's 
wind energy might not only create a new industry sector and create new jobs, but also contribute to meeting the nation's Kyoto obligation and future electricity demand.

It is well understood that some of these recommendations may raise the question of their economic viability ${ }^{29}$ under the current situation in New Zealand (i.e. in the absence of any government subsidy or initiative for wind energy that would invite alternative approaches of developing wind farms). This problem could arise in the context of economic implication of situating wind turbines in small clusters or off top wind speed areas in order to increase the chances of planning success.

This study does not claim to provide the answer to this issue but it recommends and encourages further research on the broad benefit-cost ratio and other economic aspects, associated with increasing community participation and financial involvement, where potential benefits include the chances of increasing the success rate of resource consent applications for wind farms by significantly reducing the likelihood of public opposition.

\footnotetext{
${ }^{29}$ This issue was raised and discussed after a personal comment was made by a wind industry representative at the NZWEA annual general meeting on 28 May 2003.
} 


\section{REFERENCES}

Advocate (9/2/2002), Worried by wind farm, by A. O'Rourke, Bournie, Tasmania

Andolina, C.; Casale,C. and M.Cingotti; S.Savio (1998), Visual compatibility of wind power plants with the landscape: Possible methods for preliminary assessment, In: Ratto, C.F. and G. Solari (eds), Wind energy and Landscape, p. 147-160, Balkema, Rotterdam, Netherlands

AusWEA (2002) [online], Best Practice Guideline for Implementation of Wind Energy Projects in Australia, Australian Wind Energy Association, URL: http://auswea.com.au, accessed 12/10/2002

AWEA (2002) [online], Facts about wind energy and noise, Wind energy fact sheet, American Wind Energy Association, URL: http://www.awea.org, accessed 16/12/2002

Barton, N. and A. Shawn (1999), Striking a Balance. A Practice Guide on Consultation for Project Advocates, Opus International Consultants Limited

Berrini, M., V. Tiana, S. Woes-Gallasch and A. Casciu (1998), Wind farm site selection in Sardinia considering environmental and landscape aspects, In: Ratto, C.F. and G. Solari (eds), Wind energy and Landscape, p. 147-160, Balkema, Rotterdam, Netherlands

Brittan, G.G., Jr. (2002), A View from Lake Como, In: Pasqualetti, M.J., P. Gipe and R.W. Righter (Editors), Wind Power in View, p. 215-221, Academic Press, San Diego

Buchy, M. and D. Race (2001), The Twists and Turns of Community Participation in Natural Resource Management in Australia: What is missing? Journal of Environmental Planning and Management, 44(3), p. 293-308 
BWEA (1994) [online], Best Practice Guidelines for Wind Energy Development, British Wind Energy Association, URL: http://www.britishwindenergy.co.uk/, accessed $12 / 06 / 2002$

Cherry, N.J. and V. Smyth (1987), Wind energy resource survey of New Zealand, National resource Assessment, New Zealand Energy Research and Development Committee, Report No. 140

Chevalier, J. (2001) [online], Stakeholder Analysis and Natural Resource Management, Carleton University, Ottawa, URL: http://www.carleton.ca/jchevali/stakeh2.html, accessed 12/06/2002

Clark, L. (2003), Tourists who are fans of wind farms, London Press Service, Issue 10 ( $7^{\text {th }} \operatorname{Jan} 2003$ )

Commission on Resources and Environment (2002) [online], Public Participation, URL: http://www.luco.gov.bc.ca/lrmp/plus/vol3/vol3-06.htm, accessed 19/11/2002

Connor, D.M. (1988), Breaking through the 'NIMBY' Syndrome, Civil Engineering, December 1988

Contact (27/3/2003), Belmont windmills could power Porirua-size city, by J. Jacobson, Wellington

Corydon Consultants Ltd. (2002), Essential Ingredients of Consultation, unpublished paper on consultation, Wellington

Damborg, S. and S. Krohn (1998), Public Attitudes towards Wind Towards, Danish Wind Industry Association, Denmark 
Dey, I. (1993), Qualitative data analysis, A user-friendly guide for social scientists, Routledge, London

Dominion Post (18/03/2003), No wind at Makara, please, by J. Jorgensen, Wellington

Dominion Post (5/03/2003), Wind farm planned for Makara-Titahi Bay, by M. Steeman, Wellington

Dominion Post (19/10/2002), \$35 million turbine farm in the wind, by H. Shouten, Wellington

Dorcey, M., Doney, L. and H. Rueggeberg (1994), Public Involvement in Government Decision-making: choosing the right model (Victoria, Round Table on the Environment and the Economy)

EECA (2001), Review of New Zealand's wind energy potential to 2015, Energy Efficiency and Conservation Authority, Wellington

EECA (1997), Wind energy, energy-wise Renewables 3, Energy Efficiency and Conservation Authority, Wellington

EECA (1996), New and emerging Renewable energy opportunities in New Zealand, Energy Efficiency and Conservation Authority, Wellington

EECA (1995), Energy-Wise Renewables - Guidelines for Renewable Energy Developments, Energy Efficiency and Conservation Authority, Wellington

Elias, N. (1987), Involvement and Detachment. Edited by M. Schrotter. Translated by E. Jephcott. Oxford: Blackwell 
Elliott, D.A. (2001), Wind Power in the UK - the need for a fresh start, Paper to the World Energy Council on Renewable Energy

Elliott, D.A. (1994), Public Reactions to Windfarms: the dynamic of opinion formation, in: Energy and Environment, Vol 5 No. 4, December 1994, p. 343-362

EWEA (1998) [online], European Best Practice Guidelines for Wind Energy Development, European Wind Energy Association, URL: http://www.ewea.org/doc/bpg.pdf, accessed 12/06/2002

Georgopoulou, E. and D.P. Lalas (1998), Multicriteria decision-aid tools for attaining greater public acceptance in renewable energy sources exploitation, In: Ratto, C.F. and G. Solari (eds), Wind energy and Landscape, p. 147-160, Balkema, Rotterdam, Netherlands

Geuzendam, C. (1998), Wind energy and public acceptance, IVAM Environmental Research, University of Amsterdam, In: Ratto, C.F. and G. Solari (eds), Wind energy and Landscape, p. 147-160, Balkema, Rotterdam, Netherlands

Gill, M.A. (2003) [online], Key role for Huntly as power shortage looms, URL: http://www.stuff.co.nz/stuff/waikatotimes/0,2106,2336889a6579,00.html, $\quad$ accessed $30 / 03 / 2003$

Gipe, P. (1995), Wind energy comes to age, Wiley and Sons, USA

Gipe, P. (2002), Aesthetic guidelines for a wind power future, In: Pasqualetti, M.J., P. Gipe and R.W. Righter (Editors), Wind Power in View, p. 173-212, Academic Press, San Diego

Gray, T.O. (2002) [online], Wind energy, Views on the Environment, American Wind Energy Association, URL: http://www.awea.org/policy/, accessed 11/09/2002 
Grimble, R. and K. Wellard (1997), Stakeholder Methodologies in Natural Resource Management: a Review of Principles, Contexts, Experiences and Opportunities; In: Agricultural Systems, Vol. 55, No. 2, pp. 173-193, Elsevier Applied Science, Barking, England

Harland, Jim (2000), Managing wind power development in New Zealand, Postgraduate paper in Geography, Victoria University, Wellington

Harris, R. (1995), The Demands and Principles of Consultation, Planning Quarterly, New Zealand Planning Institute, March 1995, p. 5-7

Hay, L. (2000), Qualitative Research Methods in Human Geography, Oxford University Press

Herald Sun (01/03/2003), Striking a blow for wind, by K. Mallon, Melbourne, Australia

Heritage Coast (undated), Pamphlet to object wind farm proposals in proximity to the Bay of Islands Coastal Park in Victoria, Australia

Hill, A. (2001), Trends in public opinion, British Wind Energy Association, UK

Hill, M.R. (1981), Positivism: a ‘hidden’ philosophy in geography. In Harvey, M.E. and Holly, B.P. (eds), Themes in Geographic Thought, Croom Helm, London, pp. 38-60

Hoppe-Kilpper, M. and U. Steinhaeuser (2002), Wind landscapes in the German milieu, In: Pasqualetti, M.J., P. Gipe and R.W. Righter (Editors), Wind Power in View, p. 83-99, Academic Press, San Diego

INL Newspapers (08/05/2003) [online], Govt to outline plans for new power stations, URL: http://www.stuff.co.nz/stuff/0,2106,2457117a11,00.html, accessed 12/3/03 
International Institute for Environment and Development (2001) [online], Power Tools, Tools for working on policies and institutions, URL: http://www.iied.org/forestry/tools/stakeholder.html, accessed 14/06/2002

iPlan (2003) [online], Community engagement techniques and tools, URL: http://www.iplan.nsw.gov.au/engagement/techniques/index.php, accessed 25/03/2003

Jackson, L.S. (2001), Contemporary Public Involvement: toward a strategic approach, Local Environment, Vol. 6, No. 2, p. 135-147

Kitchin, R. and N.J. Tate (2000), Conducting Research into Human Geography: Theory, Methodology and Practice, Prentice Hall, Essex, UK

Kellow, D. (1999), Wind farm development: a critique of the consultation processes used by developers of wind farms in New Zealand, Master thesis Environmental Studies, Institute of Geography, School of Earth Sciences, Victoria University, Wellington

Lake, R.W. (1993), Rethinking NIMBY, American Planning Association, Journal of the American Planning Association, Chicago, Vol.59, Issue 1, pp. 87-93

MacArthur, J.D. (1997), Stakeholder roles and stakeholder analysis in project planning: a review of approaches in three agencies - World Bank, ODA and NRI, Discussion Paper No. 73, Development and Project Planning Centre, University of Bradford

Maize, K.P. and J. McCaughey (1992), NIMBY, NOPE, LULU, and BANANA: A Warning to Independent Power, Public Utilities Fortnightly, Washington, Vol. 130, Issue 3 , pp. 19

Markley, D. (2002), It's not NIMBY anymore - it's BANANA, Broadcast Engineering, Vol. 44, No.3, pp.52-54 
May, T. (1997), Social Research, Issues, methods and process, Open University Press, Buckingham, UK

Mayan, M.J. (2001), An Introduction to Qualitative Methods: A Training Module for Students and Professionals, International Institute for Qualitative Methodology, Edmonton, Alberta, Canada

McArthur, J. (2002) [online], Wind-power windfall for farms, URL: www.afr.com/property, accessed 8/2/2002

Ministry of Commerce New Zealand (2000), New Zealand Energy Outlook to 2020, Ministry of Commerce, Wellington

Ministry of Economic Development New Zealand (“MED”) (2001), Energy Date File July 2001, Ministry for Economic Development, Wellington

Ministry of the Environment New Zealand (MfE) (2002) [online], Consultation, URL: http://www.mfe.govt.nz/management/template2.htm, accessed 19/08/2002

MRL Research Group (1994), Attitudes towards wind generation of electricity, Energy Wise Publications, Energy Efficiency and Conservation Authority, Wellington

ODA (Overseas Development Administration) (1995), Guidance note on how to do stakeholder analysis of aid projects and programmes, ODA, London, UK

O’Bryant, M. (2002), No effect on property values, Windpower monthly, Vol. 18, No. 12

O'Bryant, M. (2003), Support grows as bird kills drop, Windpower monthly, Vol.19, No.2, pp. 55-56 
O'Hare, M, Bacow, L. and D. Sanderson (1983), Facility siting and public opposition, Van Nostrand Reinhold, New York

ONE News (24/3/2003 [online]), Meridian paves way for wind, ONE News sourced from TVNZ, RNZ, Reuters and AAP, by A. Fox, URL: http://onenews.nzoom.com/onenews detail/0,1227,175562-1-7,00.html, $30 / 03 / 2003$

Pacione, M. (1999), Applied Geography: Principles and Practice, Routledge, London

Palmer, K. (2002) [online], Resource Management Law in New Zealand, Murdoch University Electronic Journal of Law, Vol 9, No 3, URL: http://www.murdoch.edu.au/elaw/issues/v9n3/palmer93.html, accessed 27/04/2003

Pasqualetti, M.J., P. Gipe and R.W. Righter (2002), Wind Power in View, Academic Press, San Diego

Pesch, J. (undated), Global thinking in Local Structures: Community Wind Projects in Southern Germany, Presentation held on the "World Wind Energy Conference", Berlin

Planning South Australia (2002), Planning Bulletin, Wind Farms, Draft for Consultation, Government of South Australia, Adelaide, Australia

Plummer, K. (1990), Documents of Life: An Introduction to the Problems and Literature of a Humanistic Method. London: George Allen and Unwin.

Portland Observer (1/2/2002), Wind farms, by L. Aitken, Australia

Potter, W.J. (1996), An Analysis of Thinking and Research About Qualitative Methods, Lawrence Erlbaum Associates, Mahwah, New Jersey, U.S.A. 
Press Release: New Zealand National Party, (17/03/2003) [online], Hodgson admits energy crisis looms, URL: http://www.scoop.co.nz/mason/stories/PA0303/S00354.htm, accessed 30/03/2003

Press Release: New Zealand Green Party, (08/05/2003) [online], Meridian wind farm breath of fresh air, URL: http://www.greens.org.nz/searchdocs/PR6286.html, accessed $12 / 5 / 03$

Press Release: New Zealand Government, (08/05/2003), Pete Hodgson Speech: New Renewable Energy - Meridian's Te Apiti Wind Farm

Press Release: Meridian Energy, (08/05/2003) [online], Meridian seeks consent for Manawatu wind farm, URL: http://www.scoop.co.nz/mason/stories/BU0305/S00101.htm, accessed 12/3/03

Ramirez, R. (1999), Stakeholder analysis and conflict management, in: Buckles, D. (ed.), cultivating peace, conflict and collaboration in natural resource management, World Bank institute, Washington, DC, USA

Recent Decisions (2000) [online], Week ending 7/7/2000, DSL Publishing, URL: http://www.geography.otago.ac.nz/Geography/Resources/envnews/recent.decisions/2000/ accessed 27/04/2003

Righter, R.W. (2002), Exoskeletal outer-space creations, In: Pasqualetti, M.J., P. Gipe and R.W. Righter (Editors), Wind Power in View, p. 19-41, Academic Press, San Diego

Robinson, G.M. (1998), Methods and Techniques in Human Geography, John Wiley \& Sons, Chichester, England 
Short, L. (2002), Wind Power and English Landscape Identity, In: Pasqualetti, M.J., P. Gipe and R.W. Righter (Editors), Wind Power in View, p. 43-58, Academic Press, San Diego

Silverman, D. (1993), Interpreting Qualitative Data, Methods for Analysing Talk, Text and Interaction, Sage Publication, London

Simon, A.M. (1996), A Summary of Research Conducted into Attitudes to Wind Power from 1990-1996, British Wind Energy Association, UK

Sinclair Knight Merz (2001), Community Consultation, Portland Wind Energy Project EES, Pacific Hydro multimedia release of Portland Wind Energy Project EES, Disk 1

Stamp, L.D. (1960), Applied Geography, Penguin Books, Harmondsworth

Stanwell Corporation Ltd (2001), Communication Plan Nirranda Wind Farm, EES Application, Queensland, Australia

Tararua District Council (1996), Consultant District Planner Report on 'Resource Consent Application by Tararua Windpower Ltd. for a proposed Wind Farm on the Tararua Ranges south of the Manawatu George'.

Tararua Wind Power (1995), Tararua Wind Power Project, Land use and subdivision consents application, Document prepared by Works Consultancy Services

Taylor, S.J. and R. Bogdan (1998), Introduction to Qualitative Reseach Methods, A Guidebook and Resource, John Wiley \& Sons, New York, U.S.A.

Teoh, T. (2000), Stakeholder Management: A Pre-requisite for Successful Wind Farm Development, Murdoch University, Perth, Western Australia 
Thayer, R.L., jr. and C.M. Freeman (1987), Altamont: Public perceptions of wind energy landscape, Center for Design Research, University of California, Davis, U.S.A.

Thayer, R.L.Jr. and H.A. Hansen (1991), Wind Farm Siting Conflicts in California: Implications for Energy Policy, Center for Design Research, University of California, Davis, U.S.A.

Toke, D. and D. Elliott (2000), A Fresh start for UK Wind Power?, International Journal of Ambient Energy, Vol.21, No.2, pp67-76.

Tranaes, F. (1997) [online], Danish Wind Energy Co-operatives, URL: http://www.windpower.org/articles/coop.htm, accessed 18/02/2003

UNSW, (2003) [online], Virtual Handbook, Applied Geography, URL: http://www.student.unsw.edu.au/handbook/programs/3010.shtml, accessed 12/05/2003

USA Today, (2002) [online], Even 'clean' wind power revs up resistance from locals, Editorial, URL: $\quad$ http://www.usatoday.com/news/opinion/editorials/2002-0805edit x.htm, accessed 08/10/2002

Wawryk, A.S. (2002), The Development Process for Wind Farms in South Australia, Environmental and Planning Law Journal, Vol. 19, No. 5, pp. 333-354

Weller, T. (1998), Improving siting acceptance by involvement analysis, In: Ratto, C.F. and G. Solari (eds), Wind energy and Landscape, p. 147-160, Balkema, Rotterdam, Netherlands

Wellington City Council (2001), A guide to Resource Consent in Wellington City, Environmental Control Business Unit, Wellington City Council, Wellington, New Zealand 
Wellington City Council (1996), Guidelines to develop a Consultation Plan, Social \& Cultural Commissioning, Wellington City Council, Wellington, New Zealand

Whalen, P. (1998), Keep NIMBY from being your nemesis, Marketing News, Vol.32, No.20, p.18

Webopedia.com, 2003 [online], Fresnel Zone, URL: http://80211planet.webopedia.com/TERM/f/Fresnel_Zone.html, accessed 02/06/2003

Wengraf, T. (2001), Qualitative Research Interviewing, Biographic Narrative and SemiStructured Methods, Sage Publications, London

Windflow (2003), Windflow Newsletter No.6, April 2003, Christchurch

Wolsink, M. (undated), Windturbine noise: a new environmental threat? In: Vallet, M (Ed.), Noise as a public health problem. Vol2, p.235-238, Inects, Bron, Fr.

Wolsink, M. (1989), Attitudes and Expectancies about Wind Turbines and Wind Farms, In: Wind engineering, Vol.13, No.4, Multi Science Publishing, Essex, UK

Wolsink, M. (1990), The Siting Problem: Wind Power as a Social Dilemma, Department of Environmental Science, University of Amsterdam, Netherlands

Wolsink, M. (1996), Dutch Wind Power Policy, Energy Policy Vol. 24 No.12

Wolsink, M (2000), Wind power and the NIMBY-myth: institutional capacity and the limited significance of public support, Renewable Energy 21, p.49-64, Elsevier Science

World Bank (2002) [online], Social Assessment, URL: http://www.worldbank.org/eessd/eessd.nsf, accessed 12/06/2002 
Yarzebinski, J.A. (1992), Handling the 'Not in My Backyard' Syndrome, Economic Development Review, Vol.10, No.3, pp.35

Yorke Peninsula Country Times (1/4/2003), Wind farm prospect generating plenty of interest, by K.C. Probst, Kadina, Australia 


\section{Appendix I: Letter to Participants}

Address: Date:

Dear,

My name is Chris Berg, I am a post-graduate research student in the Department of Geography, Victoria University Wellington. I am currently conducting a study under the supervision of Dr. Sean Weaver, Environmental Studies, focusing public consultation for the Tararua Wind Farm. This study will contribute to improve consultancy and public involvement for resource consent applications in the future.

I have approached a number of affected residents and stakeholder which have been consulted or involved in the development of the Tararua Wind Farm and was hoping you would be willing to take part in an individual discussion on the topic. Information collected will form the basis of my research project and will be used to identify problems of current consultation procedures with the aim to develop an improved approach. The response so far has been excellent and I trust that you will also be able to participate in this research.

Only Dr. Weaver and myself will have access to the information, which will be treated in a strictly confidential manner. The outcome of the research will be published as a Master thesis, a summary of the results can be forwarded to you if you wish.

I hope that you will be willing to participate in this project. If it is possible I would like to arrange an interview with you in the near future. I will soon phoning you to arrange a possible meeting at your premises.

If there are any questions left feel free to contact me under detail given below.

Yours sincerely,

\section{Chris Berg}

Department of Geography

Tel: $\quad 04-4635233+$ ext 8386

Cell: $\quad 021-1402245$

Email: chris.berg@vuw.ac.nz 


\section{Appendix II: Consent Form}

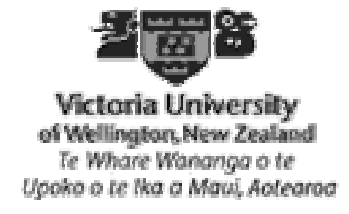

\section{Consent to Participate in Research}

Research Title: Just Hot Air? Variability of Attitudes and Opposition towards Wind Farm Developments in the Wellington Region

You are invited to give your consent to participate in this research project through a recorded interview. You may turn off the tape recorder at any point, without question.

All information obtained in this interview will be kept confidential and stored at a secure place. The access to this information is limited to the researcher and his supervisor Sean Weaver. All collected information will be destroyed after the submission of the dissertation, or at your request, returned to you. The final report will be written in a way that protects the identity of the informants.

The research results may be published in a professional or academic journal.

The participant information sheet (attached) explains this research. Please contact me with any further question you may have. You may withdraw your information from this project at any stage, up until the 31. December 2002.

Please confirm your consent to take part in the research by responding YES or NO to the following questions, and sign the statement below:

I agree to take part in the interview

YES NO

I agree to have the interview recorded

YES NO

I would like to receive a copy of the executive summary

YES NO

I agree to take part in this research.

Signature:

Date: 


\section{Appendix III: Interview Questions}

\section{A) Follow-up questions for semi-structured interview with Tararua Stakeholder}

Interview No.:

Name:

Date:

\section{Questions:}

1) Has your daily life been affected by the Tararua WF since it is operating? Have you experienced any benefits or disadvantages? If so, in which way?

2) Did your initial hopes or fears turned out as expected? Why / why not?

3) Did your attitude change towards the WF since it is operating? What do you think about the WF today?

4) What was your main motive to make a submission in the Resource Consent process?

5) What was your initial position towards the WF when you learned about the proposal?

6) How would you rate your knowledge about wind farms? And has your knowledge about wind power increased since the wind farm is operating?

7) How did you learn about the plans of developing a wind farm at Taurarua? How have you been approached by the representatives developing the wind farm?

8) If you could change the way the consultants approach you in such a matter - how would you improve it? What would you expect?

9) Have you addressed any concerns? If so, were they taken into account?

10) Did you had a chance to influence the decision making process for the wind farm? And if you had been given a chance to participate, would you be interested?

Thank you very much. 
B) Group Interview Questions for Wind Farm Development Staff

\section{Questions:}

1) What would you consider as most appropriate approach to deal with public opposition?

2) How would you describe the importance of community involvement? Which options are available to involve the community and to what extent might it be viable?

3) What would be a possible advantage/disadvantage to involve community stakeholder into the planning process?

4) How would you describe the role and importance of consultation as an requirement of resource consent process for wind farm developments in New Zealand?

5) What would you consider as necessary elements for a successful consultation process?

6) What would be the most effective consultative approach to avoid public opposition towards wind energy projects?

7) What was your consultation strategy to consult the residents in proximity of the Taurarua wind farm? What have you focused on?

8) What kind of difficulties did you have to deal with while consulting? What went well, what went wrong or could have done better?

9) Have you undertake any kind of initiative to involve the public in the planning process?

Thank you very much. 


\title{
Appendix IV: Ethical Approval
}

\author{
VICTORIA UNIVERSITY OF WELLINGTON
}

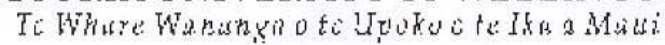

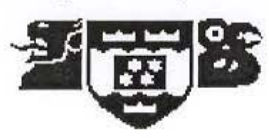

MEMORANDUM

TO: $\quad$ Christian Berg

Earth Sciences/Geography

FROM: $\quad$ Allison Kirkman

Convener, Human Ethics Committee

DATE: $\quad 4$ July 2002

SUBJECT: APPLICATION FOR ETHICAL APPROVAL: JUST HOT AIR? VARIABILITY OF ATTITUDES AND OPPOSITION TOWARDS WIND FARM DEVELOPMENTS IN THE WELLINGTON REGION.

Thank you for making the amendment to your information sheet, as requested by the Standing Committee of the Human Ethics Committee.

Your application, as amended, has now been approved. Approval is given for the period 4 July 2002 to 26 February 2003.

With best wishes for your research.

Allison Kirkman

Convener, Human Ethics Committee 